جهاد جمال الكالوتي

أ.د. عبد الرحمن إبراهيم الكيلاني

قسم الفقه وأصوله - كلية الشريعة - الجامعة

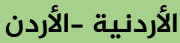

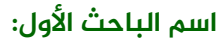

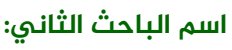

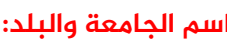

\section{الاكتفاء الذاتي: مفهومه، تأصيله، آثاره}

* البريد الالكتروني للباحث المرسل:

E-mail address :

Jihadkalouti88@gmail.com

https://doi.org/10.33976/IUGJSLS.29.3/2021/16

تهدف هذه الدراسة إلى بيان مفهوم الاكتفاء الذاتي، وتأصيله الشرعي من القرآن الكريم والسنة المطهرة، وإبراز عناية فقهاء الأمة به، وذلك باعتباره أحد مرتكزات القوة المادية للأمة، وشرطاً أساسياً لاستقلالها الاقتصادي والسياسي ولهي والحضاري. ولتحقيق ذلك، فقد اتبع الباحث المنهج الوصفي ببيان مفهوه الاكتفاء الذاتي ونشأته وتطوره، والمنهج المقارن ببيان المقابلة بين مفهوم الاكتفاء الذاتي المطلق والنسبي، والمفهوم الشرعي والاقتصادي، والمنهج التحليلي باستنباط داط المات تعدد أنواعه،

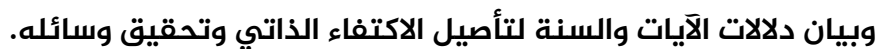

وتوصلت هذه الدراسة إلى أن مصطلح الاكتفاء الذاتي تناوله الفقهاء قديماً تحت مفهومي الكائلة الكاية والكاءت والكفاف، لا سيما فيما

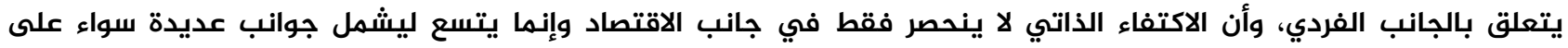

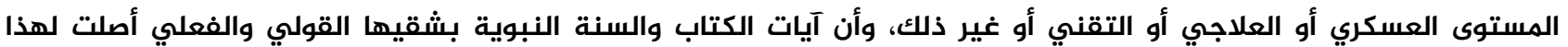

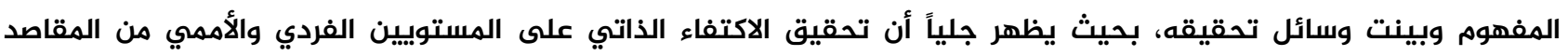
الأساسية للشريعة، بحيث تتحقق للأمة استقلاليتها ودورها في عمارة الأرض، إذ يهدف تحقيق الاكتفاء الوصول لسد الحاجات والعيش في مستوى لائق فوق حد الفقر ودون الغنس، ويكون فيه الاستغناء عن الغير.

كلمات مفتاحية: الاكتفاء الذاتي، الكفايـة، الحاجة.

\title{
Abstract:
}

Self-sufficiency: Definition, Impact, Evidence and Proof extracted from the Quran and Sunnah

is research aims at investigating the concept of self-sufficiency as a contemporary concept. It establishes its Islamic legal origins and foundations which have been thoroughly examined by Muslim jurists

To achieve these goals, the researcher has adopted a descriptive approach to portray the concept of selfsufficiency and its evolution from an Islamic viewpoint. The researcher has employed the comparative approach to highlight the comparison and contrast between absolute and relative approaches to selfsufficiency and its definition from both an Islamic jurisprudence and economic viewpoints. The research has employed the analytical approach to deduct the various types of self sufficiency and diligently examine the verses and Sunnah to derive the religious and legitimate foundations and roots of self-sufficiency and its various means.

The research concluded that self-sufficiency has its well-established religious roots in the Quran and Sunnah, which consists of both the sayings and practices of the Prophet (peace and blessings be upon him), and that both of them have clarified the means by which this concept can be accomplished. goals of self-sufficiency are to meet the basic needs , and to ensure an appropriate standard of living which is somewhere in between poverty threshold and excessive wealth whilst at the same time guaranteeing financial independence.

Keywords: Self-sufficiency, Sufficiency, The need. 
الحمد لله الولي الكافي، وصلى الله وسلم وبارك على سيدنا محمد الداعي إلى ضرورة الاكتفاء الذاتي، وعلى آله وصحبه ومن تبعهم بإحسان من القاصي والداني، أما بعد: فإن هذا البحث الموسوم بـ (الاكتفاء الذاتي: مفهومه، تأصيله، آثاره)، يأتي في هذا الوقت الحرج من الزمن، محاولة من

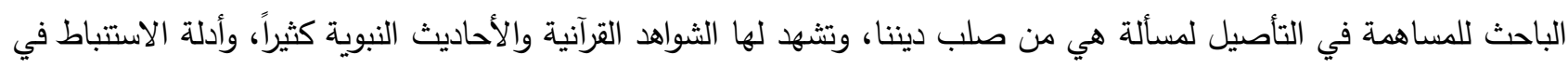

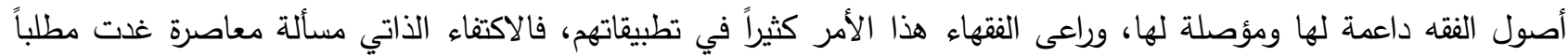
للجميع، ومع هذا فلم يجد الباحث من أولى هذا الموضوع اهتماماً حقيقياً، إلا في أبحاث صغيرة، لطوله أو في إطار تتظيري ضيق.

مشكلة الاراسة:

تتلخص مشكلة الدراسة في الإجابة عن الأسئلة التالية: أولاً: ما هو مفهوم الاكتفاء الذاتي؟ تاني ثانياً: ما مدى عناية فقهاء الأمة بمفهوم الاكتفاء الذاتي؟ مفرو الاكياء

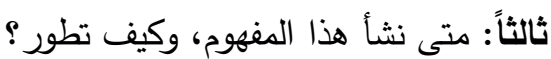
رابعاً: ما هي أنواع الاكتفاء الذاتي، ومدى أهميته؟ خامساً: ما شواهد الاكتفاء الذاتي من الترآن الكريم والسنة المطهرة؟ أهداف الدراسة:

تتخلص أهداف الدراسة في الأمور التالية: أولاً: توضيح مفهوم الاكتفاء الذاتي، ومدى أهميته على مستوى الفرد والأمة في التأصيل الفقهي. ثانياً: إظهار اتساع هذا المفهوم، وتعدد أنواعه. ثالثاً: بيان مدى اعتناء نصوص الثريعة والأحاديث النبوية بمسألة الاكتفاء الذاتي. أهمية الدراسة: أولاً: يعد موضورع الاكتفاء الذاتي موضوعاً معاصراً ومهماً، يُنادى به في المؤتمرات والسياسات العالمية كحل لما يعانيه اليوم العالم من تحديات، لا سيما التحديات الاقتصادية. ثانياً: اعتتت الشريعة بمفهوم الاكتفاء الذاتي عناية خاصة ببيان المقصود منه وتأصيله كمقصد من مقاصد التشريع، حفاظاً على هوية الأمة ودورها الريادي، وحرصاً على الحياة اللائقة بالإنسان. ثالثاً: لم ينل مفهوم الاكتقاء الذاتي حظه من الدراسة الكافية، لا سيما الفقهية منها، ولذلك لا لا بد من دراسة عميقة فقهية لهذا

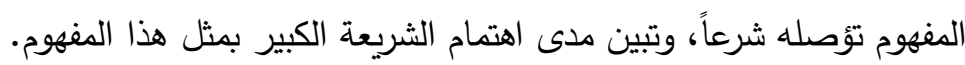

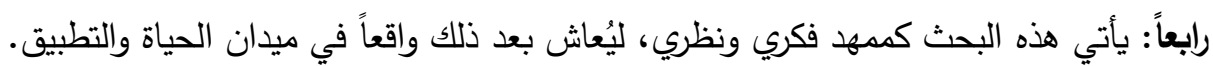

الاراسات السابقة:

تتاول الباحثون موضوع الاكتفاء الذاتي بالبحث والدراسة كأثر اقتصادي من آثار التتمية المستدامة في المجتمع، وتكلموا عن مفهومه وطرقه ووسائله وغاياته ومجالاته وأنواعه، إلا أن بحثهم كان مقتصراً على دراسة الجانب الاقتصادي على على اعتبار أن

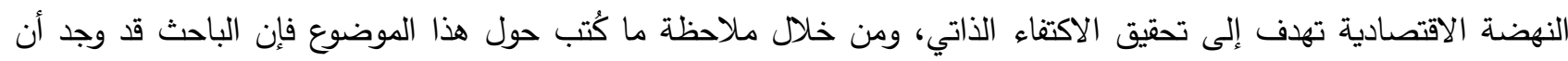

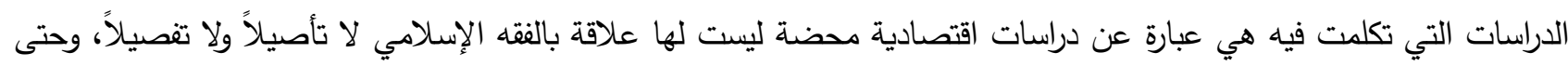
الدراسات التي تتاولت البعد التشريعي فيه فهي عبارة عن دراسات قاصرة لم تتناول موضوع الاكتفاء الذاتي بدراسة مستقلة، وإن كانت فمجتزأة، ومن خلال البحث في قواعد البيانات البحثية المعتمدة في الجامعات والمراكز العلمية فإن الباحث لم يجد في حدود 
اطلاعه دراسةً علمية فقهية تؤصل لموضوع الاكتفاء الذاتي في الفقه الإسلامي، ومن هنا جاءت هذه الدراسة، وفيما يلي عرض لبعض الدراسات السابقة التي تتاولت جزءاً من الموضوع: أولاً: مظاهري، محمد عامر عبد الحميد، مبأ الاكتفاء الذاتي في بعض الأحكام القرآنية، بحث محكم في مجلة الجامعة الإسلامية للعلوم الشرعية في المدينة المنورة، مجلد 42، عدد علد 148، 2009م.

حيث عرض الباحث في هذه الدراسة بيان حقيقة التشريع القرآني لمبدأ الاكتفاء الذاتي في بعض تشريعاته لضمان

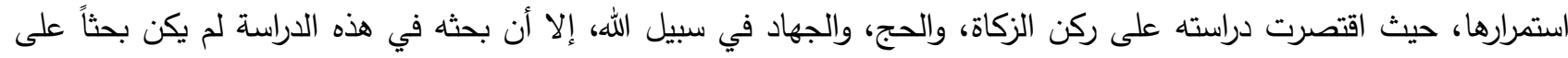
الطريقة الفقهية التي تؤصل لمادة الموضوع، وإنما هو بحث قرآني إعجازي، وهو قاصر على ثلاثة تطبيقات فقط في هذا الموضوع.

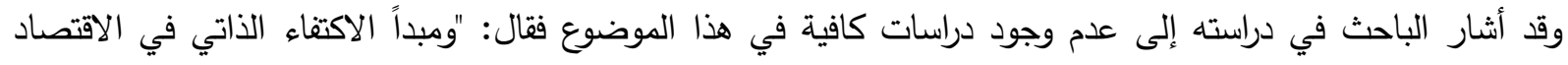

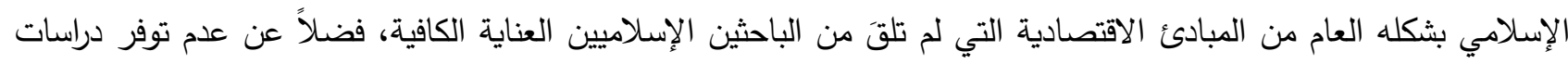
تهتم بالصورة المباشرة بالأحكام التي بصددها هذا البحث، وحتى ركن الزكاة الذي لاقى بعض الإنى العناية في الدراسات الإسلامية

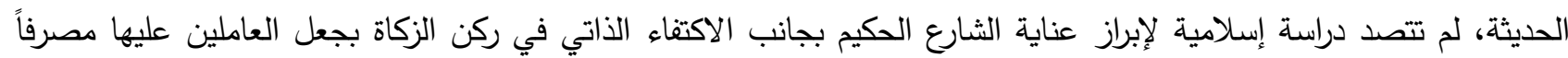
من مصارف الزكاة الثمانية، وكل ما يمكن الوقوف عليه بهذا الصدد يتمثل في الفتاوى التي تحصلت عليها الجهات الخيرية من أصحاب الفضيلة العلماء تبيح الأخذ من الزكاة على قدر حاجة العاملين عليها من أجل حل المشكلة التشغيلية لهذه الجهات

الخيرية"(1). (1).

ثانياً: الجنزوري، علي محمد أحمد، منهج سيدنا يوسف التنموي الاقتصادي، بحث محكم في مجلة البحوث الإدارية في

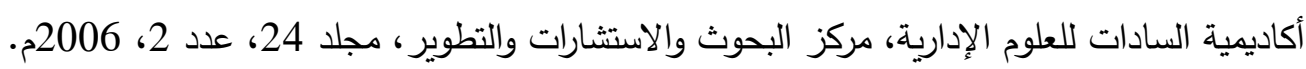
وقد انطلق الباحث في هذه الدراسة إلى بيان منهج سيدنا يوسف -عليه السلام-وأنه منهج تتموي اقتصادي أساساً، وتأييد الإسلام له، بل وإمكانية تطبيق منهج سيدنا يوسف -عليه السلام- في الوقت الحاضر حتى يوم القيامة، ولكن هذه الدراسة تتنمي إلى حقل الدراسات القرآنية الاستقرائية وليست إلى البحوث على الطريقة الفقهية، وهي دراسة أعم من المطلوب بحثه في هذه الدئه الدراسة، فلا تتوجه إلى الاكتفاء الذاتي مباشرة، وإنما يستفاد منها حين عرض الأدلة القرآنية التي تدل على مبلى مبدأ الاكتفاء الذاتي في التشريع منيه الإسلامي. منهج البحث:

سلك الباحث وفقاً لطبيعة الدراسة المناهج الآتية: أولاً: المنهج التحليلي: تحليلاً للنصوص القرآنية والنبوية لبيان أوجه الدلالة فيما يبين مدى حضور الاكتفاء الذاتي في نصوص الشريعة، وبيان أنواع الاكتفاء الذاتي. ثانياً: المنهج المقارن: وأعرض من خلاله لبعض التان الاتجاهاهات والآراء المتباينة، ودراستها وتمحيصها. ثالثأ: المنهج الوصفي: بحيث يتم بيان مفهوم الاكتفاء الذاتي ونشأته وتطوره.

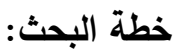
انتظم البحث في ثلاثة مباحث، على النحو الآتي:

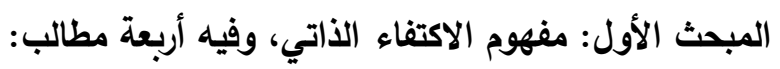
المطلب الأول: تعريف الاكتفاء الذاتي لغة واصطلاحاً. المطلب الثاني: نشأة مفهوم الاكتفاء الذاتي وتطوره. المطلب الثالث: مصطلحات اقتصادية ذات الصلة. 


$$
\text { المطلب الخامس الرابع: أنواع الاكتفاء الذاتي. }
$$

المبحث الثاني: تأصيل الاكتفاء الذاتي من القرآن الكريم والسنة المطهرة، وفيه أربعة مطالب:

المطلب الأول: تأصيل الاكتفاء الذاتي من القرآن الكريم.

المطلب الثاني: تأصيل الاكتفاء الذاتي من السنة النبوية.

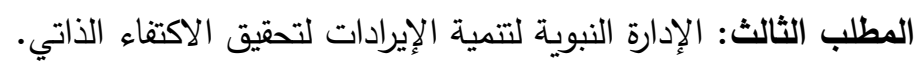

$$
\text { المطلب الرابع: السوق النبوي. }
$$

\section{الخاتمة والتوصيات}

المطلب الأول: تعريف الاكتفاء الذاتي لغة واصطيات التوصناً

الاكتقاء الذاتي مركب وصفي، من الاكتفاء والذاتي، وسأعمد إلى تعريف ألفاظ هذا المركب لغة واصطلاحاً، وذلك على ولى

$$
\text { الاكتفاء الأاتي لغة: }
$$

تأتي كلمة الاكتفاء بمعانٍ متعددة متقاربة، ومن ذلك لكاء

(1)

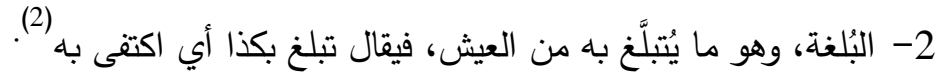

3- أجزأه الثيء

4- من كفى، يكفيك الثيء كفاية واكتفى به، بمعنى اضطلع (4).

5- ما فيه سدّ الخلّة وبلوغ المراد في الأمر (5).

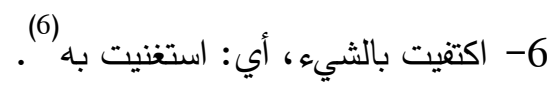

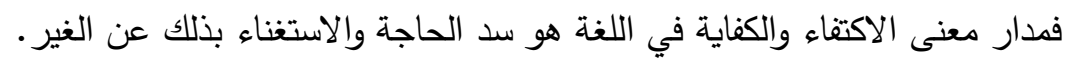

وقد يفيد زيادة البناء في لفظة الاكتفاء، أن الاكتفاء وصول للحد في سد الحاجة وزيادة على ذلك.

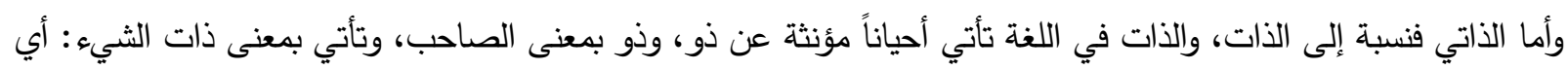

حقيقته وخاصته، وكذا بمعنى ما تملك يداه من الأموال إن أضيفت لليد، فيقال: قلَّت ذات يده (7)، وهكذا فصطلح الاكتفاء الذاتي

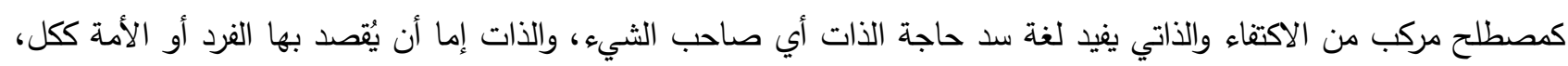
بحيث تصل الأمة بمجموعها للاكتفاء الذاتي بتعدد مناطقها وطبائعها وشعوبها. تعريف الاكتفاء الذاتي اصطلاحاً:

$$
\begin{aligned}
& \text { (1) الزبيدي، تاج العروس من جواهر القاموس (ج272/2) . (272). }
\end{aligned}
$$

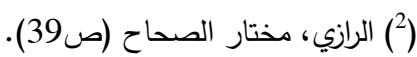

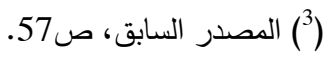

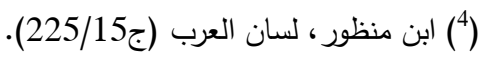

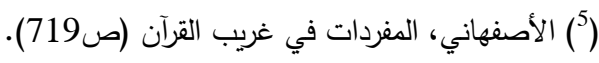

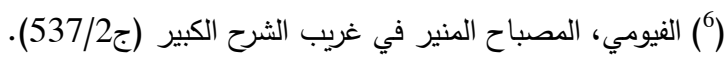

$$
\begin{aligned}
& \text { (7) الزبيدي، تاج العروس من جواهر القاموس (7423/40). }
\end{aligned}
$$


الاكتفاء الذاتي مصطلح حديث لم يرد في التراث الفقهي، لكن يمكن الوقوف على بعض مصاديقه ومفاهيمه في عدد من المباحث والمصطلحات التي تتاولها الفقهاء، ويمكن إجمالها على النحو الآتي: أولاً: الكفاية.

ثانياً: الحاجة الأصلية. ثالثاً: الكفاف. رابعاً: الغنى.

والكفاية والحاجة الأصلية بمعنى واحد، فالأحناف يعبرون عن الكفاية بالحاجة الأصلية (1)، والكفاية مفهوم يُبحث فيه في عدة أبواب فقهية كالزكاة والحج والنفقة والكفارة والأجرة، وقد اختلف الفقهاء في تحديد معنى الكفاية، وفيما يلي ذكر تعاريف الفقهاء لمصطلح الكفاية: تعريف الأحناف للكفاية: "وهي ما يدفع الهلاك عن الإنسان تحقيقاً كالنفقة ودور السكنى وآلات الحرب والثياب المحتاج إليها لدفع الحر أو البرد أو تقديراً كالََّّنْ، فإن المديون محتاج إلى قضائه بما في يده من النصاب دفعاً عن نفسه الحبس الذي هو

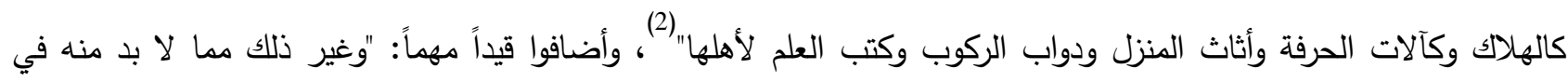
معاشها" (3)، لتعم جميع الحاجات الأساسية. تعريف المالكية للكفاية: لم أجد فيما وقفت عليه من كتب الفقه المالكي تعريفاً للكفاية، وإنما ذكروا وصف مَن يستحق

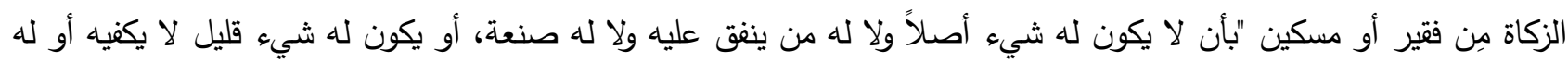

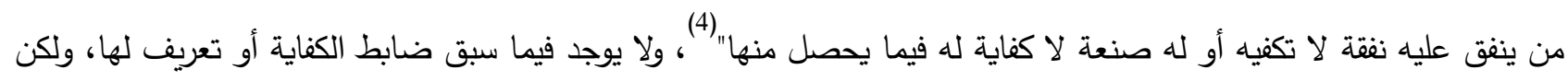

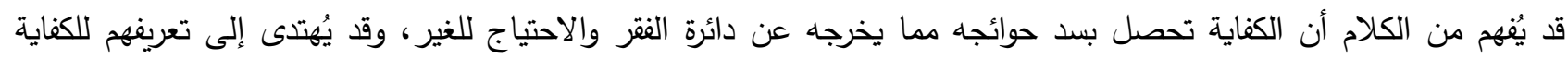

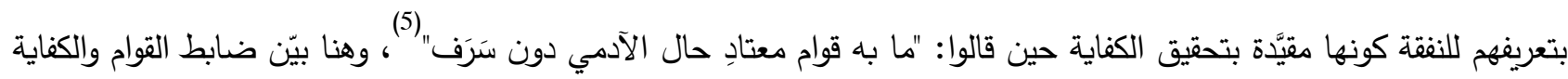
بأنه ما جرت عليه العادة. تعريف الثافعية للكفاية: ما يسد حاجته من مطعم ومشرب وملبس ومسكن وسائر ما لا بد منه على ما يليق بالحال، من غير إسراف ولا تقتير لشخصه ولمن هو في نفتته (6). تعريف الحنابلة للكفاية: "ما يحتاج هو وأهله إليه، من مسكن وخادم وما لا بد منه، وأن يكون فاضلاً عن قضاء دَينه؛ لأن قضاء الدَّين من حوائجه الأصلية" (7). وهكذا فالتعاريف بالجملة متقاربة المعنى في أن الكفاية تكون "بسد حاجاته الأصلية، وهي ما يدفع عن الإنسان الهلاك تحقيقاً

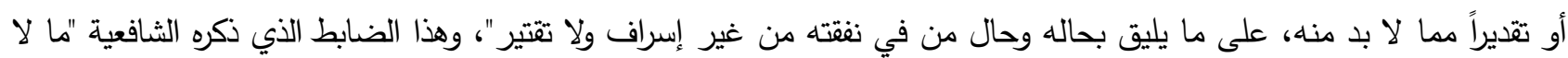
بد منه على ما يليق بالحال" (1) يعطي مرونة باستيعاب الحاجات المتجدة بتتجد الزمن، مع ما يُفهم منه من ترشيد الاستهلاك. 
ولا بد من التتويه أن الحاجة الأصلية المقصودة هنا فيما يُفهم من التعاريف ليست من قبيل الحاجيات بالمعنى الأصولي المقاصدي (2) بل يُّصد بها هنا كل ما يشمل ضمان أساسيات الحياة والعيش اللائق، فتشمل الحاجة هنا الضروريات والحاجيات وما لا بد منه من التحسينيات، فالكفاية سد الحاجات، والحاجة في اللغة: "الاضطرار إلى الثيء" (3) فسد الحاجة بأن لا تكون مضطراً إلى الغير بل مستغنياً عنهم، هذه هي الكفاية، فالكفاية إن تخلّفت حصلت الحاجة، وإن سُّدّت الحاجة حصلت فئ الكفاية.

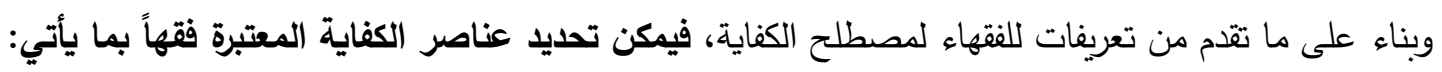

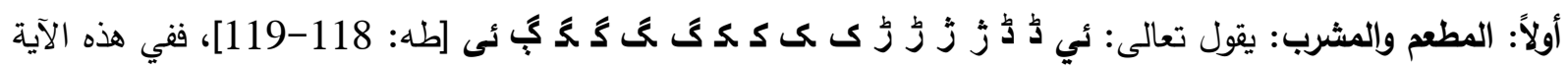

إثارة إلى احتياج الإنسان للمطعم والملبس والمسكن والمشرب، وحد الكفاية فيها بما يليق به وبمن يعول في عرف الناس (4).

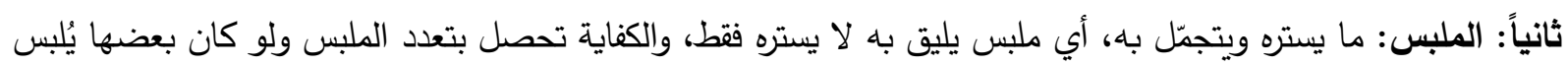

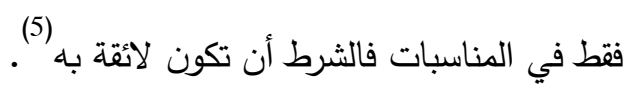
ثالثاً: المسكن: ذهب الحنفية (6) والمالكية (7) والثافعية (8) إلى أن الكفاية تكون بمِلك السكن لا باستئجاره، وقد يكون هذا راجعاً

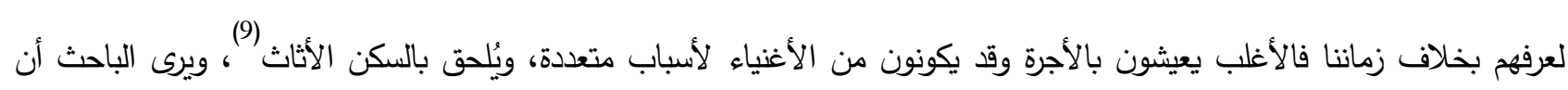

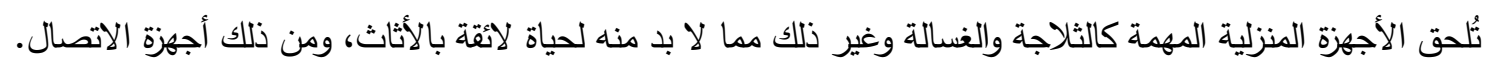

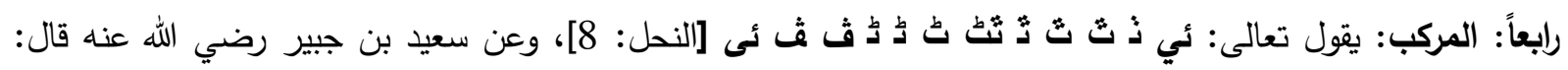
"يُعطى من الزكاة من له الدار والخادم والفرس" (10)، وقد اتفقت المذاهب الأربعة (11) على أن المركب من الحوائج الأصلية، وقد يتغير هذا بتغير العرف والظروف. خامساً: التعليم: اتفق فقهاء المذاهب على جواز إعطاء الزكاة للفقير المشتغل بالعلم الشرعي (1) واشترط الثافعية والحنابلة أن يكون انثغاله بالكسب يمنعه من طلب العلم، ويرى الباحث أن يُلحق هنا من يتفرغ للعلم حتى وإن لم يكن شرعياً، لأن من أن

(1) وزارة الأوقاف والثؤون الإسلامية، الموسوعة الفقهية الكويتية، (ج35/ 11 11).

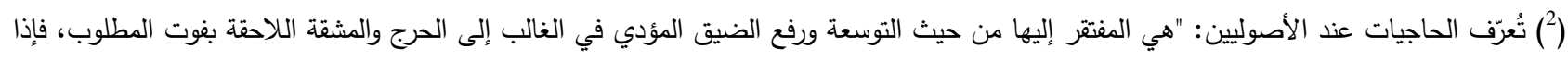

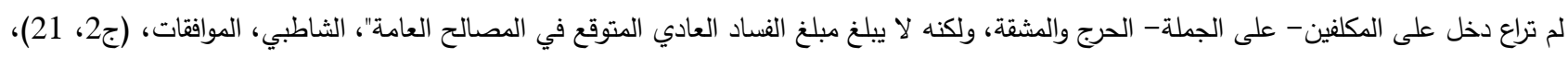

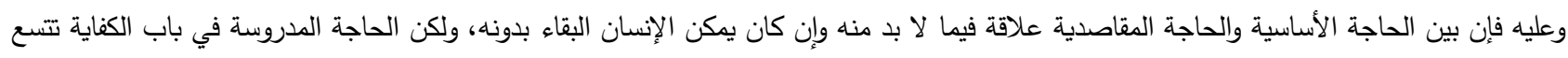
للضروريات كنلك وبعض التحسينيات.

$$
\begin{aligned}
& \text { (1) ابن فارس، معجم مقاييس اللغة (ج114/2). }
\end{aligned}
$$

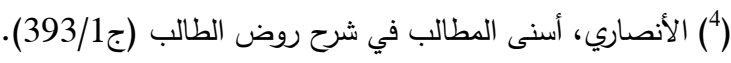

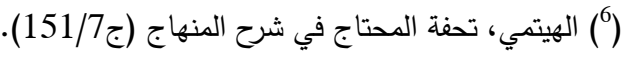

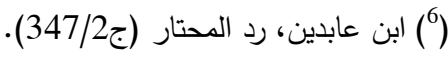

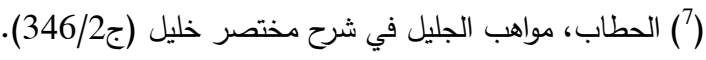

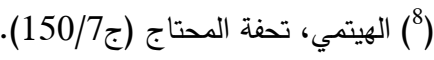

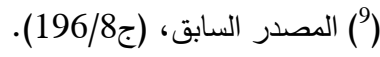

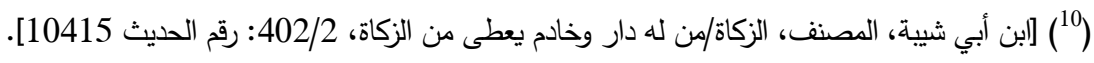

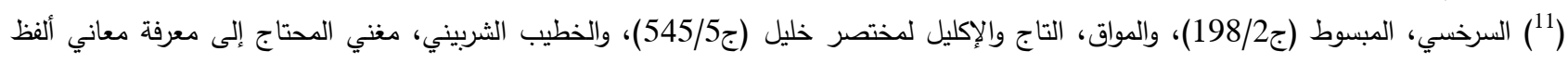

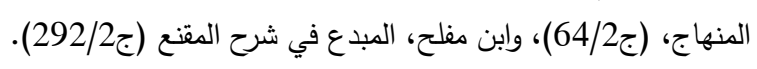


فروض الكفاية أن يكون في الأمة من يتخصص في سائر العلوم تحقيقاً لنهضتها وهذا من تحقيق الاكتفاء الذاتي على مستوى

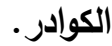

سادساً: آلة التظيف وأدوات الزينة: يجب للزوجة على زوجها آلات التنظيف كالمشط والدهن للرأس، ويلزمه ما تضار

الزوجة بتركه من أدوات الزينة، فقد فرق الفقهاء بين الزينة التي تزيل الثعث وبين الزينة المحضة (2).

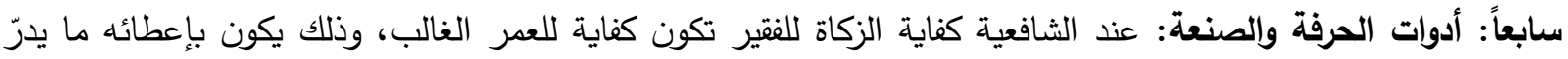
عليه كفايته من أدوات حرفة (3). ثامناً: تكاليف الزواج: اعتبر بعضُ الفقهاء (4) تكاليفت الزواج حاجة أصلية تُصرف لها الزكاة؛ لأن الزواج من حاجات الإنسان وفيه تحقيق مقاصد الشريعة، "وأنه لو كان يكتسب كفايته من مطعم وملبس ولكنه محتاج إلى النكاح فله أخذها لينكح؛ لأنه من تمام كفايته" (5). تاسعاً: أجرة العلاج وثمن الاواء: لـ ينص الفقهاء على اعتباره من عناصر الكفاية، بل لا يلزم الزوج نفقة دواء زوجته عند

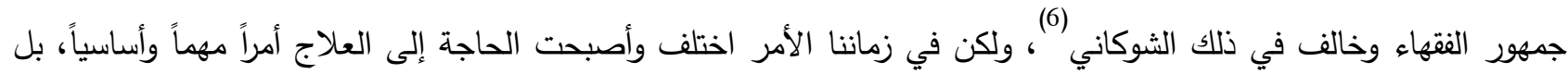

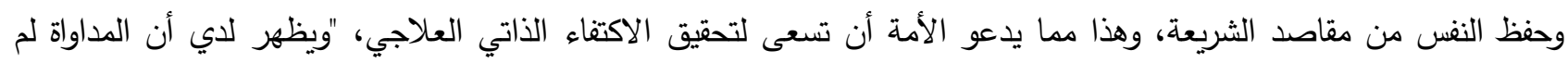

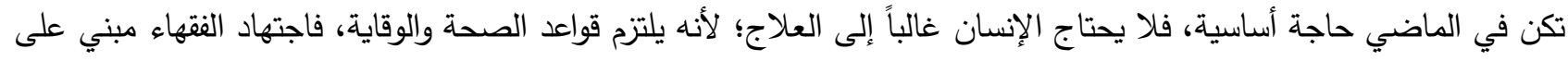

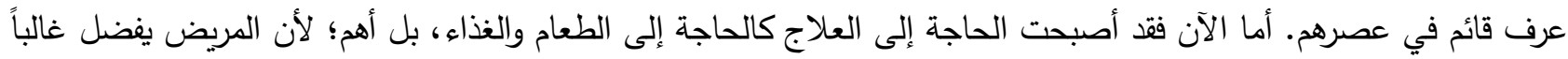

ما يتداوى به على كل شيء" "7) بل عدّ بعض الثافعية أن من كفاية القريب أجرة طبيب وثمن دواء (8).

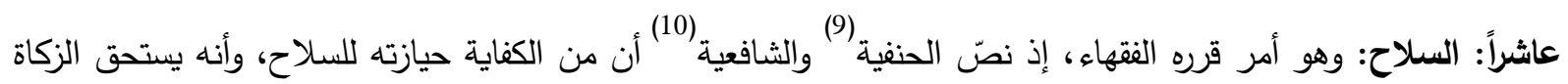

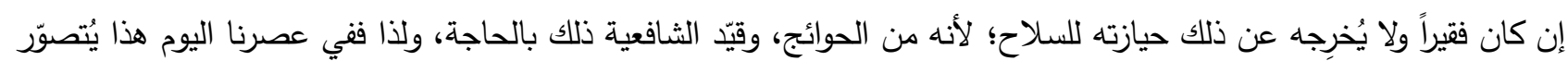

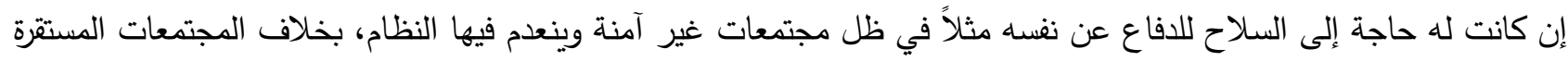

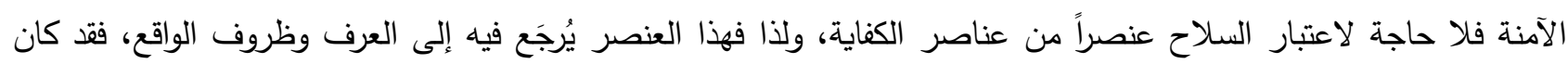

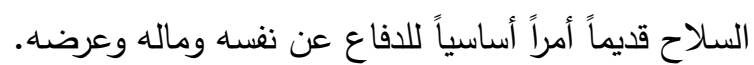
حادي عثر : قضاء الديون: فمن مصارف الزكاة الغارمين، فقضاء الديون مقصد شرعي ومن الحوائج التي تُسد كما بين الأحناف ذلك بدفع الهلاك عن الإنسان تقديراً في تعريفهم كما سبق. فئ.

(1) ابن عابين، رد المحتار (ج240/2)، والحطاب، مواهب الجليل في شرح مختصر خليل (ج2/26/2)، والنووي، المجمع شرح المهنب (ج6/6) 190/)، والبهوتي، كثاف القناع عن متن الإفناع (ج2/271).

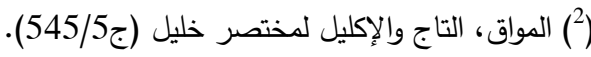

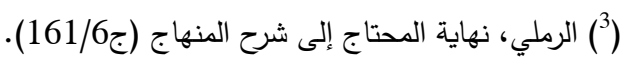

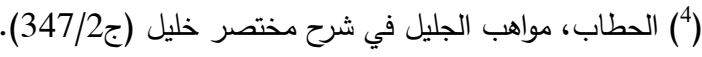

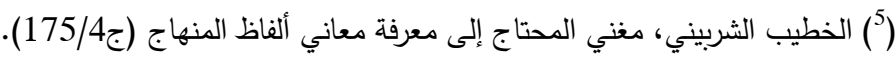

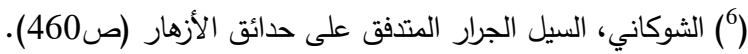

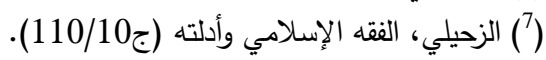

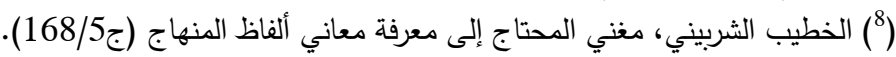

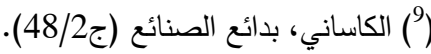

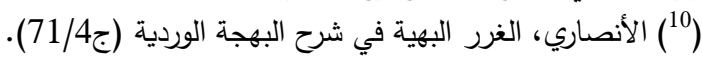


ثاني عشر: الخادم: وهذا يُتصوّر في حق من يقتضي حاله وجود خادم يخدمه، نظراً لحاجته إليه في قضاء حوائجه

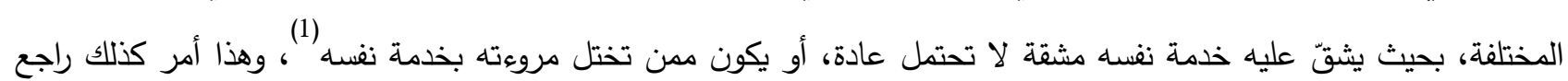
للعرف، يختلف باختلاف الزمان والمكان.

ويتسع المجال ويضيق في تحديد عناصر الكفاية بحسب الحال والعرف، فقد راعى الفقهاء حاجات أزمانهم، ولكنهم قيدوا

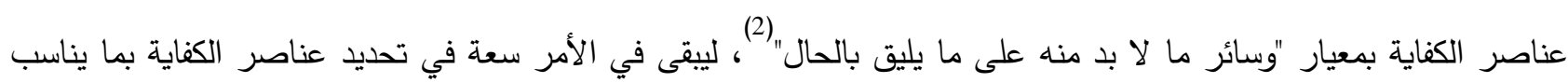

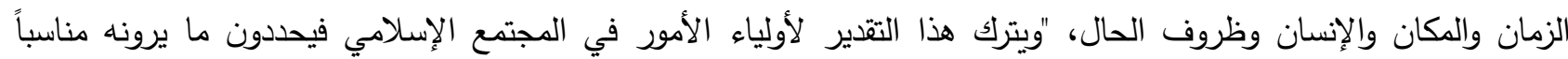
بمعاونة أهل الاختصاص ممن حولهم من أهل الشرع وأهل الاقتصاد" (3)، وكذلك يختلف تقدير حد الكفاية بتغير الزمان والمكان والأشخاص، لتعدد ظروفهم، "وأما تحقيق المناط فهو أن يتفق على علية وصف بن بنص أو إجماع، ويجتهذ في وجودها في صورة

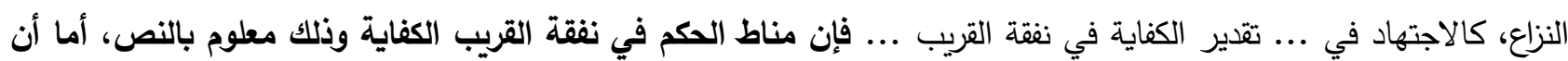
الرطل كفاية لهذا الثخص أم لا فيُّرك بقول المقوّمين" (4)، ومن التطبيقات المعاصرة لذلك بأنه يستفاد من تحديد حد الكفاية في تقدير الرواتب والأجور (5). وبهذا يتضح أن مفهوم الكفاية ربما يختلف من مذهب لآخر ، ويتجدد مع تجدد الزمن، وأنه لا يكتفي بسد الضروريات بل

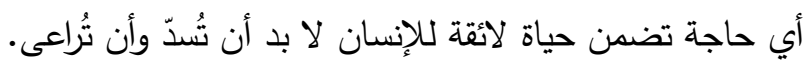

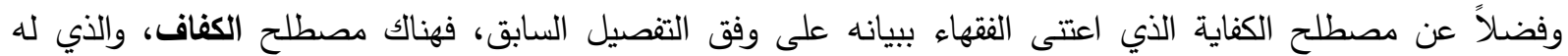
اتصال بمجال البحث، والكفاف في اللغة من كفت عن الثيء بمعنى تركه، ويقال: قوته كفاف، أي: مقدار حاجته من غير زيادة ولا نقص؛ سُمّي بذلك لأنه يكف عن سؤال الناس ويُغني عنهم (6)، وأما المعنى الاصطلاحي فليس مختلفاً عن المعنى اللغوي ونه بالعموم، وقد ذكر العلماء عدة تعريفات للكفاف راجعة في محصلها إلى أن الكفاف: "ما كان بقدر الحاجة من غير زيادة" (7)،

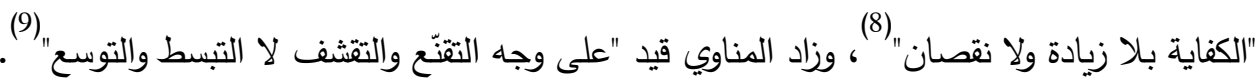

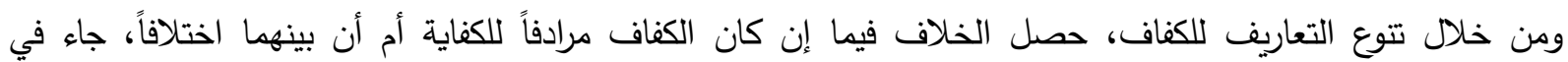
الموسوعة الفقهية الكويتية: ويختلف حد الكفاف في الإنسان عن حد الكفاية، من أن حد الكفاف يتتصر على سد الضروريات القصوى من مطعم ومسكن وملبس، أما حد الكفاية فيتعدى نلك إلى ما لا بد للإنسان منه على ما يليق بحاله، من نكاح وتعليم وعلاج وقضاء دين، وما يتزين به من ملابس وحلي وغير نلك" (10)، وفي هذا يقول الفاروق عمر رضي الله عنه: "إني حريص على أن لا أرى حاجة إلا سددتها، 
ما اتسع بعضنا لبعض، فإذا عجز ذلك عنا تأسينا في عيشنا حتى نستوي في الكفاف"(1)، فالكفاف الحد الأدنى من المعيشة ويتعلق

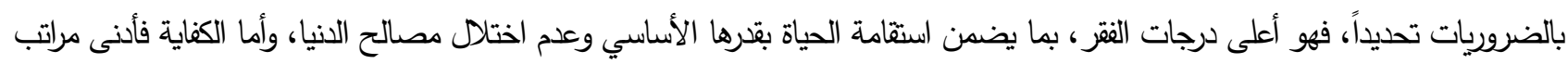
الغنى ويتعلق بالضروريات والحاجيات والتحسينيات، بما يضمن سد الحاجات والعيش بحياة لائقة ورفع الحرج، وبناء عليه فمن كان عنده حد

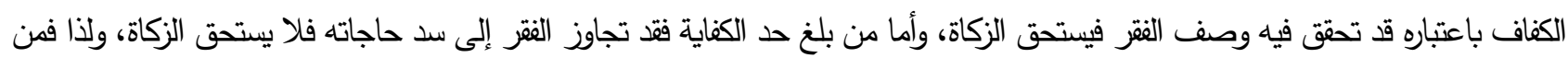

مقاصد الشرع أن يصل الأفراد لحد الكفاية، فالكفاية حق إلهي مقدس يعلو فوق كل الحدود (2). وفي المقابل، فقد ورد في تعاريف الكفاف التي نقلها الباحث أنه الكفاية وأنه سد الحاجات، فيكون بين الكفاف الكاف والكفاية

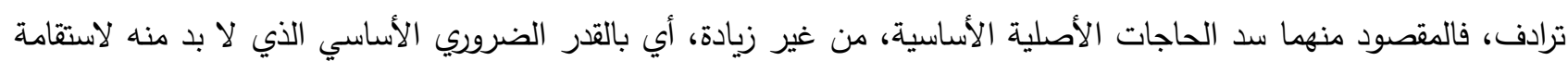

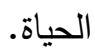

ويمكن الجمع بين القولين، بأنهما إن اجتمعا في سياق الورود افترقا في المعنى، وإن افترقا اجتمعا، ولعل الأرجح التفريق

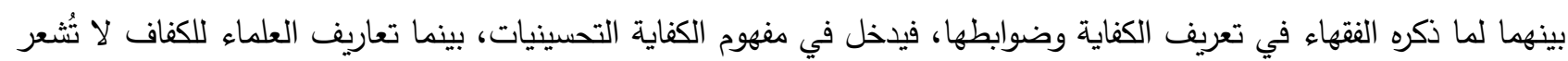

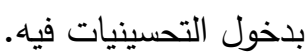
وهذا التمييز بين المفهومين (الكفاية / الكفاف) يُسهِم في القدرة على تفسير المستويات المعيشية، ويقدّم محاولة للتحليل الاقتصادي بصورة أفضل (3). وأما مصطلح الغنى فمرتبط بمفهوم الكفاية، إذ حصل الخلاف فيما إن كانت الكفاية أدنى مراتب الغنى أم أن الكفاية دون الغنى، فيكون الغني هو من يملك الكفاية وزيادة. ولعل هذا راجع إلى تعريف الغنى، فالغنى في اللغة يطلق على الكفاية وعلى اليسار، وأما في الاصطلاح، فقد ذهب

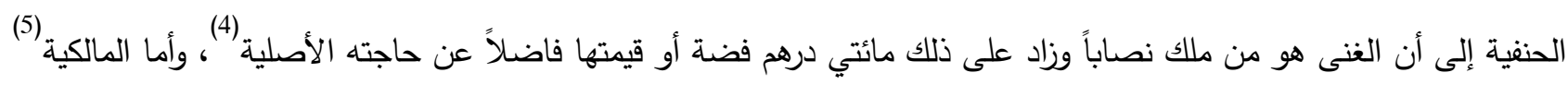
والحنابلة (6)فالغنى عندهم أمر عرفي، فلا يَحُدُ الغنى حدّ وإنما على المعروف بين الناس، وأما الثافعية فالغنى عندهم هو القدرة

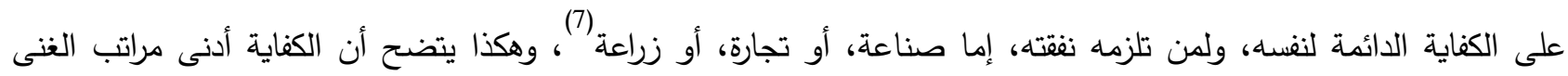

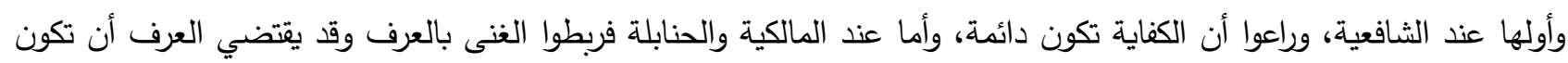

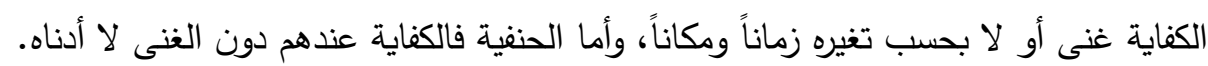

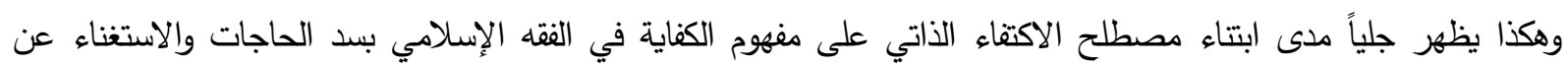

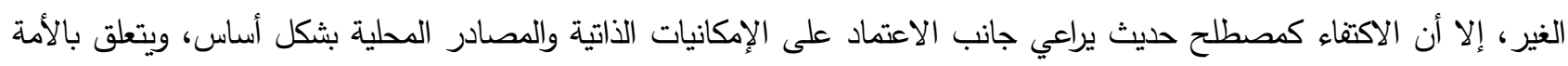

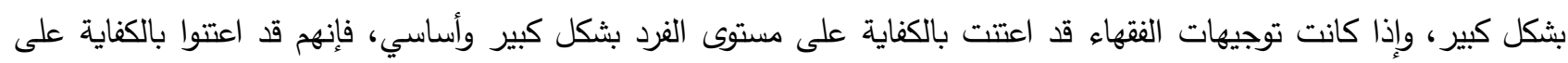

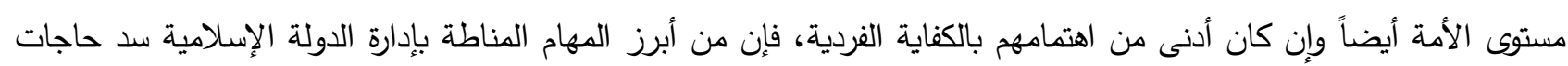

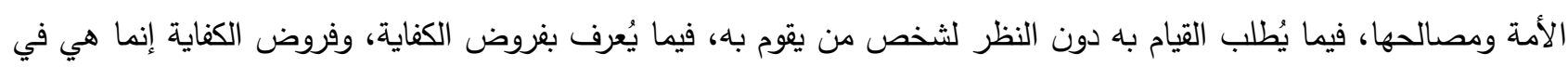

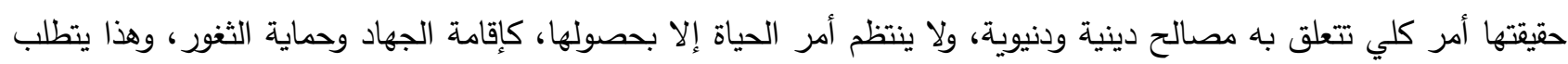

(1) (1) (بن كثير ، البداية والنهاية (ج46/7).

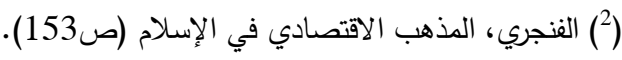

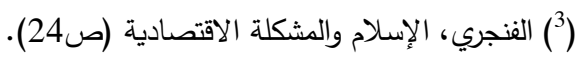

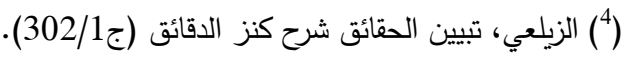

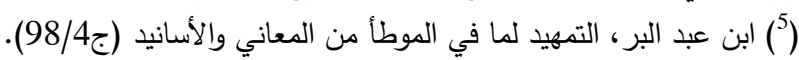

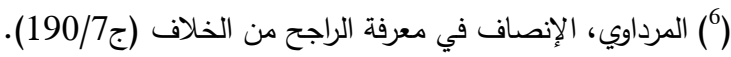

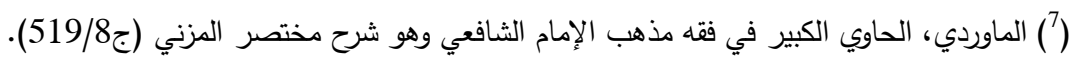


جنوداً، وكايجاد المفتين والعلماء بقدر الحاجة لإرساء قواعد العلم ودفع الشبه، وكذلك سد الحاجات في شؤون الحياة الزراعية والصناعية والتقنية، "فلا يتعجب من قولنا إن الطب والحساب من فروض الكفايات فإن أصول الصناعات أيضاً من فروض فلاء الكفايات كالفلاحة والحياكة والسياسة بل الحجامة والخياطة فإنه لو خلا البلد من الحجام تسارع الهلاك إليهم وحرجوا بتعريضهم أنفههم للهلاك" (1) بل لولي الأمر أن يلزم أهل الصنع كالفلاحين والنساجين والبنائين وغيرهم بأعمالهم مقابل أجرة المثل تحقيقاً

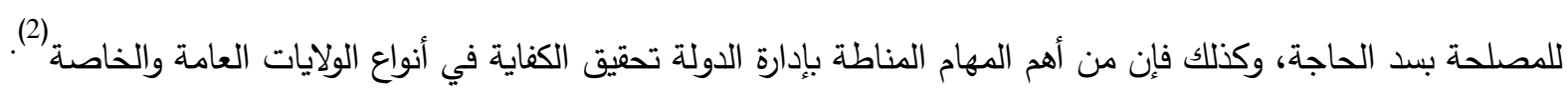

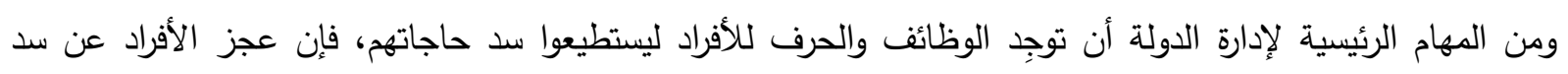
حاجاتهم، فعلى الدولة أن تشرف على سد حاجاتهم وإدارة ذلك من خلال توزيع الزكاة والصدقات، وتكليف الأغنياء بالمساهمة في

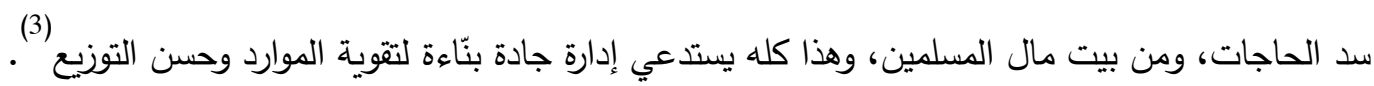

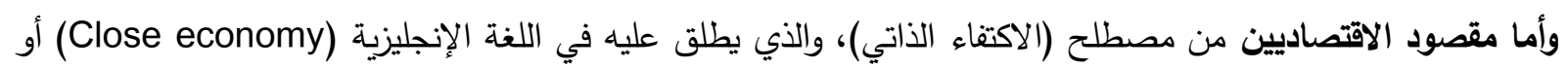
(4utarky)

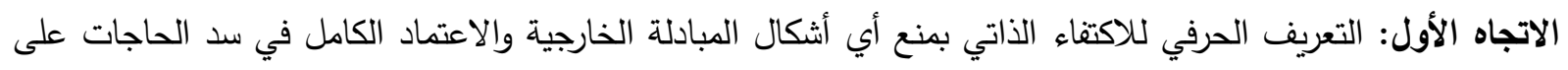

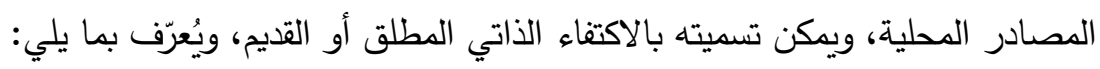
- "هي حالة عدم الانخراط في التجارة الدولية، وتطبيق الاستقلال الاقتصادي، بحيث تكتفي الدولة بما لديها من موارد

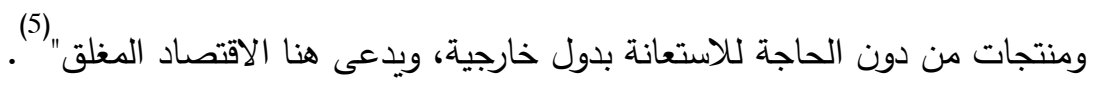
- أضاف مطانيوس حبيب على التعريف السابق قيداً يوسع من مصداق الاكتفاء الذاتي ليكون بجانب الاكتفاء الذاتي

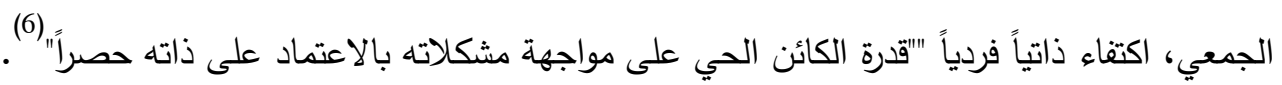

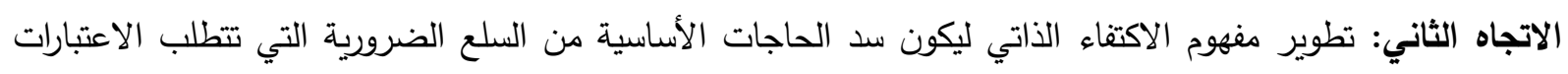

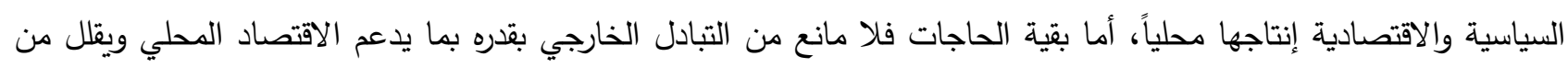
التبعية السياسية، ويُكن تسميته بالاكتفاء الذاتي النسبي أو الحديث (7). ويظهر الفرق بين الاتجاهين في نقاط ثلاث:

أولاً: الاكتفاء الذاتي القديم مبني على اعتبارات سياسية فقط، بينما الاكتفاء الذاتي الحديث مبني على اعتبارات سياسية واقتصادية، فالاكتفاء الذاتي النسبي لا يمانع من التخصصية في السلع ولاء يمنع التبادل التجاري.

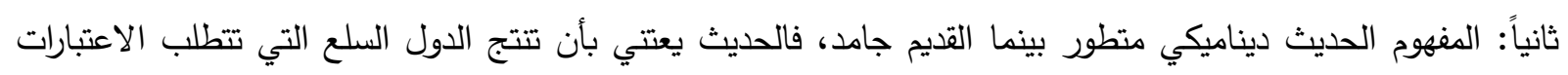

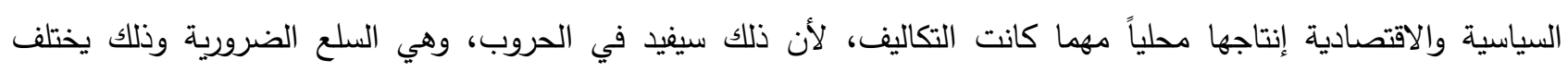
باختلاف الزمن والظروف.

\author{
(1) (1) الغزالي، إحياء علوم الدين (ج/16). (208).

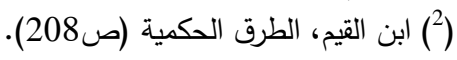

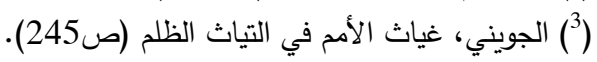

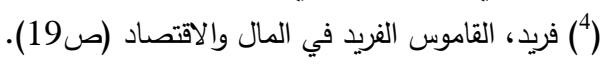

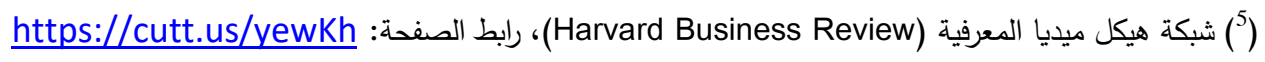


ثالثاً: أن المفهوم الحديث تأثر بما فرضته الدول الكبرى على النامية من نوع السلع التي تتخصص بها، ولذا لا بد من (1)

التخصص في السلع المناسبة لطبيعة وموارد البلد ويرى الباحث أن يُعرّف الاكتفاء الذاتي جمعاً بين المفهومين الفقهي والاقتصادي على النحو الآتي: "الاكتفاء الذاتي هو سد حاجات الأفراد والأمم جميعها، فيما لا بد منه لاستقامة الحياة وتحقيق مستوى لائق من المعيشة

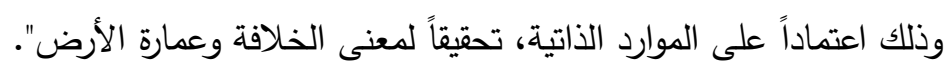

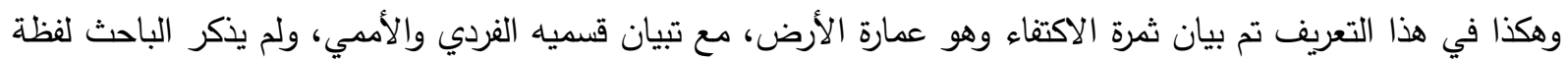
الدولي، بل حرص على ذكر لفظة الأممي ليدل على الاكتفاء الذاتي في كيان الأمة بمجموعه، وبلفظة (جميع) في سد الحاجي فئات

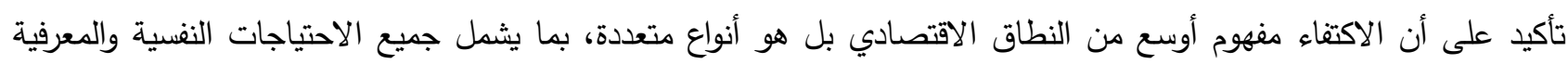
والاقتصادية والعسكرية وغير ذلك.

المطلب الثاني: نشأة مفهوم الاكتفاء الذاتي وتطوره وفئه يرجع هذا المفهوم في أصله اللغوي إلى مادة (كفي) كما تبين في المطلب السابق، ويفيد الاستغناء عن الغير وسد الخُلّة والحاجة الأساسية والأصلية، وبنفس المعنى اللغوي كان المعنى الاصطلاحي الفقهي بأن يسدّ المرء حاجته وحاجة من يعول بكسب، فإن عجز فيأتي دور المجتمع والدولة بسد حاجات العاجزين، ومن ثم تطور المفهوم لا سيما عند الاقتصاديين المعاصرين ليكون

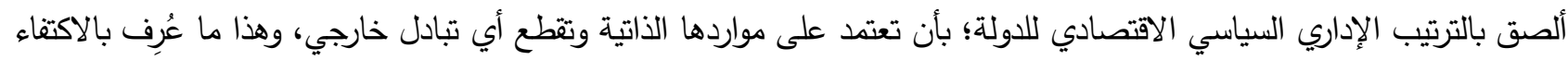

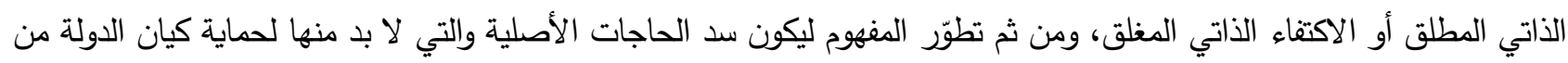
الموارد المحلية وسمي هذا بالاكتفاء الذاتي النسبي أو الاكتفاء الذاتي الحديث، ويرى الباحث أن الاكتفاء الذاتي بما ذكر الفقهاء من عناصر الكفاية والحوائج الأصلية المعتبرة وأن ضابطها ومردها العرف أوسع من أن تحصر بالجانب الاقتصادي، فالاكتفاء الذاتي

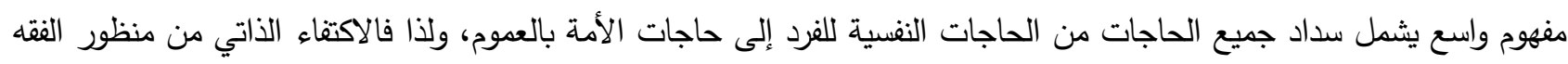
الإسلامي مفهوم كلي يتسع لعدد كبير من الفرعيات الفقهية. وأما نشأة المصطلح فيُرجع البعض أصل نشأته إلى الفيلسوف أرسطو في كتابه "السياسة"، إذ يُعرِّف دولة المدينة بصفتها حشد من المواطنين في مكان صالح لحياة الاكتفاء الذاتي (2) ويقصد بذلك اعتماد كل دولة على مواردها المحلية مع عدم التبادل الخارجي مطلقاً، وهو في الحقيقة أصّل للمفهوم من غير ذكر المصطلح، وأما ظهور المصطلح كمصطلح فلم أقف عليه.

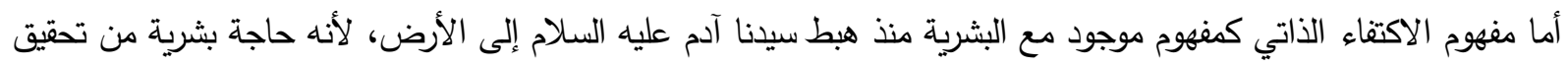

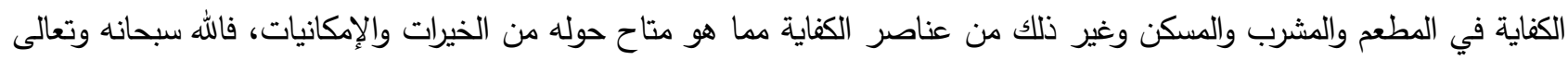

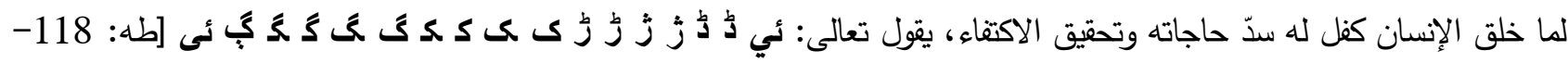

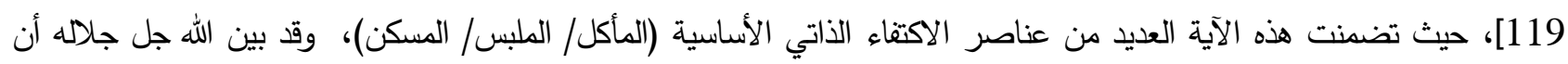

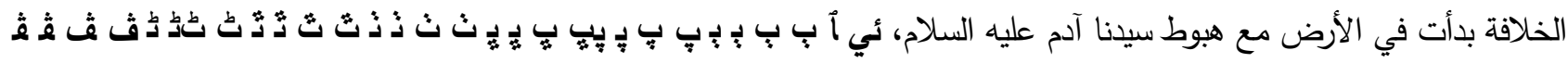

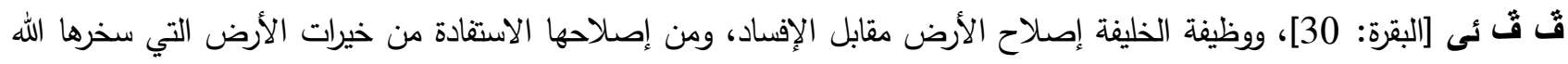

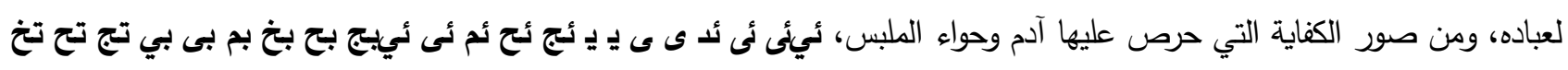

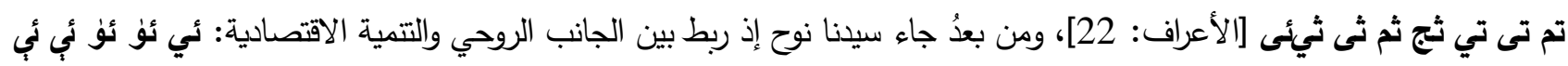

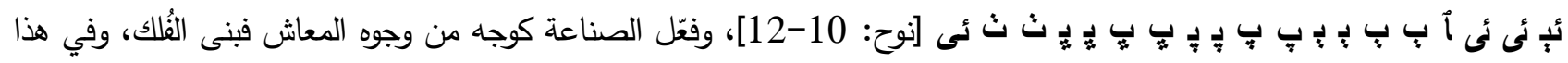


"الإشارة إلى قِدم النجارة؛ لأنه لم تصح حكاية عنها قبل خبر نوح عليه السلام، فجعل كأنه أول من تعلمها، فتقهّم أسرار الصنائع في الخليقة" (1)، وهكذا دأب الأنبياء فقد كان سيدنا إبراهيم كثير الهجرة والتتقل، كثير المال، وكان له اهتمام كبير بالثروة الحيوانية حتى أنه تقاسمها مع ابن أخيه لوط عليه السلام. واختار لوط الأردن لخيراتها الكثيرة إنماءً لماله (2)، ومن بعد ازدهرت الصناعة لا سيما صناعة الحديد واللباس العسكري

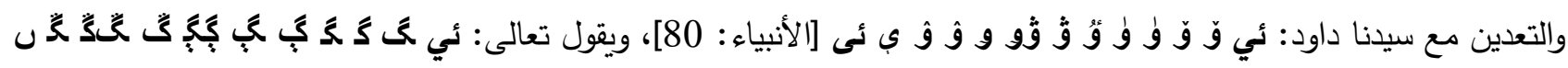

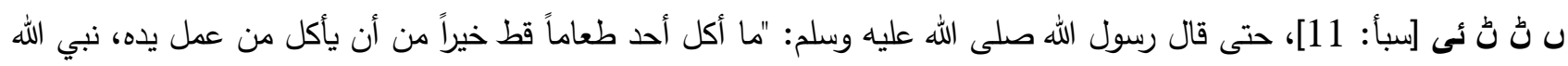

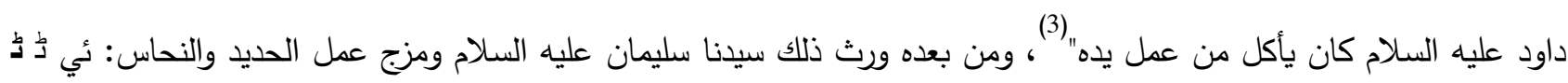

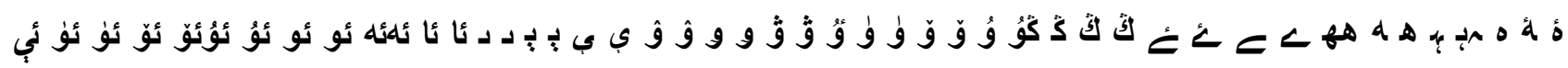
لئي ئى [سبأ: 12-13]، ويمثل سيدنا يوسف عليه السلام النموذج الأجلى في تحقيق الاكتفاء الذاتي بحسن تصرفه أمام الدورات

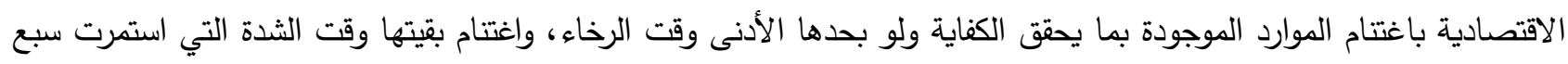

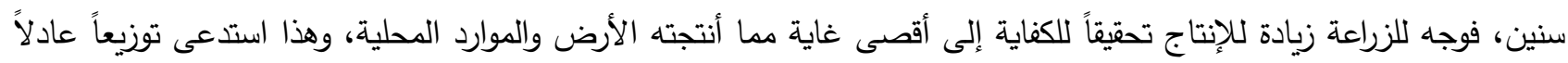

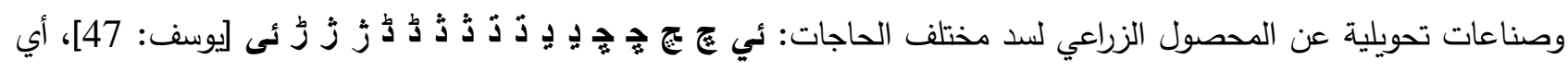

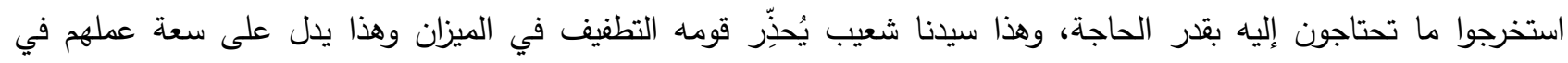

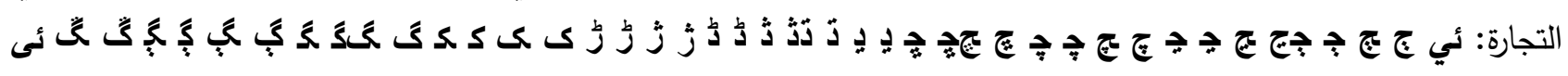

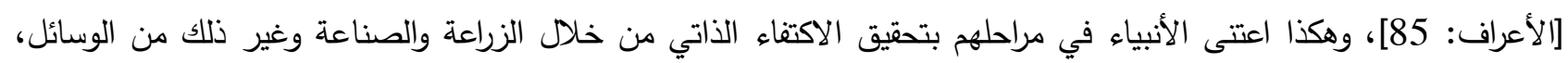
وسيأتي الكلام عن دور سيدنا محمد عليه الصلاة والسلام في تفعيل وتأصيل الاكتفاء الذاتي.

المطلب الثالث: مصطلحات اقتصادية ذات صلة داتل يتتاول الاقتصاديون مفاهيم لها صلة بالاكتفاء الذاتي، ومن أبرز هذه المفاهيم ما يلي:

أولاً: التنمية المستدامة:

ترجع جذور فكرة التتمية المستدامة لسنة 1968م حيث تم تأسيس نادي روما بهدف دراسة مشاكل العالم السياسية والبيئية

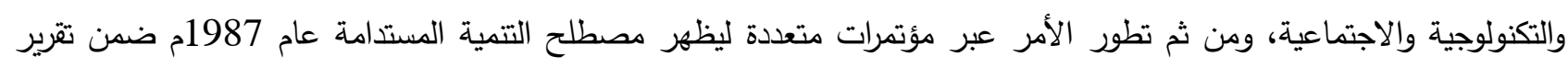
اللجنة الدولية للبيئة والتتمية التابع للأمم المتحدة، وقد عرّفت اللجنة التتمية المستدامة بأنها "نوع من التتمية التي تُلبّي احتياجات الحاضر دون المساس بقدرة الأجيال المقبلة على تلبية احتياجاتها الخاصة" (4)، ولذا فالتتمية المستدامة سد حاجات الأفراد الآن

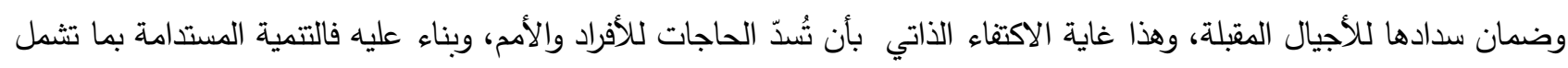
من خطة متكاملة للتنمية بغية سد الحاجات تُعدّ وسيلة غايتها تحقيق الاكتفاء، فإن من المعايير الإسلامية للتتمية تحقيق الاكتقاء 


\section{ثانياً: الأمن الغذائي:}

تعددت تعاريف الأمن الغذائي، ومن ذلك ما جاء من تعريف يماثل تعريف الاكتقاء الذاتي إلا أنه محصور فيما يخص الغذاء "توفير احتياجات الدولة من الغذاء دون الحاجة إلى الاعتماد على مصادر خارجية" (1)، وهذا عين تعريف الاكتفاء الذاتي المطلق، وعرفه

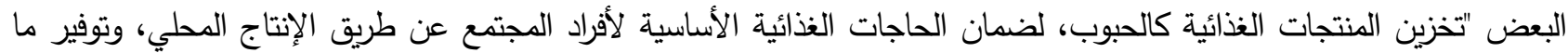

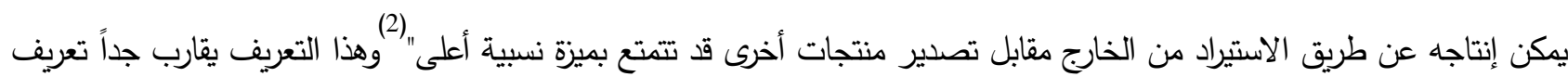

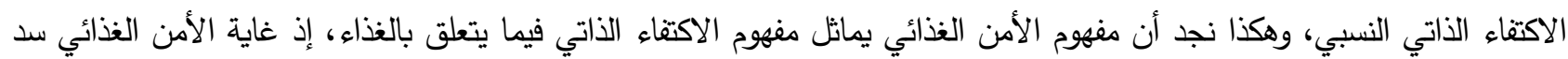

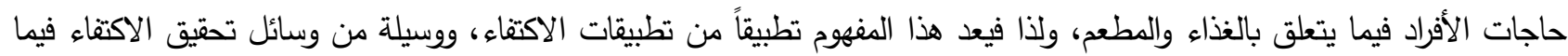

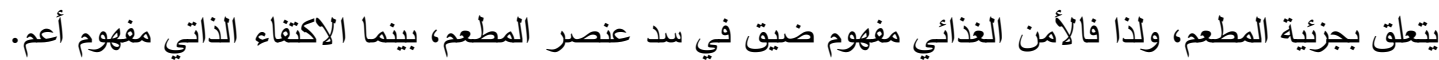
ثالثاً: الأمن البيئي: ترجع أصول نشأة مفهوم الأمن البيئي (الأمن الإيكولوجي) إلى القرن الثامن عشر مع أعمال "براون" (3)، حيث أعاد تعريف الأمن الوطني وجعل من أقسامه الحاجة إلى تقييم التهديدات النابعة عن علاقة الإنسان بالطبيعة، ليتطور بعد ذلك عبر الإنكان أبحاث متعددة وبتطور التحديات التي يعانيها العالم اليوم ليُعرّف بـ "قدرة أمة أو مجتمع على الصمود أمام ندرة الأصول البيئية، والمخاطر لئه

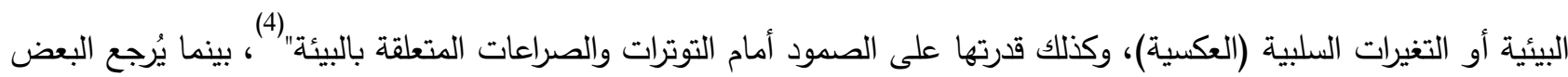
نشأة المفهوم بعد الحرب الباردة (5) وبالأخص عام 1992م بعد مؤتمر الأمم المتحدة للبيئة والتتمية ب"ريودي جانيرو" (6)، فالأمن

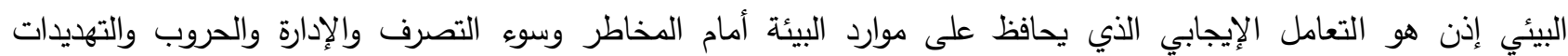
كالتصحر ومشكلة طبقة الأوزون والنمو الانفجاري للسكان وإزالة الغابات والحرائق والنفايات وتراجع مخزون الماء ل...الخ، وبهذا المعنى فالأمن البيئي لا بد منه للوصول للاكتقاء الذاتي، أي أن الأمن البيئي وسيلة من وسائل تحقيق الاكتئاء الذاتئي.

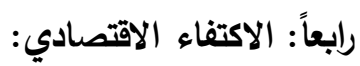
هذا المصطلح يُقصد به الاكتفاء الذاتي في المجال الاقتصادي، فُيُقال الاكتفاء الاقتصادي، أو الاكتفاء الاقتصادي الذاتي، ولذا فهذا المصطلح يعتني بجانب من جوانب الاكتفاء الذاتي، أما الاكتقاء الذاتي ففهوم أوسع يشمل مجالات الحياة المختلفة. المطلب الرابع: أنواع الاكتفاء الذاتي

تتعدد أنواع الاكتفاء الذاتي بتعدد الاعتبارات، ومن ذلك يمكن تقسيم الاكتفاء الذاتي باعتبار مُتعلَّقه إلى ما يلي:

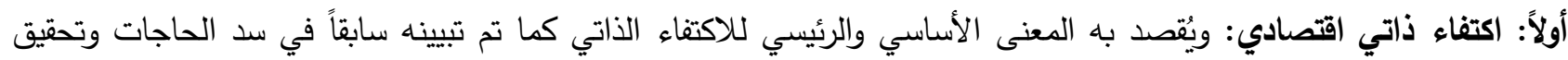
الكفاية للأفراد بجهودهم ابتداء من غير اعتماد على غيرهم، وعلى مستوى الأمة بحسن الاعتماد على الموارد المحلية واغتتامها

(1) طاهر وعصفور ، الدليل الموحد لمفاهيم ومصطلحات التخطيط في دول مجلس التعاون لدول الخليج العربية (ص59).

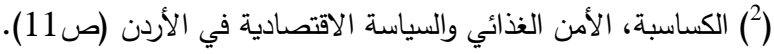

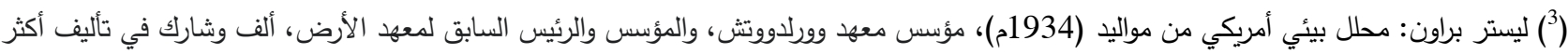

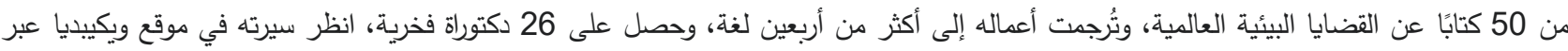
الرابط التالي: ليستير ر. براون - ويكيبيديا (wikipedia.org).

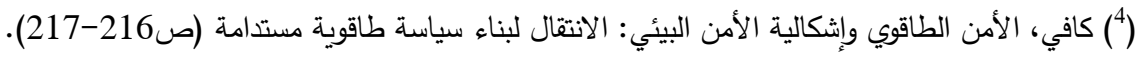

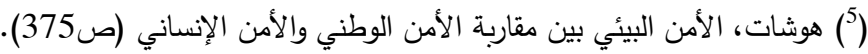

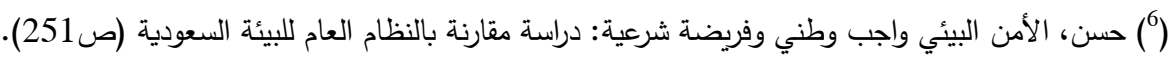


ثانياً: اكتفاء ذاتي في الكوادر: ويُقصد به سد الحاجة في الكوادر البشرية بمختلف التخصصات، وهذا يتطلب فقه الأولويات وتحقيق فروض الكفاية بتأهيل وتوفير كوادر زراعيين وصناعيين ومفتين وقضاة إلى غير ذلك مما يسد الحاجة في الكوادر .

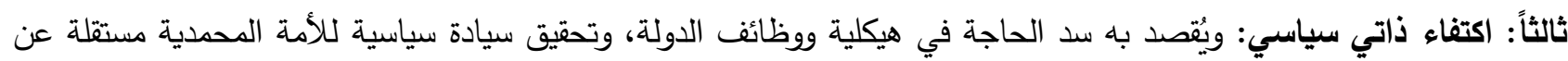

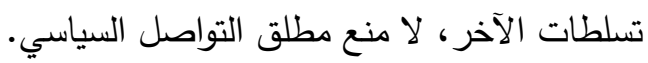

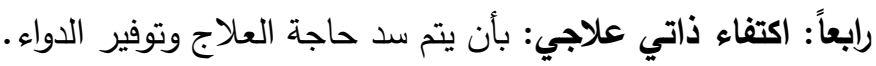

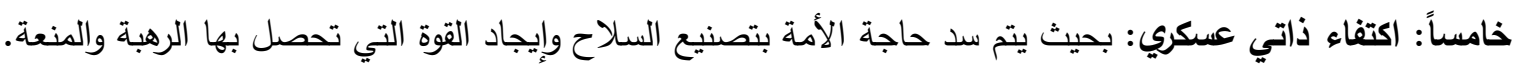
سادساً: اكتفاء ذاتي تقني: ويتم من خلاله سد حاجة الأفراد والأمة بما يتم تصنيعه لمختلف المجالات، وبتأمين سائر الخدمات لتحقيق مستوى لائق للمعيشة. وهذه الأنواع للاكتفاء بهذا الاعتبار مبنية بشكل أساسي على ما ذُكِر من عناصر الكفاية، ولذا أنواعه قد تزيد على ما تم ذكره، فيدخل في هذه الأنواع كذلك (اكتفاء ذاتي زراعي/ اكتفاء ذاتي صناعي/ اكتفاء ذاتي غذائي/ وغير ذلك من الأنواع) ولكنها بجملتها راجعة لما تم ذكره.

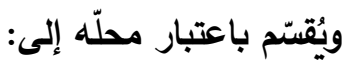
أولاً: اكتفاء ذاتي على مستوى الأفراد.

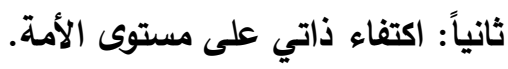

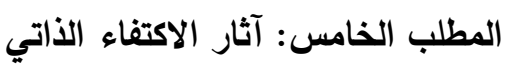
أولاً: الوصول للاكتفاء الذاتي يساهم في تحقيق الأمن الثامل، فسدّ حاجات المطعم يحقق الأمن الغذائي، وسد الحاجات في فروض الكفايات فيما يتعلق بالكوادر يقلل من البطالة ويؤدي إلى الأمان الوظيفي، وهكذا في بقية أنواع الاكتفاء الذاتي،

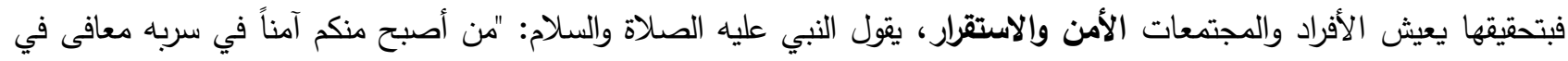

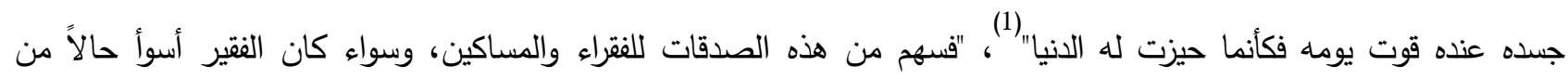

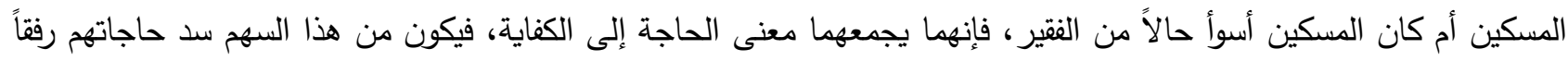

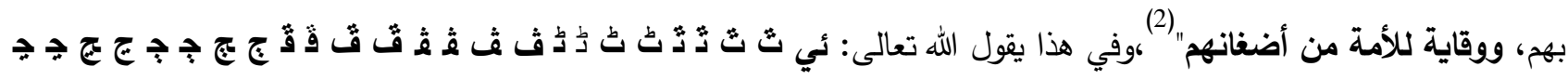
ج ئى [النحل: 112]، "العقلاء قالوا: ثلاثة ليس لها نهاية ... الأمن والصحة والكفاية" (3)، فالكفاية والأمن مرتبطان ارتباطاً وثيقاً.

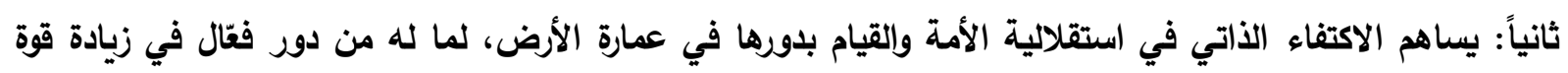

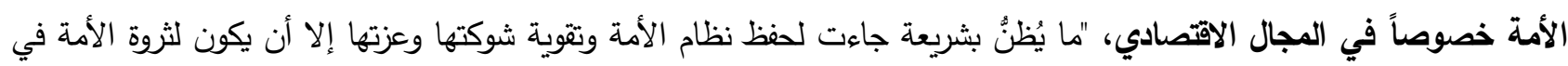
نظرها المكان السامي من الاعتبار والاهتمام"(4)، والثروة وسيلة الاكتفاء، لأن هذا المال المتداول بالبيع وغيره يؤدي لتحقيق الاكتفاء

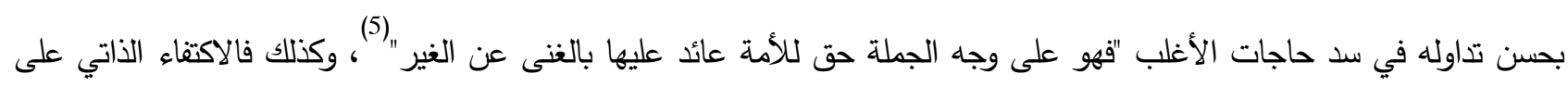

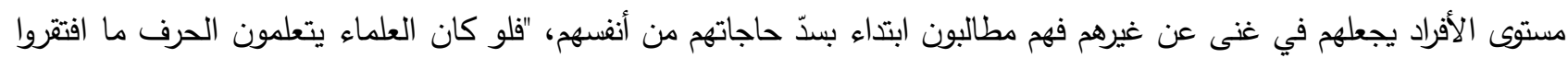

(1') الترمذي: سنن الترمذي، الزهد/باب في التوكل على الله، 574/4: رقم الحديث 2346]، قال الترمذي: هذا حديث حسن غريب.

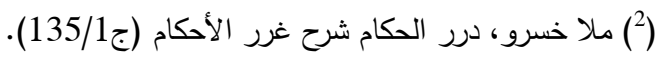

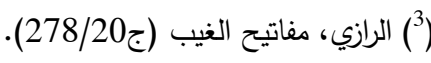

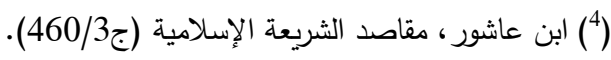

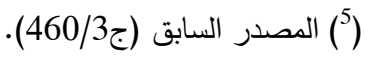


حتى يطمعوا في أموال الناس" ") ومن هنا كثرت المقولات والأمثال الدالة على ضرورة الاكتفاء: "من لا يأكل من فأسه، لا يتكلم

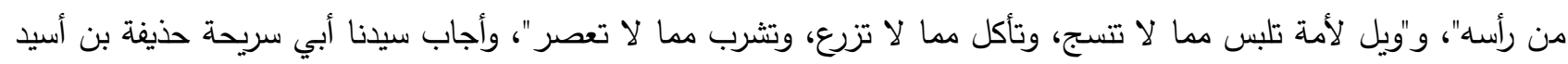

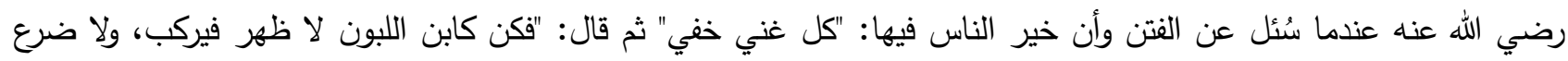
فيحلب"(2) "فالاعتبار المصيري ما يرفع شأن الأمة أمام أعدائها كالاهتمام بالزراعة ومنتجاتها وصناعاتها التحويلية وإقامة مبدأ

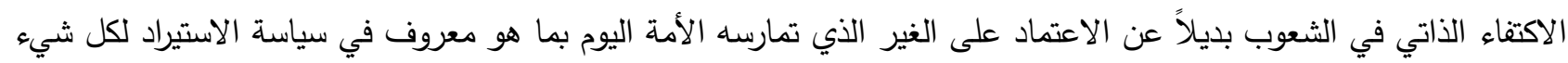

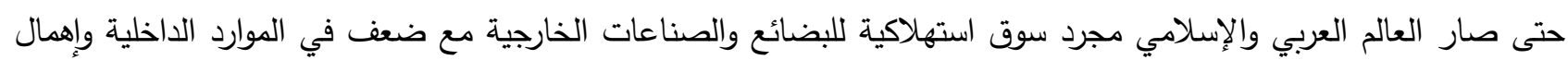
للزراعة وتربية الحيوان" (3). ثالثاً: تحقيق الاكتفاء يساهم في تأمين مستوى معيشي لائق لحياة الأفراد والأمم (4)، "فإن الثريعة قصدت من تشريعها في (كي التصرفات المالية إنتاج الثروة للأفراد ولمجموع الأمة" (5). رابعاً: الاكتفاء الذاتي الحل أمام الفتن، يقول النبي عليه الصلاة والسلام:"إنها ستكون فتن: ألا ثم تكون فتتة القاعد فيها خير من الماشي فيها، والماشي فيها خير من الساعي إليها. ألا، فإذا نزلت أو وقعت، فمن كان لله إبل فليلحق بإبله، ومن كانت لله غنم فليلحق بغنمه، ومن كانت له أرض فليلحق بأرضه" (6)، وهذا نص يرمز إلى ضرورة الاكتفاء الذاتي في الثروة النباتية

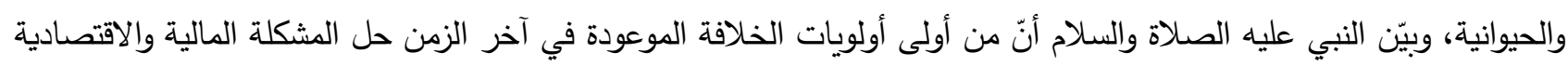

بعد أن يكون قد عم الفقر والجريمة، "يكون في آخر أمتي خليفة يحثي المال حثياً، لا يعده عدداً"(7).

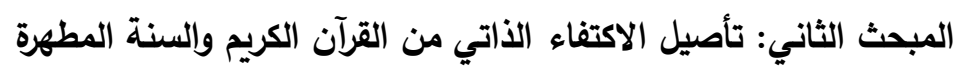
المطلب الأول: تأصيل الاكتفاء الأتي من القرآن الكريم الاكيفاء تضافرت آيات الكتاب العزيز لتأصيل الاكتفاء الذاتي وبيان وسائل تحقيقه، ولكثرة الثواهد القرآنية التأصيلية يمكن تقسيمها إلى زمر ومجموعات بحسب الموضوع. أولاً: الآيات القرآنية الدالة على الحاجات الأساسية للإنسان وتحقيق الكفاية فيها:

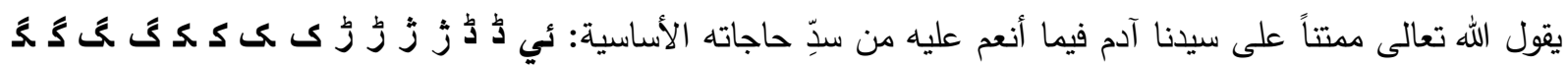
جُ ئى [طه: 118-119]، "الثبع والري والكسوة والكنّ (8) هي الأقطاب التي يدور عليها كفاف الإنسان، فذكره استجماعها له في (1) الكتاني، التراتيب الإدارية والعمالات والصناعات والمتاجر والحالة العلمية التي كانت على عهد تأسيس المدنية الإسلامية في المدينة المنورة العلمية (2) [الحاكم: المستررك على الصحيحين، الفتن والملاحم/أما حديث أبو عوانة، 574/4: رقم الحديث 8612]، قال الحاكم: بأنه حديث صحيح الإسناد، وعلق الذهبي أنه على شرط البخاري ومسلم. (3) المشهور، الأسس والمنطلقات في تحليل وتفصيل غوامض فقه التحولات وما يرتبط به من سنن المواقف والدلالات المستنبطة من علامات الساعة

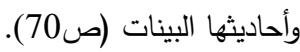

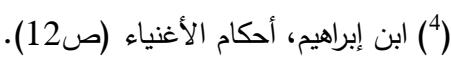

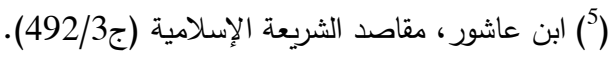

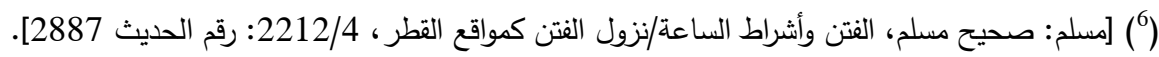

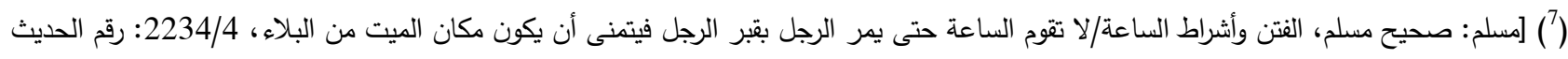


الجنة، وأنه مكفي لا يحتاج إلى كفاية كاف ولا إلى كسب كاسب كما يحتاج إلى ذلك أهل الدنيا"(1)، وهكذا بينت هذه الآية أبرز ما

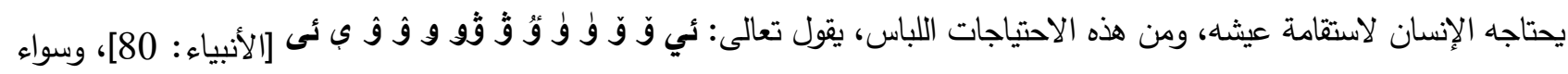
على القول بأن المراد هنا عموم اللباس أو اللباس الحربي وهو الدرع، فكلاهما حاجة إما لستر البدن أو لحماية المقاتلين أو غيرهم وقت الحروب وانعدام الأمن (2).

وهكذا فقد بيّن الله عز وجل في كتابه نماذج من الحاجات الأساسية للإنسان التي لا بد من سدها وتحقيق الكفاية فيها.

$$
\text { ثانياً: الآيات التي تحثّ على العمل والكسب: }
$$

بيّنت الآيات أن الإنسان خليفة في الأرض ودوره عمارتها، ومن أجل ذلك سخّر الله عز وجل لهات له ما في السماوات والأرض كما أتت بذلك نصوص الكتاب، وهذا كله يدفع الإنسان إلى العمل ليقوم بدوره الأساسي في هذه الأرض وسداً لحاجاته الأساسية، بل إن الله عز وجل ربط العبادات كذلك بمقاصد اقتصادية تساهم في تحقيق الاكتقاء الذاتي، فاغتتم الإسلام التجمعات الكبرى الإنى الإنى

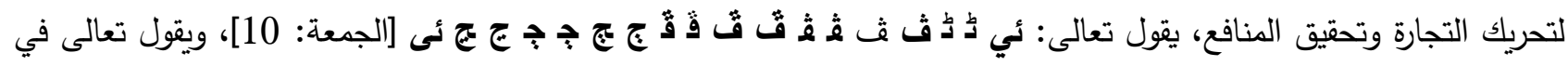

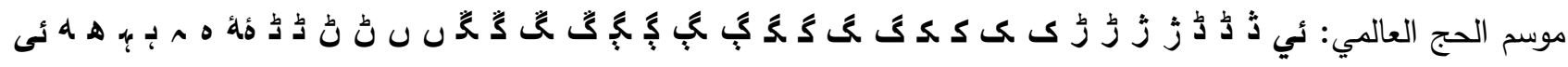
[الحج: 27-28]، "منافع في الدنيا ومنافع في الآخرة فأما منافع الآخرة فرضوان الله تعالى، وأما منافع الدنيا فما يصييون من لحوم البدن في ذلك اليوم والذبائح والتجارات" (3).

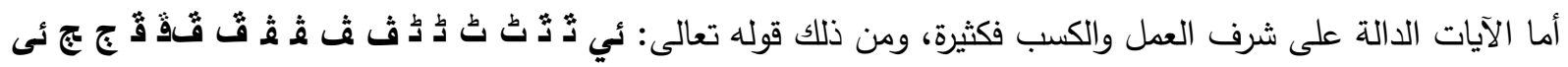

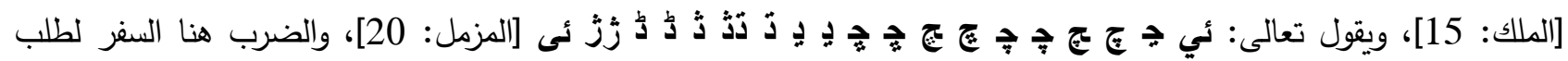

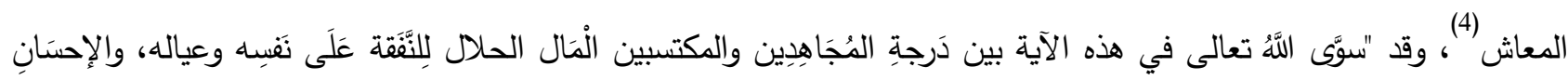

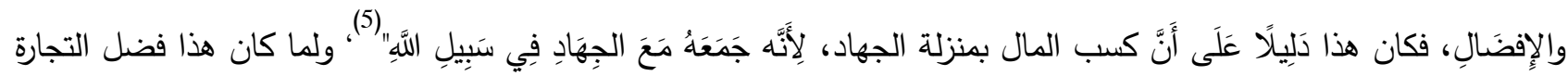
كانت عقوبة الحرابة من أثد العقوبات لما فيها من إخافة الناس عن السفر، فيلزموا البيوت وتتسد أبواب التجارات (6)، وحينها تفقد الأمة اكتفاءها ومن قبل الأفراد. وغاية هذا الضرب في الأرض، وهذه التجارات وهذا الكسب، هو الوصول للاكتفاء الذاتي وتحقيق سد الحاجات الأساسية لكأفراد والأمة.

\section{ثالثاً: الآيات الحاثة على الإنفاق وأداء واجب الزكاة لتحقيق التكافل بين أفراد المجتمع:}

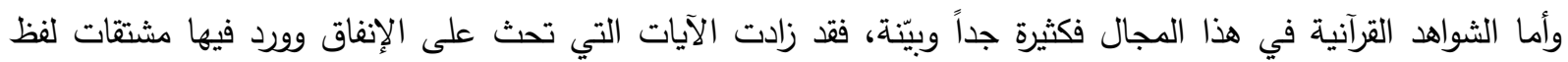
(نقق) عن سبع وخمسين آية بأكثر من اثثين وسبعين تكراراً لهذه المشتقات، ووردت كلمة الزكاة في القرآن في اثثين وثثلاثين آية،

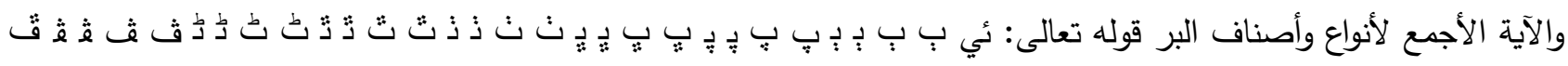

$$
\begin{aligned}
& \text { (1) الزمخشري، الكثاف عن حقائق غوامض التنزيل (ج2/3) (168/22). } \\
& \text { (2) (الرازي، مفاتيح الغيب (ج) (168/22). }
\end{aligned}
$$

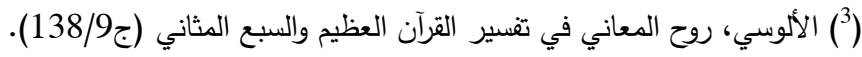

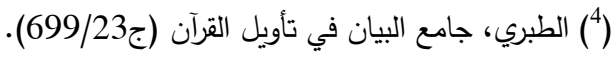

$$
\begin{aligned}
& \text { (5) القرطبي، الجامع لأحكام القرآن (ج5/19). } \\
& \text { (6) المدر السابق (ج157/6). }
\end{aligned}
$$




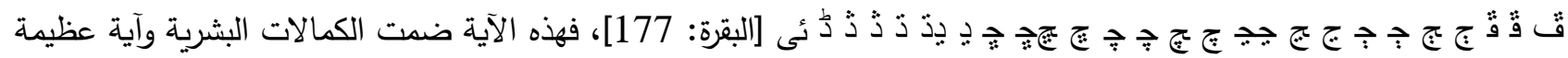
من أمهات الأحكام (1) وتُعدّ الزكاة والصدقة والإنفاق أعظم الوسائل لسد الحاجات الأساسية وتحقيق الكفاية لمن لم يستطع سدها، فهذه الوسائل تمثل تحقيقاً وتطبيقاً للاكتفاء الذاتي كحل من حلول الثريعة لمشكلة عدم كفاية الحاجات الأساسية لطبقات في المجتمع.

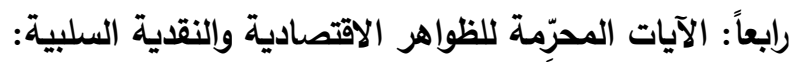
تناولت آيات القرآن كثيراً من الظواهر التي تؤثر سلباً على العملية الاقتصادية، وبالتالي فإن ذلك سيؤدي إلى عرقلة تحقيق الاكتفاء الذاتي، بما يرتبط بهذه الظواهر من مشكلات كبرى تلحق الإنتاج والتوزيع العادل للدخل وغيرها من مشاكل التضخم الاقتصادي وضعف القوة الشرائية وغير ذلك مما يزيد الفقر في المجتمعات وعدم تحقيق الكفاية. ومن أبرز هذه الظواهر التي حاربتها آيات الكتاب (الاكتناز / الربا).

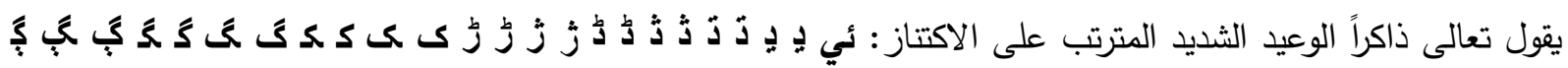

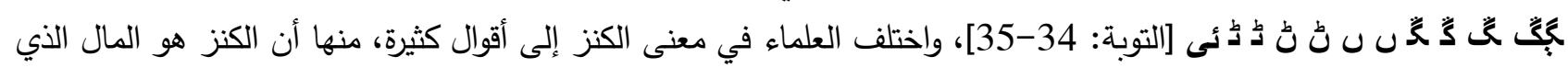
لم تؤدَّ زكاته وهذا قول المذاهب الأربعة (2)، وقيل هو ما فضل عن الحاجة وهذا رأي أبي ذر، وبين العلماء أن هذا على فرض

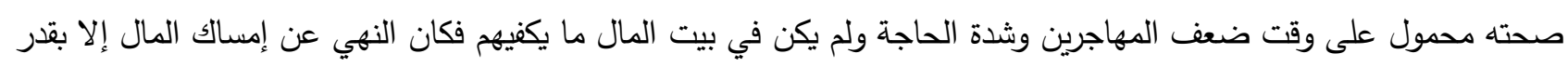

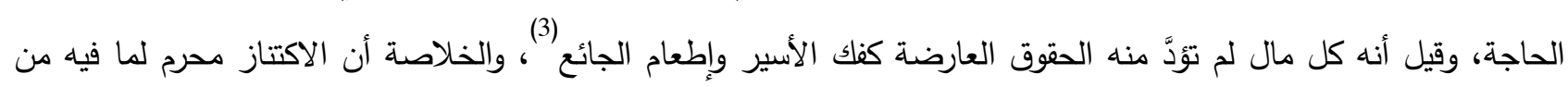

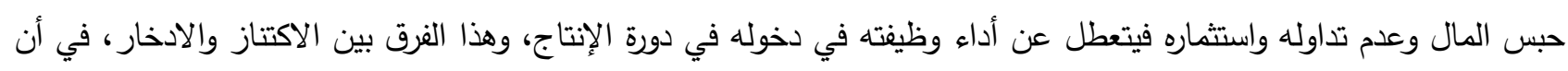

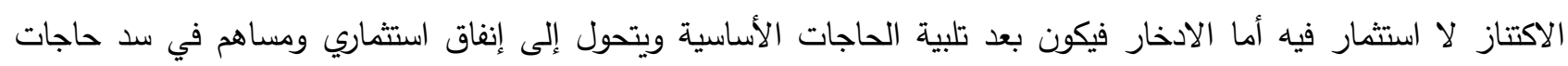

المجتمع.

وأما الربا فقد جاء تحريمه صريحاً في أكثر من موضع من كتاب الله عز وجل، يقول تعالى: ئي ثـ دُّد ف فـث ئى [البقرة:

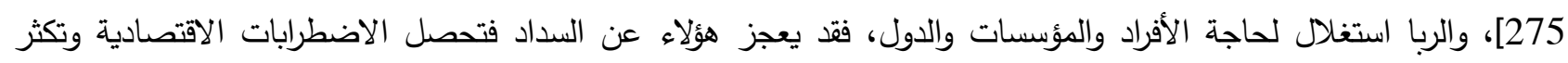
الجرائم وتزداد الطبقية المجتمعية والاقتصادية ويحصل التضخم ويزداد الفقر ويزول تحقيق الاكتفاء الذاتي، ولذلك وعد الله من يلتزم

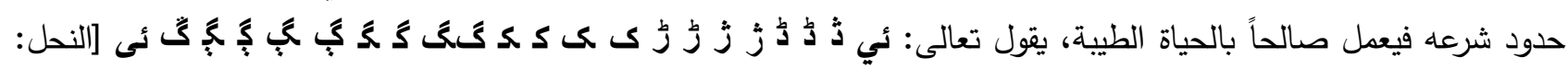
97، جاء في معنى الحياة الطيبة أنها الكفاية(4). خامساً آيات المواريث والوصايا:

تتوعت وسائل سد حاجات أفراد المجتمع، وكذلك وسائل دخلهم، ومن ذلك نظام الميراث والوصايا في الإسلام، ففيه يكون

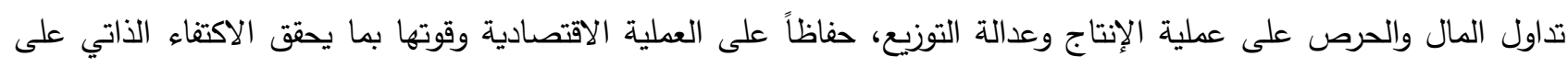

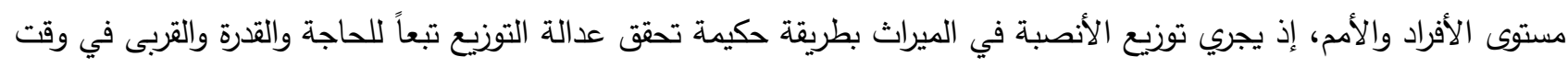
واحد، فالذكر يُعطى ضعف نصيب الأنثى؛ لأنه مكلف بالإنفاق على نفسه وعلى الأنى من يعول، وكذلك يُراعى في توزيع الأنصبة وجود

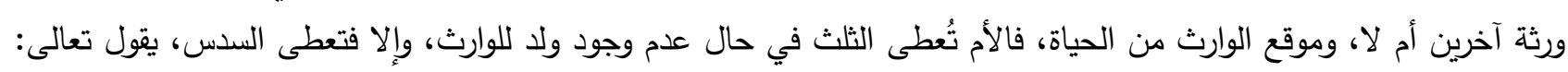

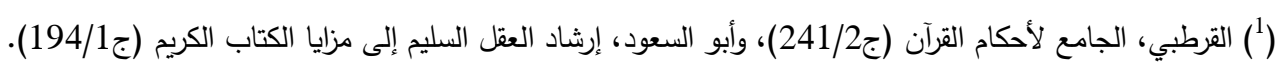

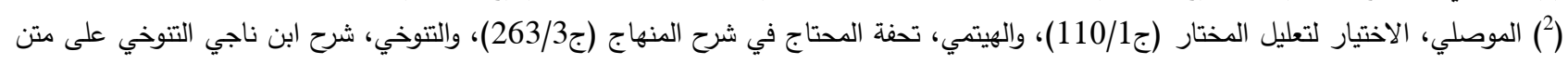

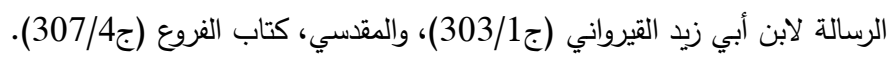

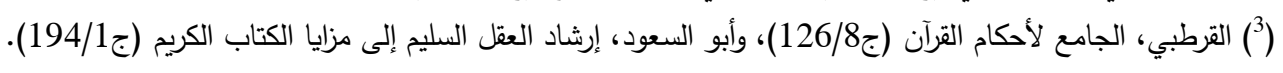

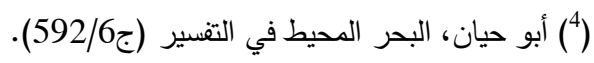




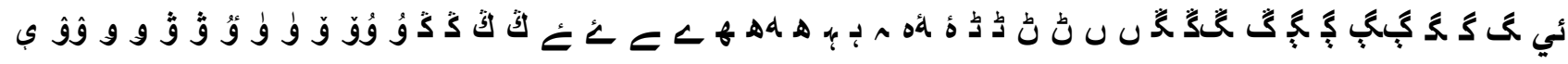

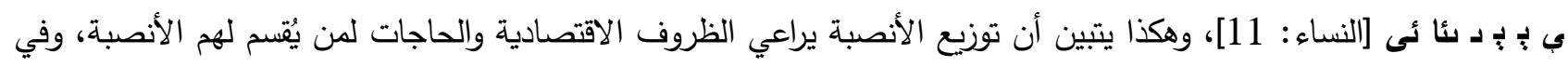

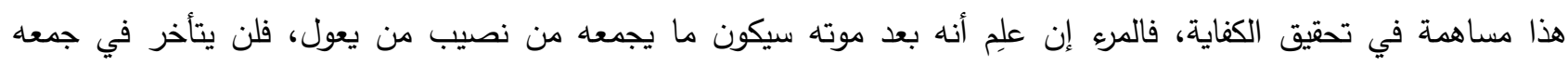
وسيحرص عليه كفاية لمن بعده ؛) وكذلك في الوصايا فينفتح فيها باب الإنفاق في وجوه الخير مع مراعاة كفاية الورثة فلا تكون الوصية أكثر من الثلث، وفي هذا رعاية لحق المحتاجين ولحق الورثة. سادساً: آيات النفقة:

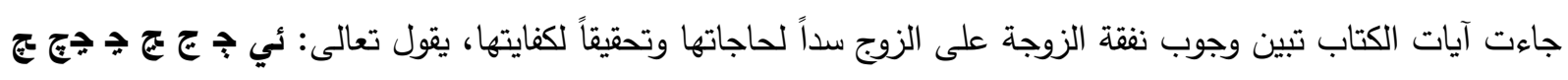

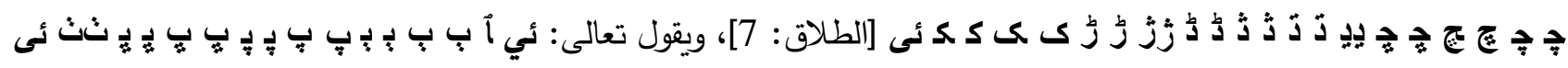
[النساء: 34]، "لينفق أي لينفق الزوج على زوجته وعلى ولده الصغير على قدر وسعه حتى يوسع عليهما إذا كان موسعاً عليه،

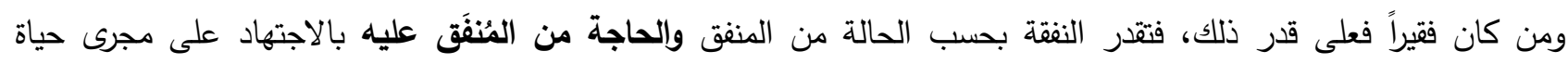
العادة" (2) وهكذا فيكون الإنفاق بحسب حال الزوج وبحسب كفاية الزوجة كذلك.

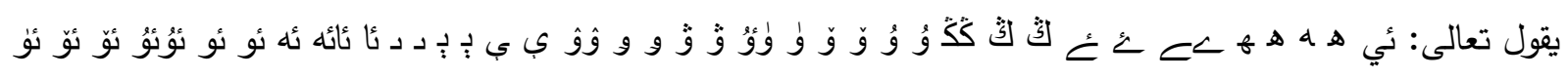

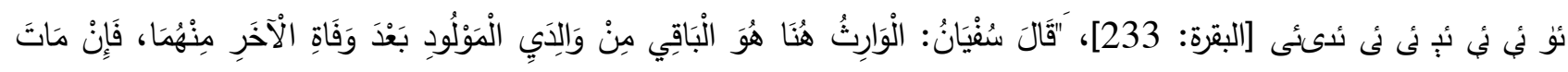

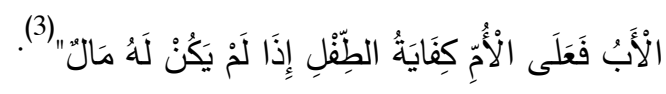

سابعاً: الآيات الدالة على ضرورة تأهيل السفهاء والأيتام لتحقيق كفايتهم:

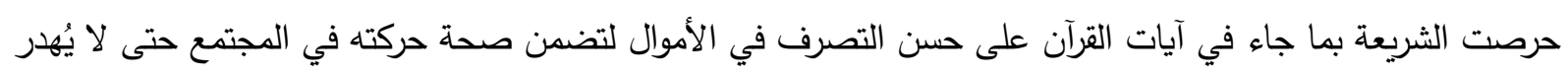

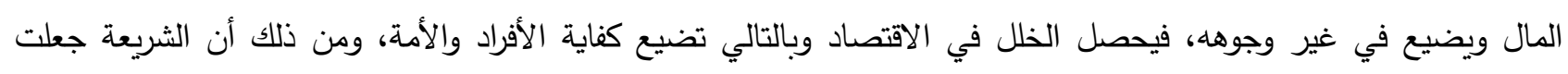

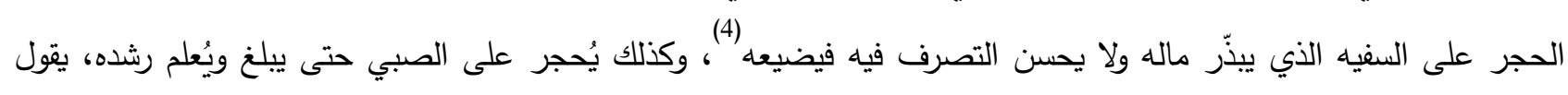

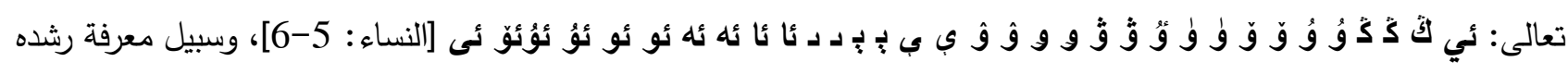

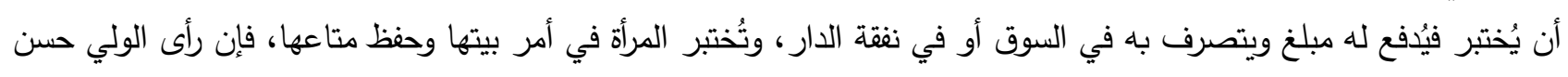
تصرفه ورشده يدفع له المال (5)، وهذا كله للتأكد من قدرة الإنسان على كفاية نفسه بنفسه وتأهله لذلك، وحفظاً للمال فلا يضيع سدى ويضيع معه الاكتفاء الذاتي. ثامناً: الآيات الدالة على دور الدولة في توزيع الثروة وتحقيق الكفاية للمواطنين:

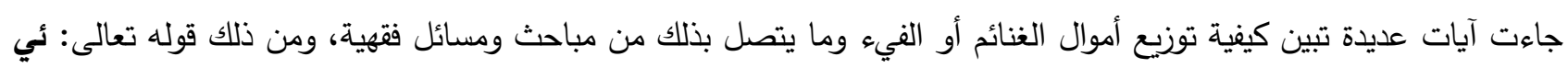

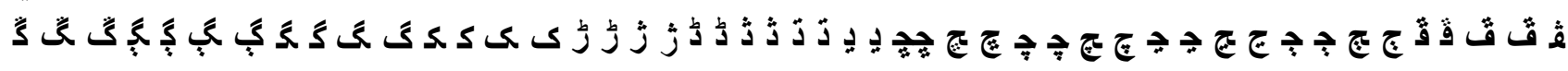

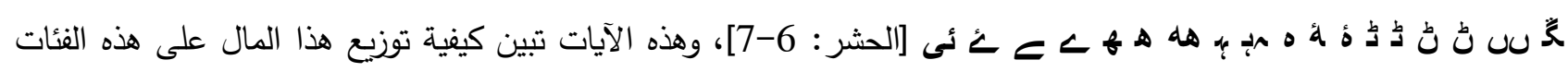

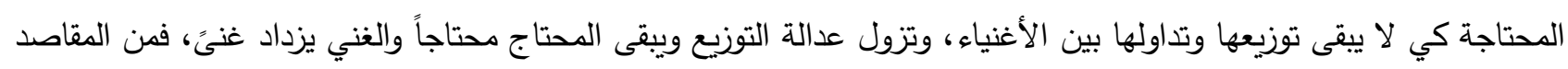

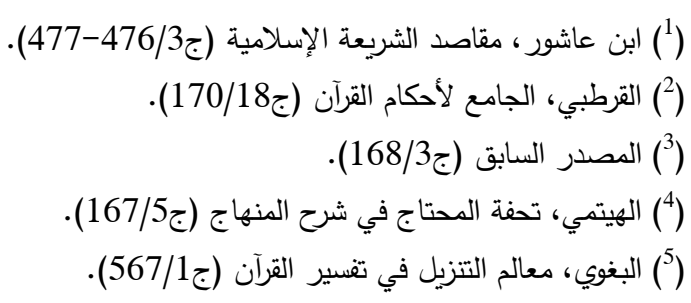


الثرعية للأموال الرواج، والرواج يحصل بأن يدور المال بين أيدي أكثر من يمكن من الناس بوجه حق (1)، وإن هذا من أعمال

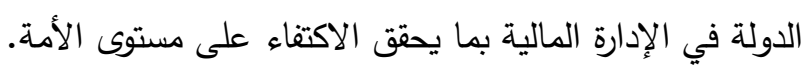

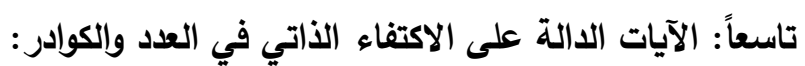

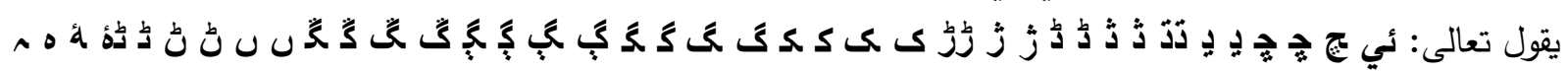

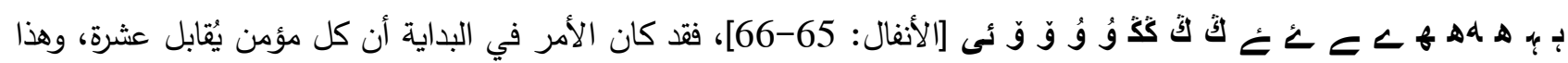

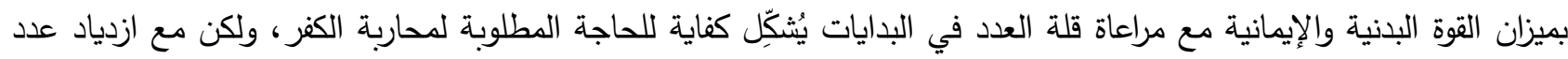
المسلمين وبروز الضعف البدني تغير معيار الكفاية ليكون الواحد يقابله اثنان من أهل الكفر .

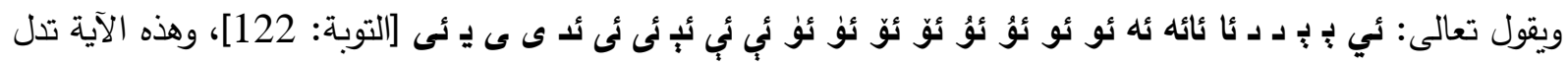

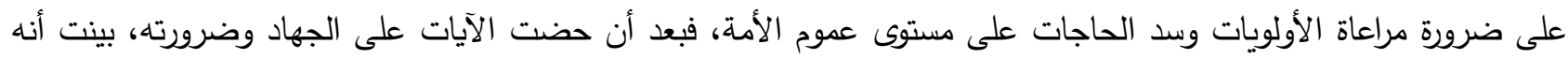
ليس من المصلحة تمحّض المسلمين كلهم ليكونوا غزاة، بل لا بد من وجود طائفة تتفرغ لتعلم الدين والفقه، ليسدوا الحاجة ويحققوا

للأمة كفايتها في جانب التعليم والإرشاد (2). عاشراً: الآيات الدالة على الاكتفاء الذاتي من أسباب القوة في مواجهة العدو:

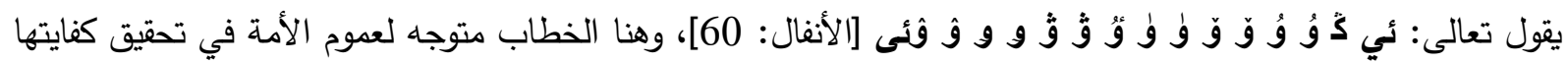

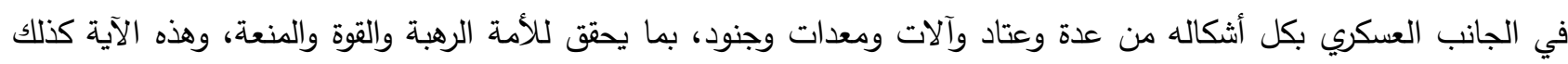
تؤصل للاكتفاء الذاتي على مستوى عموم الأمة.

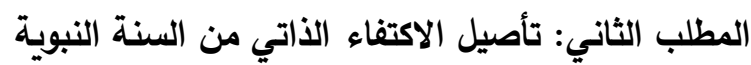

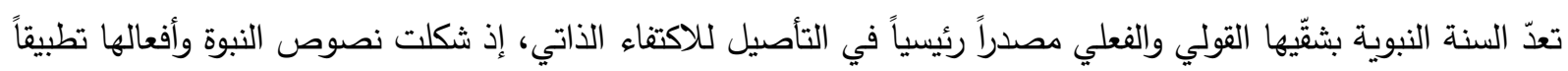
حقيقياً للسعي نحو الاكتفاء الذاتي وتثجيعه وتأصيله وبيان وسائله، ومن ذلكئك الكئل أولاً: السنة النبوية الدالة على ضرورة سد الحاجات وتحقيق الكفاية فيها:

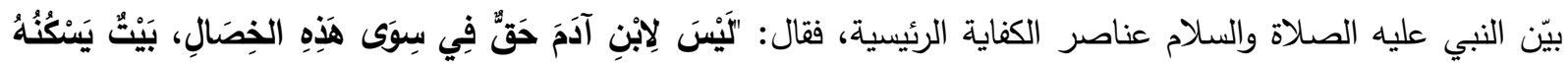

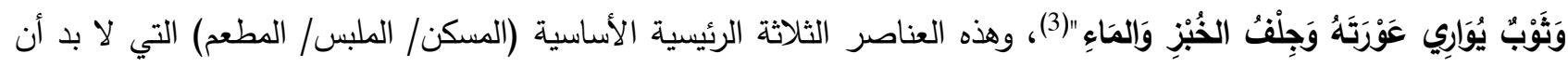

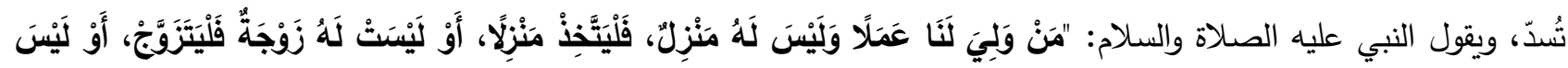

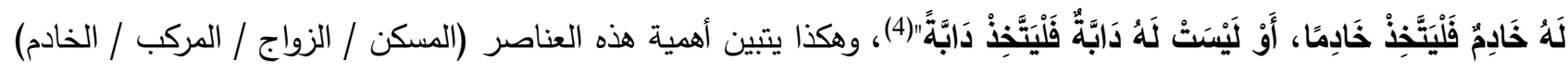
بأن يسدها الإنسان من عمله.

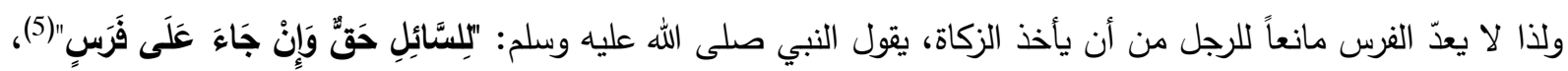

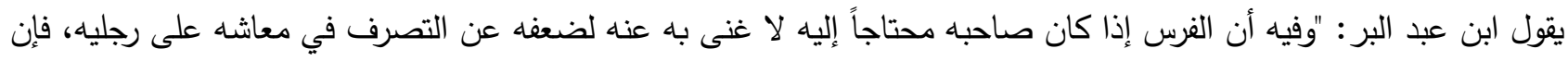
ملكه للفرس لا يخرجه عن حد الفقر "(6).

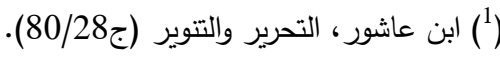

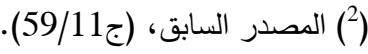

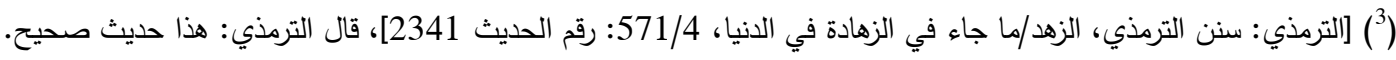

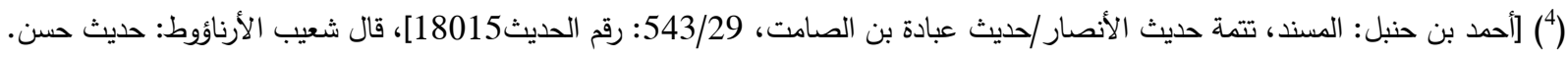

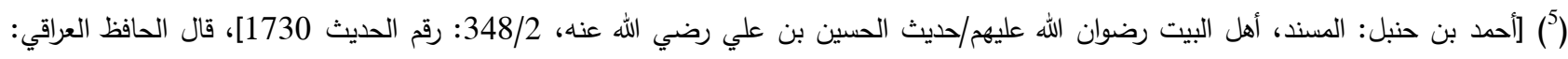

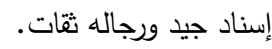

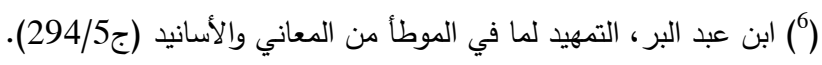




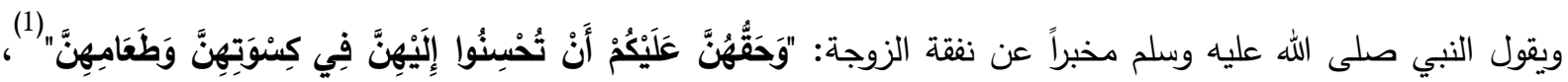

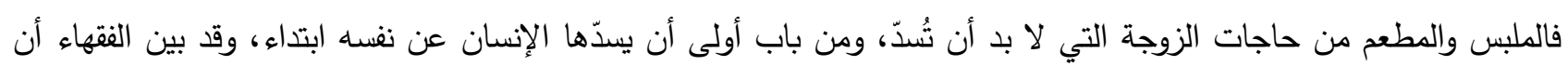
هذه معتبرة بكفايتها وليست مقدرة بالشرع (2) لاختلاف الطول والقصر والسمن والهزل (3) واختلاف البلاد في الحر والبرد (4)، فكل ذلك يُراعى في كفاية الزوجة في ملبسها. ويقول النبي عليه الصلاة والسلام مخبراً عن ضرورة أن يسدّ الرجل حاجة زوجته وأولاده ومن يعول بالتعليم لا سيما في

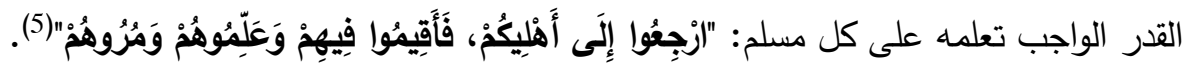

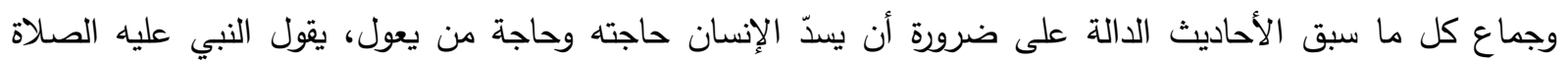

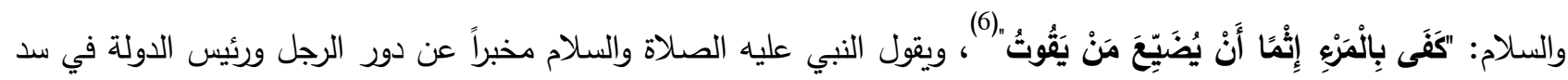

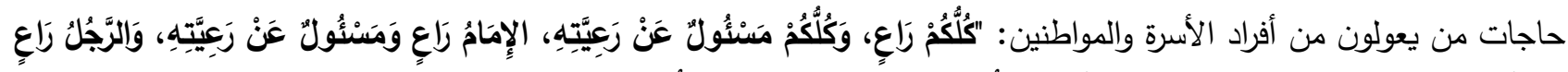

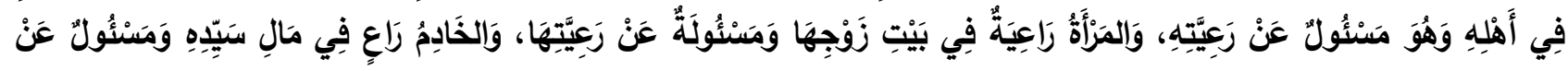

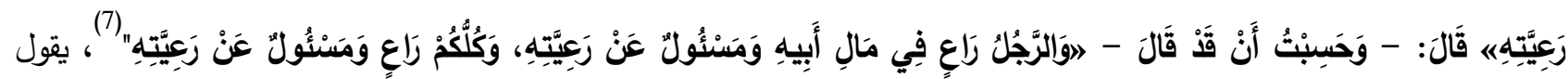

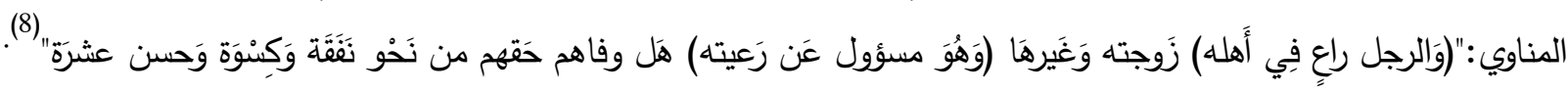
ومن هنا كان النبي عليه الصلاة والسلام يحبس لأهله قوت سنتهم (9)، وفي كلمة (أهله) بيان بسعيه عليه الصلاة والسلام

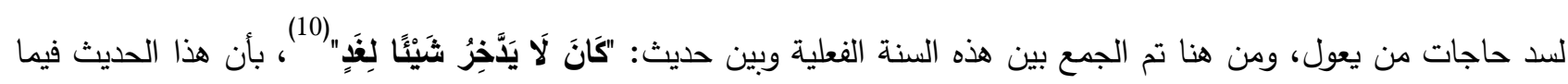
يدخره لنفسه وذاك فيما يدخره لأهله تحقيقاً لكفايتهم (11). وسد الحاجات لا يقف عند حاجات البشر، بل يتسع ليشمل سد حاجات الحيوان، يقول النبي عليه الصلاة والسلام: "بَيْنَمَا

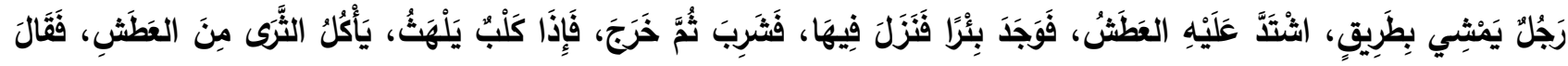

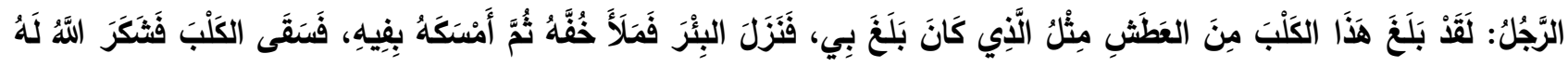

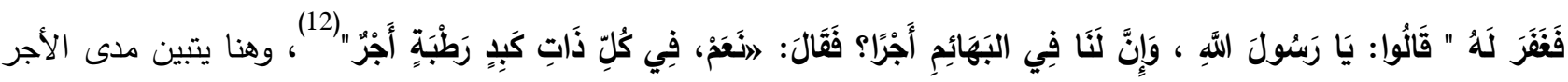

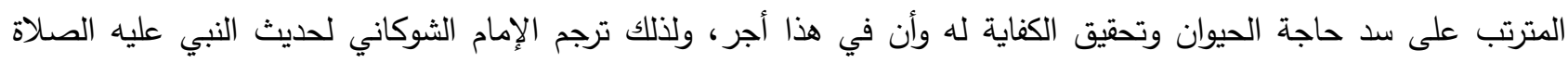

(1) [الترمذي: سنن الترمذي، الرضاع/ما جاء في حق المرأة على زواجها، 459/3: رقم الحديث 1163]، قال الترمذي: حديث حسن صحيح.

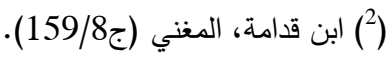

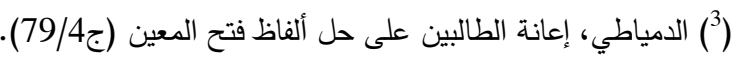

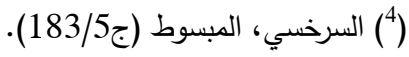
(5) [البخاري: صحيح البخاري، الأذان/الأذان للمسافر إذا كانوا جماعة والإقامة وكذلك بعرفة وجمعة وقول المؤذن الصلاة في الرحال في الليلة الباردة أو

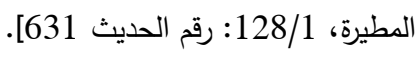
(6) [أحمد بن حنبل: المسند، الشاميين/حديث المستورد بن شداد، 36/11: رقم الحديث 6495]، قال شعيب الأرناؤوط: حديث صحيح.

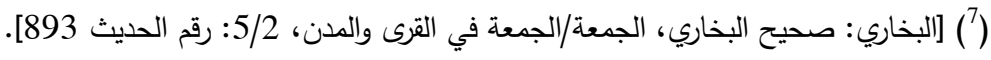

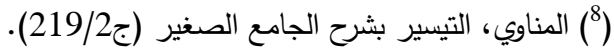

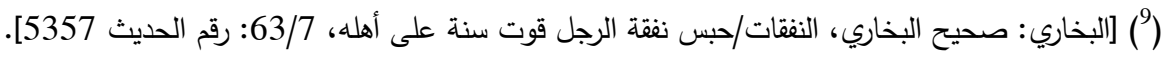
(10) [البيهقي: شعب الإيمان، حب النبي عليه الصلاة والسلام/في زهد النبي صلى الله عليه وسلم وصبره على شدائد الدنيا، 65/3: رقم الحديث 1402]، قال أبو سهل: حديث صحيح.

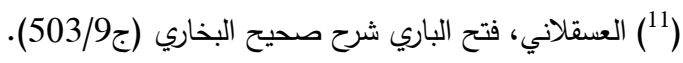

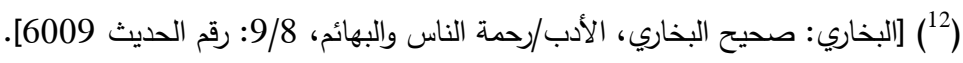




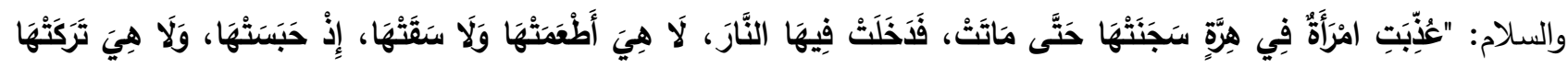

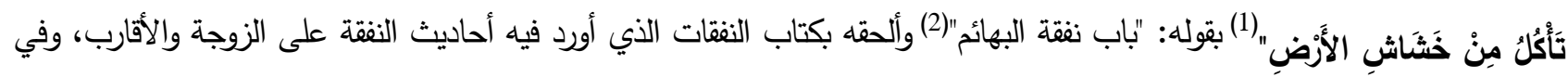
هذا إثارة بأنه كما تسدّ حاجات من يعوله الإنسان فقسدّ حاجات الحيوان.

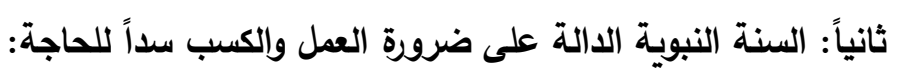

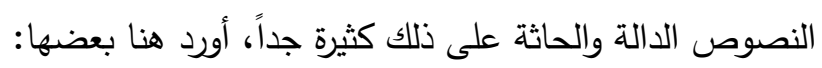

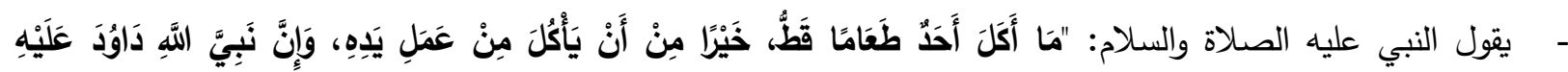

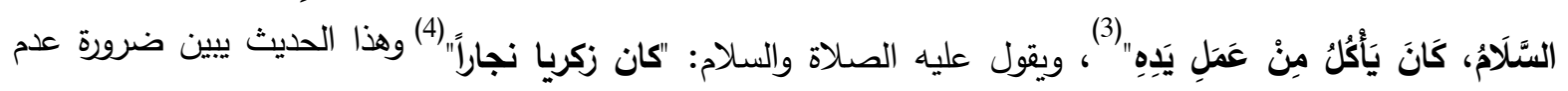

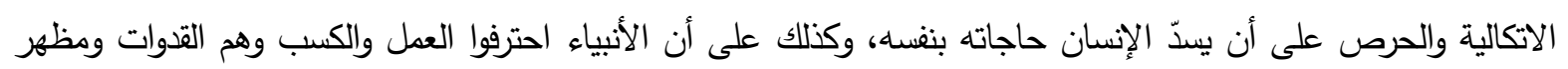
التأسي.

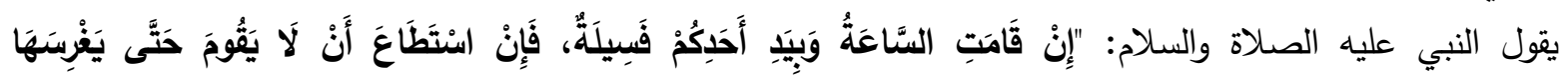

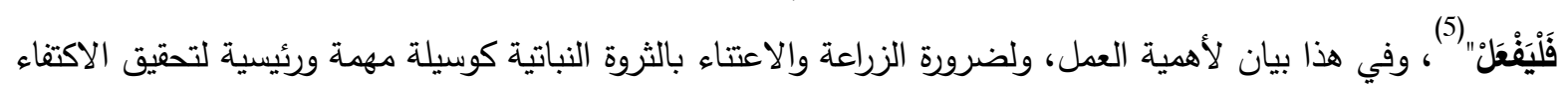

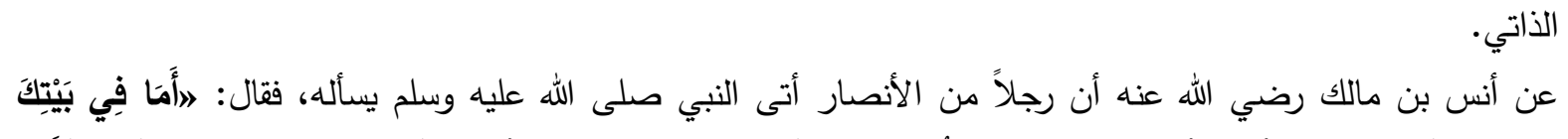

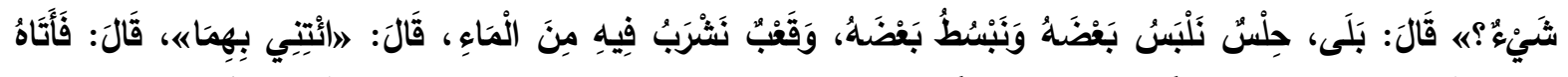

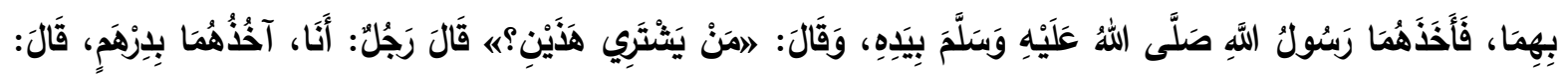

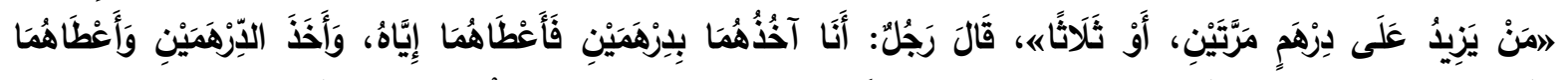

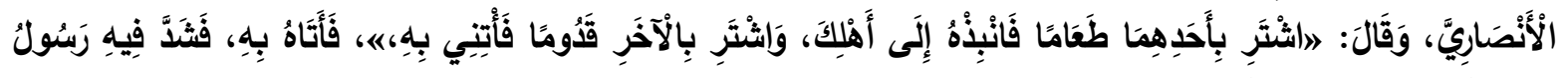

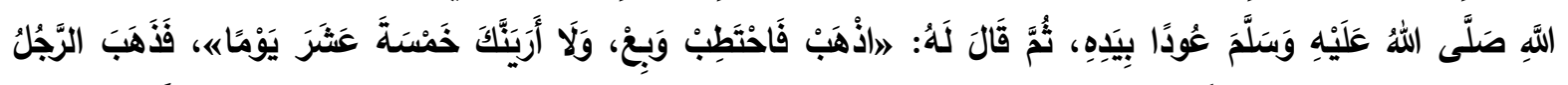

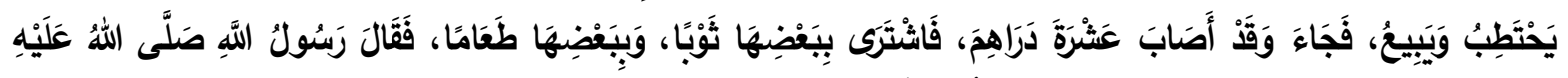

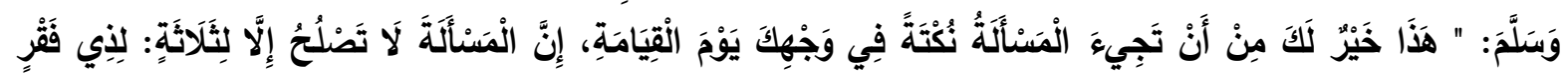

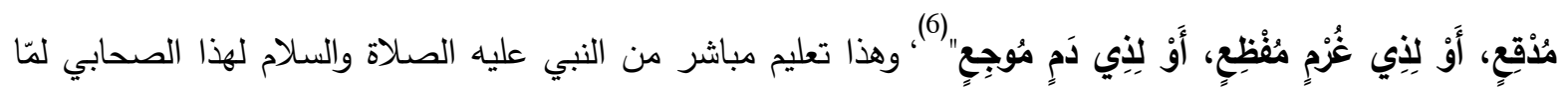

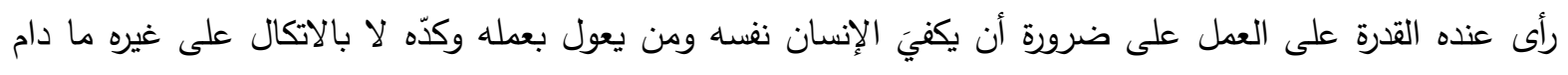

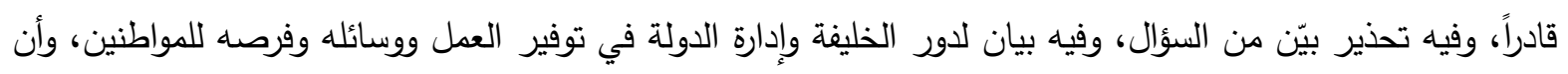

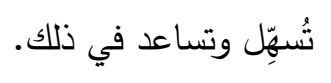

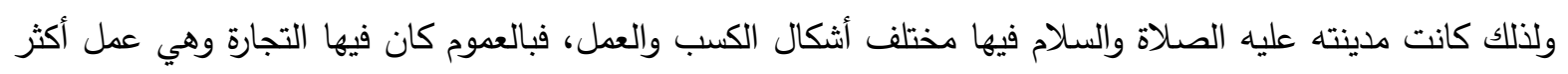

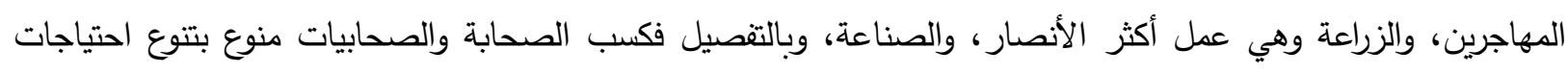

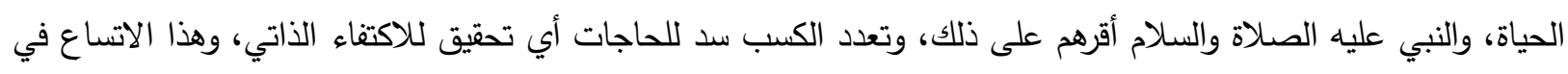

(1) [البخاري: صحيح البخاري، أحاديث الأنبياء/حديث الغار ، 176/4: رقم الحديث 3482].

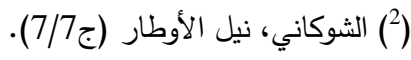

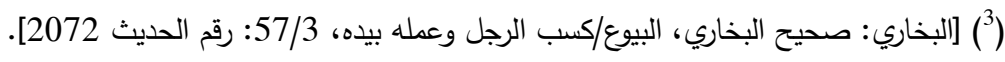

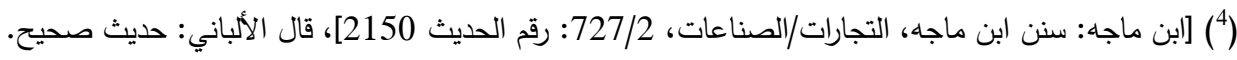

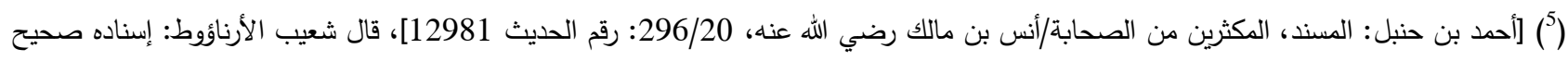


المهام والأعمال يدل على حسن الإدارة النبوية وتوجيه المهام لسد جميع الحاجات وتحقيق الاكتفاء والحث على العمل والإنتاج، وأن الإنسان وسيلة التنمية وتحقيق الكفاية. ويلحق بهذا القسم التوجيهات النبوية الحاثة على الاستثمار، والاستثمار من أوسع الأبواب لتحقيق الاكتفاء، وهذا الاستثمار محكوم بعدد من الموجهات النبوية، ومن ذلك التوات

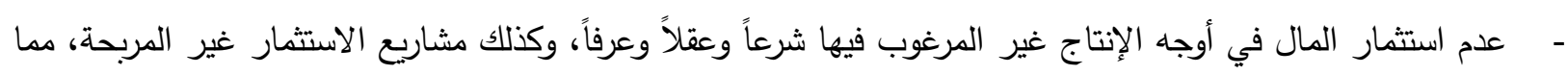

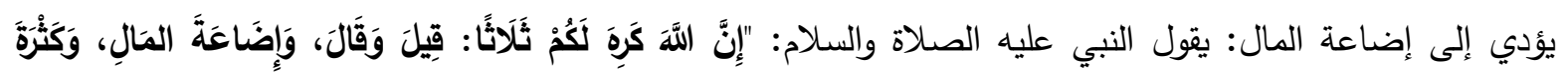
(السُؤَألِ" (1). - الحرص على الأماكن والأزمان المناسبة للاستثمار : يقول ابن عباس رضي الله عنهما: "كانت عكاظ ومجنة وذو المجاز

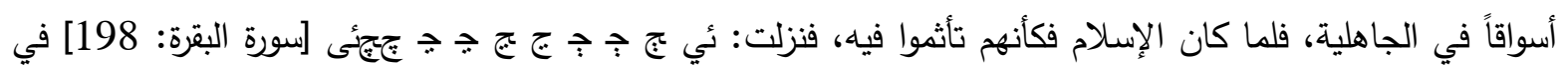
مواسم الحج" قرأها ابن عباس (2) وفي هذا اغتتام لمواسم العبادة التي فيها التجمعات للاستثمار، فمواسم عكاظ ومجنة

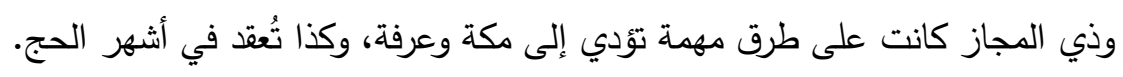

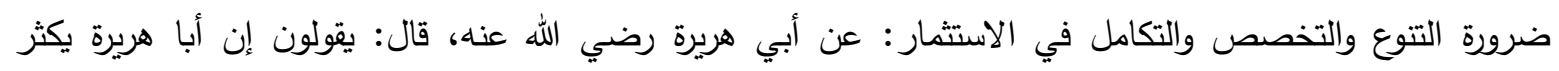

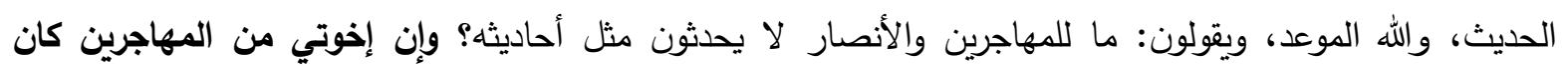
يثغلهم الصفق بالأسواق، وإن إخوتي من الأنصار كان يشغلهم عمل أموالهم..." (3).

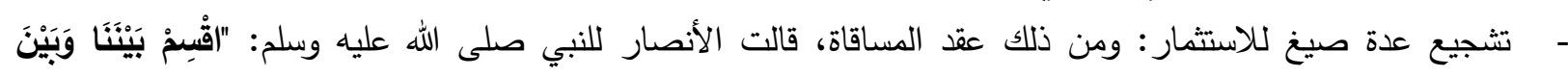

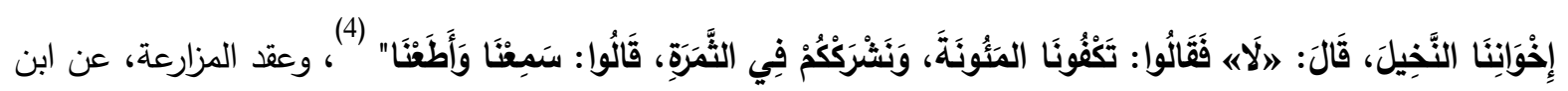

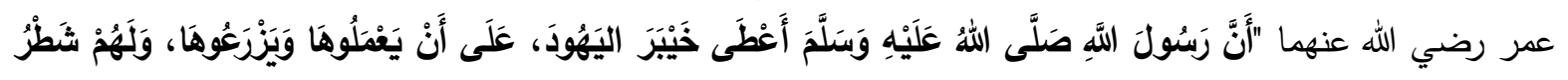
مَا خَرَجَ مِنْهَا" (5) وهذه تُعدّ من صيخ الاستثمار المشجعة للإنتاج الزراعي، ومن صيغ الاستثمار التي تُعدّ من قبيل تمويل الإنتاج المستقبلي (عقد السَّلَ)، عن ابن عباس رضي الله عنهما، قال: قدم النبي صلى الله عليه وسلم المدينة وهم

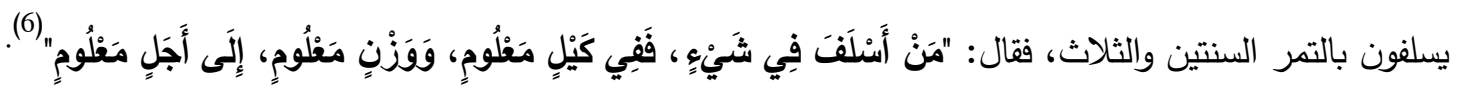

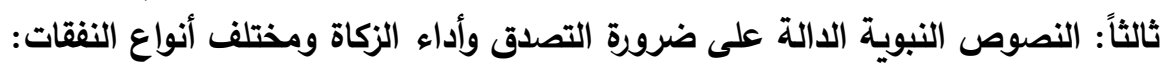

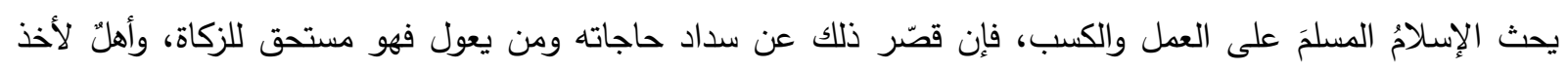

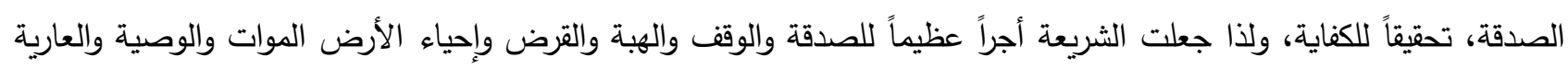
وغير ذلك من صور المعونات. والزكاة من أعظم أركان الإسلام، فهو نظام تكافلي يضمن سد الحاجات بين أفراد المجتمع الواحد، ومن أهم أدوار الدولة

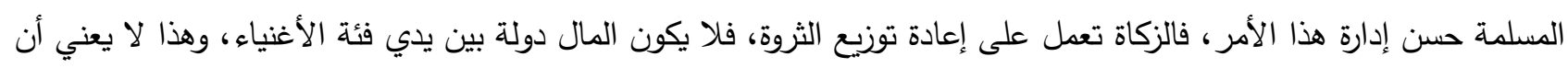

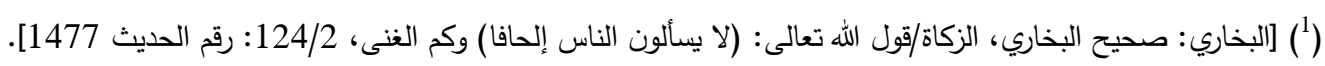
(2) [البخاري: صحيح البخاري، البيوع/ما جاء في قوله تعالى: (فإذا قضيت الصلاة) وقوله: (وإذا رأوا تجارة أو لهؤا....) وقوله: (لا تأكلوا أموالكم)، 53/3: رقم الحديث 2050].

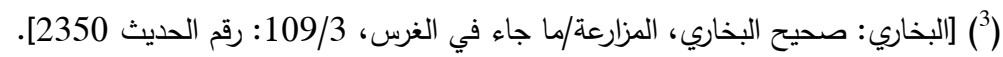

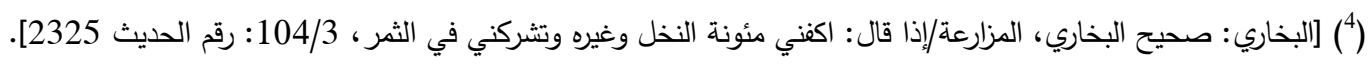

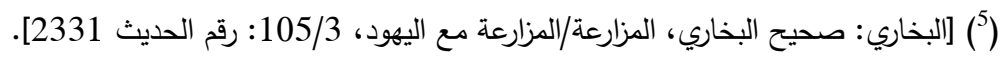

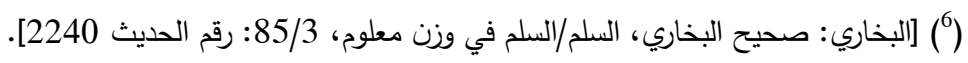


يؤدي ذلك إلى إضعاف الأغنياء، فأنصبة الزكاة راعت أن يعيش المُزكّي عيشة كريمة، فشاة واحدة في أربعين إلى مائة وعشرين

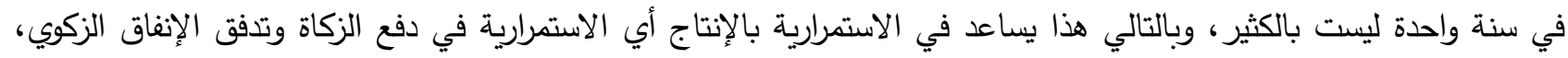

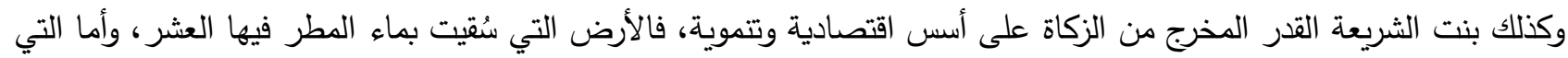
سُقيت بماء النضح فنصف العشر، وهكذا فنصوص النبوة حثت وأكدت على ضرورة الزكاة وبينت أنصبتها والقدر المخرج عن أموالها بالتفصيل، وحذرت من تركها، لما في ذلك من إخلاء بتحقيق الاكتفاء، يقول النبي صلى الله عليه وسلم: "...ولا مَنَع قومٌ الزكاة إلا حَبس اللهُ عنهم القَطر" (1)، فيظهر ارتباط منع دفع الزكاة بتوقف نزول المطر وبالتالي تأثر الإنتاج الزراعي، فمنعوها خوفاً على مالهم فابتلاهم الله في رزقهم. أما الصدقة فجاءت النصوص في الحث عليها، وأن يتصدق الإنسان بعدما يفي بحاجاته وحاجات من يعول، وأن الأولى

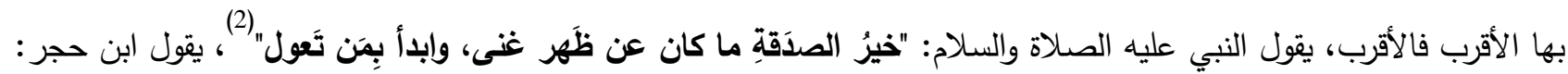

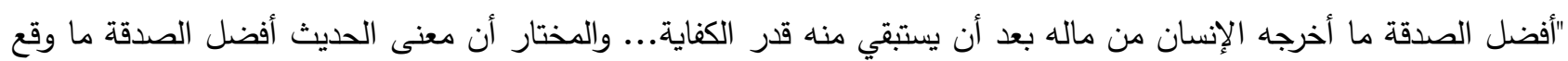
بعد القيام بحقوق النفس والعيال بحيث لا يصير المتصدق محتاجاً بعد صدقته إلى أحد"|(3)، والصدقة أوسع من الزكاة في مجالات مصارفها والحالة المالية للمُتصدق، فهي تُقيل كثيراً من العثرات لا سيما وقت الجوائح.

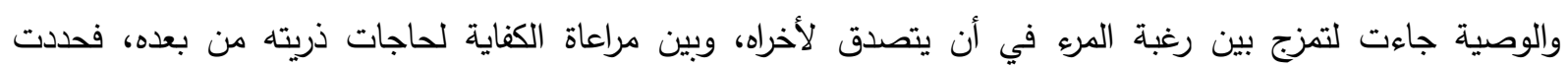

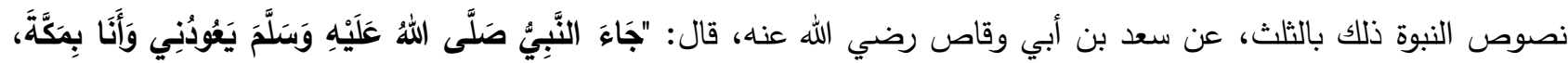

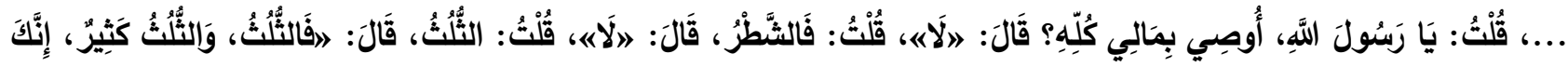

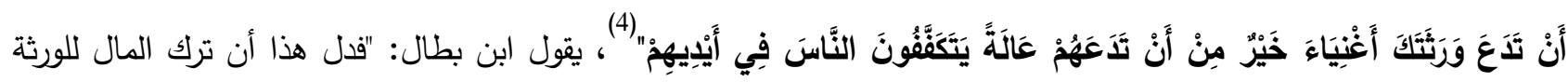
خير من الصدقة به" (5). وقد جاءت الشريعة بوسائل متعددة من الإنفاقات لتغطي مختلف احتياجات المجتمع، ومن ذلك أنه قد يصعب على البعض

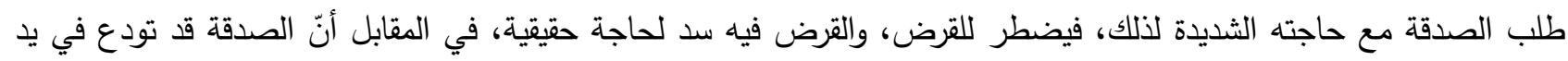

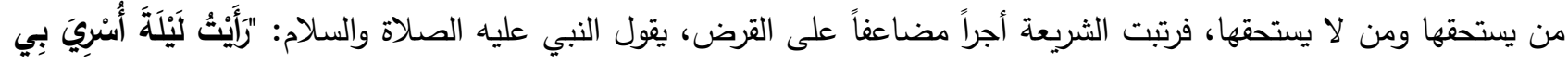

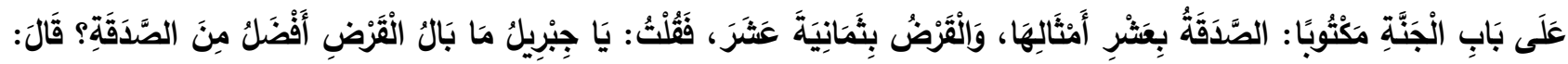

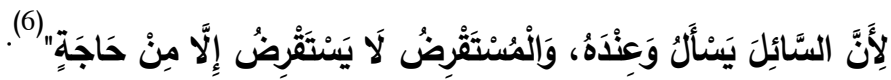

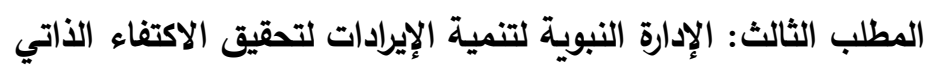
من أهم الوظائف النبوية في زمنه، الإثراف الاقتصادي وبناء قوة اقتصادية للمسلمين، وهذا يتطلب إدارة متقنة للإيرادات والنفقات، وحسن العدالة في الإنتاج والتوزيع، تحقيقاً للتمية، وفي هذا سد لحاجات الأفراد والأمة، وتنوعت الإيرادات في مرحلة

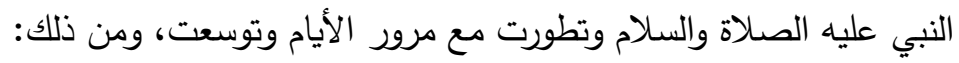

(1) [البيهقي: شعب الإيمان، الزكاة/التشديد على منع زكاة المال، 21/5: 13040]، قال ابن حجر : إسناده حسن.

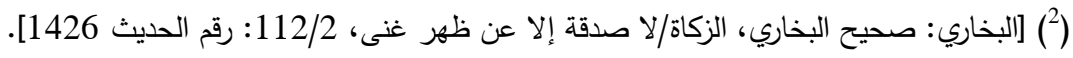

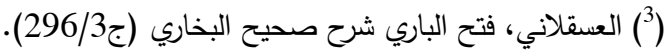

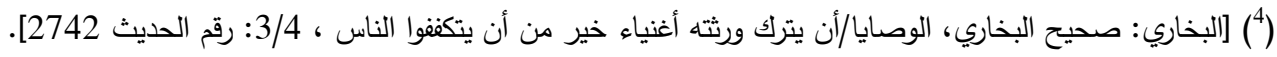

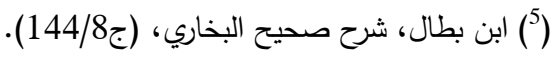

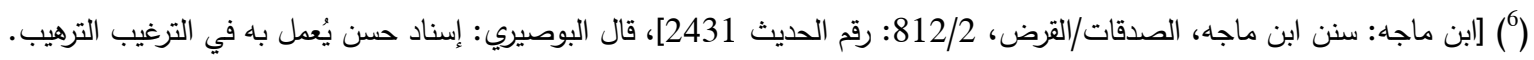
407 IUG Journal of Sharia and Law Studies (Islamic University of Gaza) / CC BY 4.0 
أولاً: الزكاة، ثانياً: زكاة الفطر، ثالثاً: الجزية: وهي "الوظيفة المأخوذة من الكافر لإقامته بدار الإسلام في كل عام"(1)،

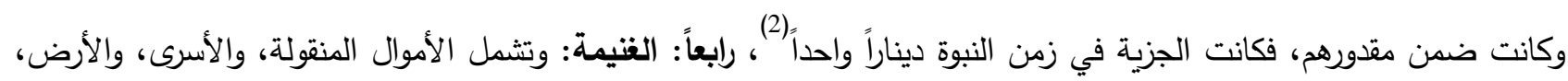

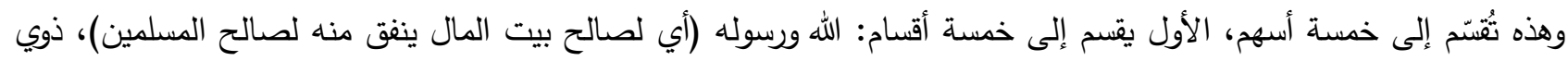
القربى، اليتامى، المساكين، ابن السبيل، وأما الأربعة أخماس الباقية فتوزع على من شهد الوقعة من الرجال البالغين الأحرار العقلاء، وأما الأرض فتُقسّم بين الغانمين، أو توقف لدصالح المسلمين ويضرب عليها خراجاً، وهذ راجع للمصلحة (3)، خامساً: الفيء: وهذا يصرف في مصالح المسلمين، كرزق القضاة والمفتين، وغير ذلك، ومما أفاءه الله على حبيبه عليه الصلاة والسلام أموال بني النضير (4)، سادساً: الهبات والتبرعات، سابعاً: الوقف: كوقف عمر أرضه في خيبر (5)، ثامناً: الكفارات: ككفارة الحنث باليمين، وكفارة الظهار ، وارتبطت الكفارات بعتق الرقاب وبالإطعام، وفي هذا تفعيل لكل وسيلة تسد الحاجات، تاسعاً: القروض: لوضات كاقتراض النبي عليه الصلاة والسلام لصالح المسلمين من أبي ربيعة أربعين ألف درهاًً(6)، عاشراً: صدقات التطوع. الحادي عشر: المزارعة والمساقاة: فقد زارع النبي عليه الصلاة والسلام يهود خيير على شطر إنتاج الأرض التي آلت ملكيتها للمسلمين (7) لما

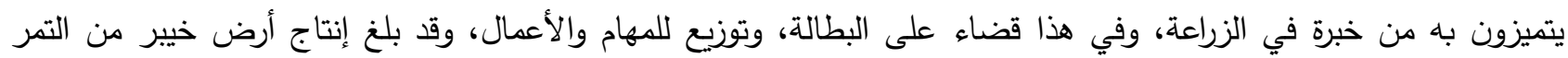
أربعين ألف وسق "8) الثاني عشر : الواردات من السوق النبوي.

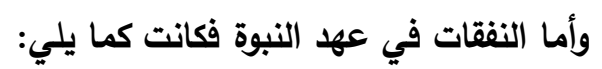
أولاً: مصارف الزكاة الثمانية، ثانياً: مصارف الغنيمة والفيء : وقد تم بيانها، وكان النبي عليه الصلاة والسلام يصرف ما قُقِيم له لصالح المسلمين. وهذان من قبيل المصارف المخصصة. ثالثاً: كانت تصرف الإيرادات التي ليس لها مصارف محددة، في الجهاد وشراء السلاح والخيل، ولبناء المساجد وشراء الأراضي، ولحفظ الأمن الداخلي، ورواتب القضاة والولاة كالذي جعله رسول الله لعتاب بن أسيد عندما بعثه النبي عليه الصلاة والسلام على ولاية مكة مقابل درهم كل يوم (9)، وما كان من هدايا يهديها رسول الله، وكان النبي عليه الصلاة والسلام يدخر لأهله قوت سنة. وتحقيقاً للتمية والنهوض بالاكتفاء الذاتي على مستوى الأمة، أقطع النبي عليه الصلاة والسلام عدداً من أهل الخبرة من الصحابة أراضٍ لاستثمارها، كالزبير بن عوام أقطعه النبي عليه الصلاة والسلام أرضاً من أموال بني النضير (10).

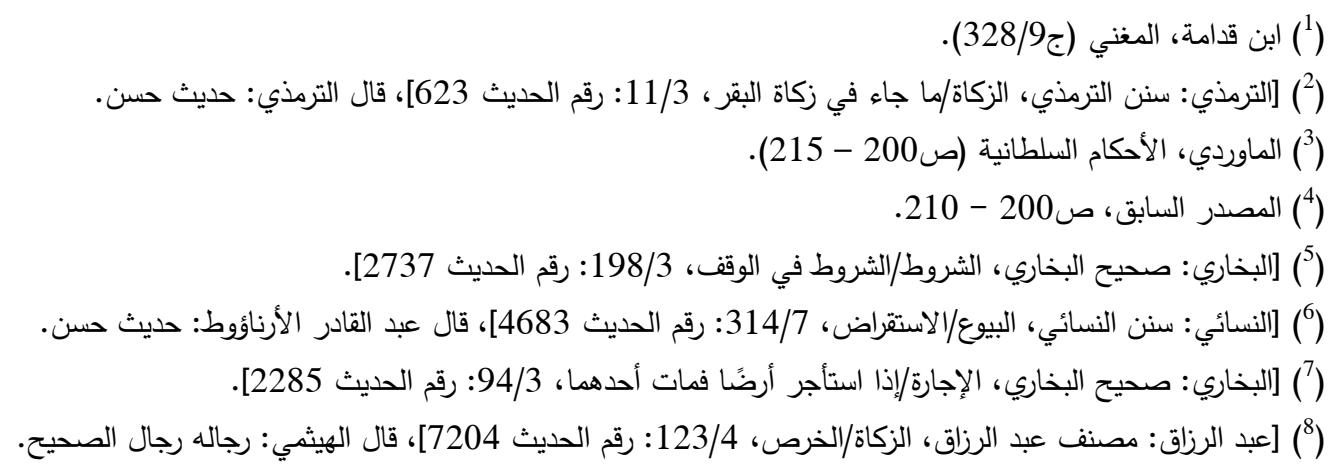

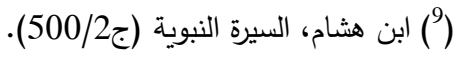
(1015) [البخاري: صحيح البخاري، فرض الخمس/مان/ كان النبي عليه الصلاة والسلام يعطي المؤلفة قلوبهم وغيرهم من الخمس ونحوه، 95/4: رقم الحديث 
وهكذا يتضح مدى اهتمام النبي عليه الصلاة والسلام بتوسيع دائرة الإيرادات، واستدامتها كالجزية السنوية والزكاة السنوية، وتخصيص أموال للمشاريع التتموية، وهذا كله يُسهم في تحقيق الكفاية لأفراد المجتمع وبناء قوة واستقلالية للأمة الإسلامية. المطلب الرابع: تطبيقات الإدارة النبوية (السوق النبوي مثالاً)

واجه النببي عليه الصلاة والسلام يوم وصل المدينة المنورة مهاجراً العديد من التحديات، ومن أبرزها المشكلة الاقتصادية،

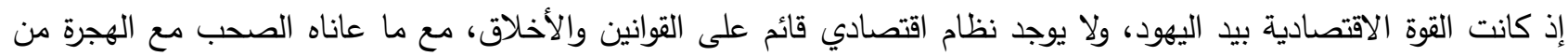

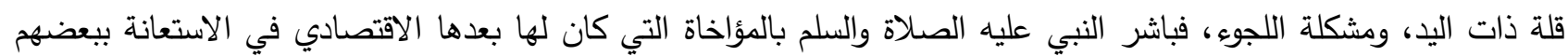

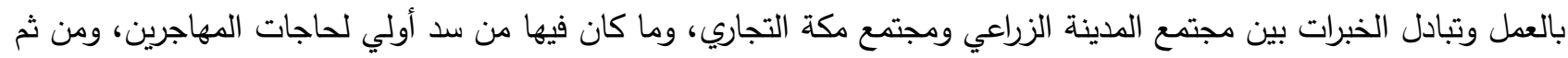

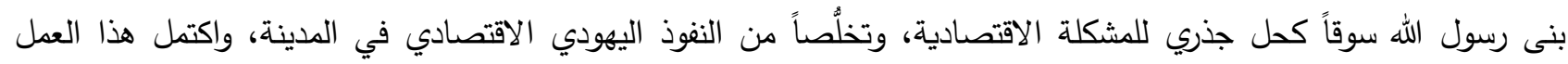
الاقتصادي مع إخراج اليهود من المدينة في السنة السابعة للهجرة بإخراج يهود خيير ، وعُدّت تلك السنة سنة الوصول للاكتفاء

الذاتي، يقول ابن عمر : "ما شبعنا حتى فتحنا خيبر" (1). وقد كان للعرب عموماً ما يزيد عن عشرة أسواق رئيسية كبرى، بعضها يسيطر علئ عايه النفوذ الأجنبي لا سيما في المناطق المسيطر عليها الفرس كسوق عُمان، وبعضها خالص من النفوذ الأجنبي (2)، وكان في المدينة المنورة بين يدي قدوم النبي إليها

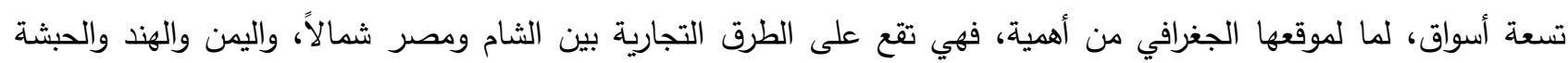
جنوباً، وكان أقوى هذه الأسواق سوق بني قينقاع، وأعظم ما يعملون فيه صياغة الذهب والدروع (3)، فجاء النبي عليه الصلاة والسلام وخط سوقاً برجليه(4)، وذهب إلى سوق النبيط فقال: "'يسن لكُم هذا بسُوق" (5)، إعلاناً عن رفضه عليه الصلاة والسلام للتبعية لليهود اقتصادياً.

\section{مميزات السوق التي أنشاها النبي عليه الصلاة والسلام:}

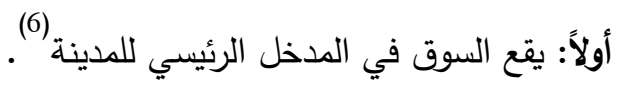

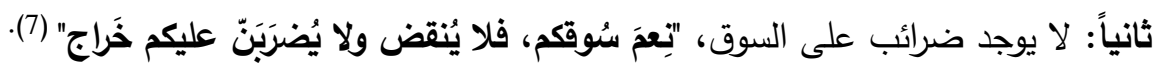

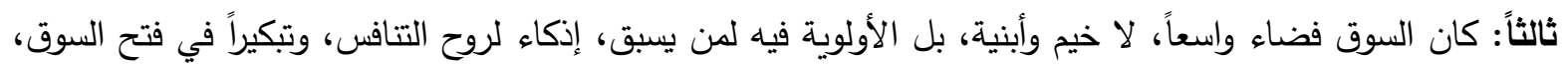

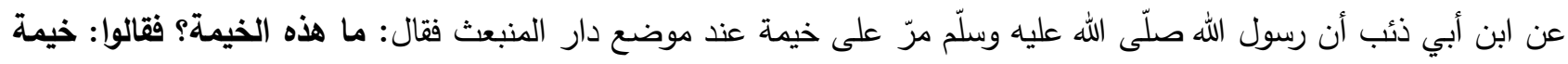
لرجلٍ من بني حارثة كان يبيعُ فيها التمر، فقال: حرِقوها، فحرِّرقت (8). رابعاً: يضبط السوق قوانين أخلاقية لها بعدها الاقتصادي، فمنع النبي عليه الصداة والسلام الغش والربا والسمسرة وغير

(1) [البخاري: صحيح البخاري، المغازي/غزوة خيبر، 140/5: رقم الحديث 4243].

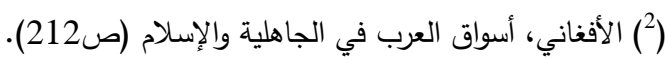

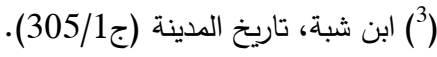
(4) [الطبراني: المعجم الكبير، الميث/حديث الزبير بن أبي أسيد عن أبيه، 264/19: رقم الحديث 586]، قال الهيثمي: فيه الحسن بن علي بن الحسن أبي الحسن البراد، ولم أجد من ترجمه. (5) [ابن ماجه: سنن ابن ماجه، التجارات/الأسواق ودخولها، 751/2: رقم الحديث 2233]، قال البوصيري: هذا إسناد ضعيف.

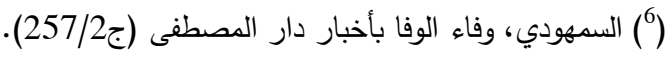

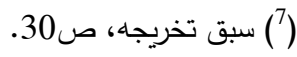
( أل) السمهودي، وفاء الوفا بأخبار دار المصطفى (ج) (257/2). 
خامساً: اعتماد الصنع المحلي مع انفتاح على الأسواق الخارجية القوية، بما يحقق قوة للسوق ويسعى لدعم عملية التتمية المُفضية إلى قوة اقتصادية تحقق كفاية المجتمع، "...كان الناس إنما طعامهح بالمدينة التمر والثعير، وكان الرجل إذا كان لله

يسار فقدمت ضافطة من الثام من الدرمك، ابتاع الرجل منها فخص بها نفسه، وأما العيال فإنما طعامهم التمر والثعير" ".

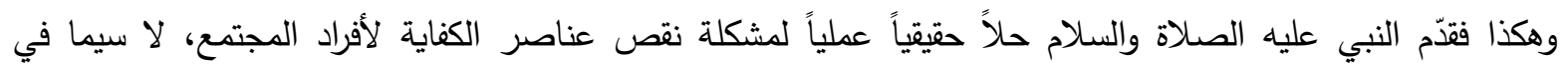
السنوات الأولى للمسلمين في المدينة المنورة وقد كانوا أقلية، فتأسس لهم كيانهم الاقتصادي بشتى أشكاله ومن أبرزها السوق وهو من أعظم الوسائل لتحقيق الاكتفاء، والتخلص من التبعية لليهود. الخاتمة والتوصيات:

بعد هذا العرض لمفهوم الاكتفاء الذاتي وأنواعه وأهميته، وتأصيله من القرآن والسنة، توصَل الباحث إلى النتائج التالية:

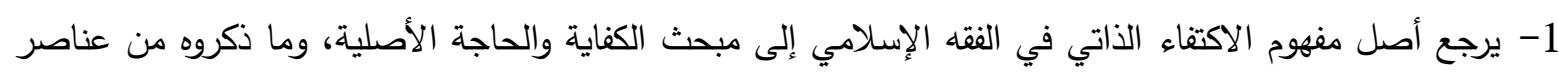
الكفاية وضوابطها. 2- يهدف مفهوم الاكتفاء الذاتي إلى سد جميع الحاجات بمختلف أنواعها سواء على المستوى الفردي أو الأممي بما

$$
\text { يحقق مستوى لائق من المعيشة. }
$$

3- الاكتفاء الذاتي يسعى لتحقيق الكفاية لا الكفاف، فالكفاف سد الضروريات، وأما الكفاية فسد الضروريات والحاجيات

$$
\text { وبعض التحسينيات التي لا بد منها لتحقيق حياة لائقة. }
$$

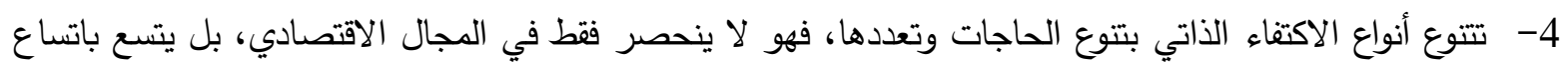

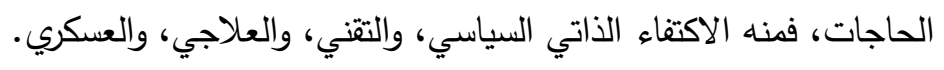

5- المقصود بالاكتفاء الذاتي الجمعي ما يكون على مستوى الأمة لا الدولة الواحدة، فيحصل التكامل لا التماثل بين

$$
\text { دول العالم الإسلامي ككل. }
$$

6- اعتتت نصوص الثريعة لا سيما في مصادرها الأصلية الأساسية والأفعال النبوية بتأصيل مفهوم الاكتفاء الذاتي،

وبيان وسائله، تأكيداً على أن تحقيق الاكتفاء الذاتي من مقاصد الشريعة ومن أولوياتها.

$$
\text { هذا ويوصي الباحث بما يلي: }
$$

1- ضرورة العناية بالاكتفاء الذاتي تأصيلاً وتطبيقاً لنهضة للأكة.

2- الاعتناء بمفهوم الاكتفاء الذاتي في الأوراق البحثية والمؤتمرات.

3- العناية بالتدابير المعاصرة التي على الدول اتخاذها لتحقيق الاكتفاء الذاتي على مستوى الفرد والأمة ككل، وأن يكون

$$
\text { 4- نشر ثقافة الاكتفاء الذاتي في المقالات واضحة مع مراعاة الأولويات في سد الحاجات والصات. }
$$

(1) [الترمذي: سنن الترذذي، تقسير القرآن/ومن سورة النساء، 244/5: رقم الحديث 3036]، قال الألباني: حديث حسن، والضافطة: من يجلب المتاع إلى الى

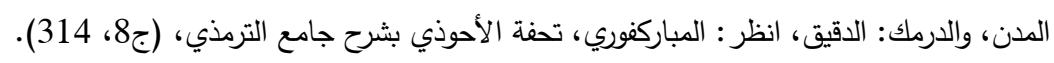




\section{المصادر والمراجع}

ابن أبي شيبة، عبد الله بن محمد (1409 هـ)، المصنف، ط1، تحقيق كمال يوسف الحوت، مكتبة الرشد، الرياض، السعودية.

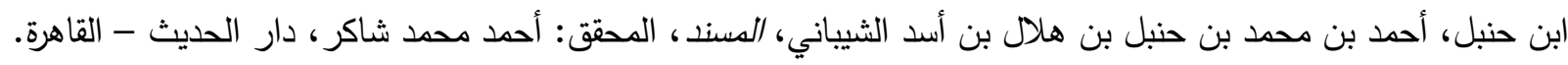
ابن خلدون، عبد الرحمن بن محمد (2004م)، مقدمة ابن خلدون، ط1، تحقيق عبد الله محمد درويش، دار يعرب، دمشق، سوريا. ابن شبة، عمر بن شبة بن عبيدة البصري (1399 هـ)، تاريخ المدينة، تحقيق: فهيم محمد شلتوت.

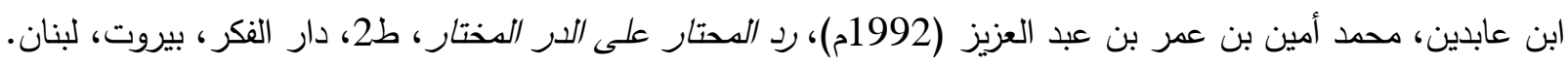

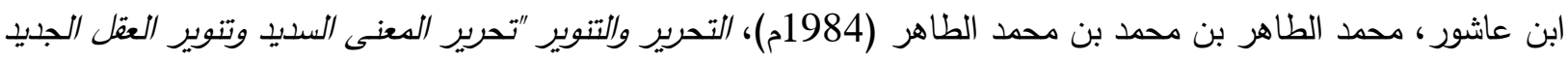

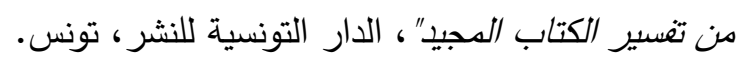

ابن عاشور، محمد الطاهر بن محمد بن محمد الطاهر، مقاصد الشريعة الإسلامية، تحقيق: محمد الحبيب ابن الخوجة، وزارة

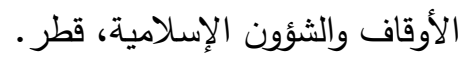

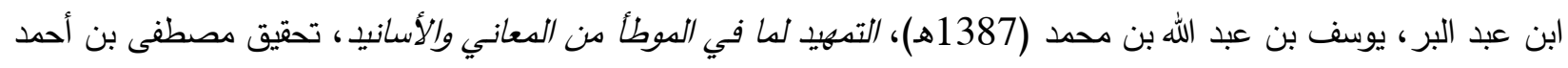

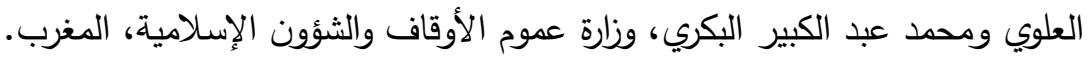

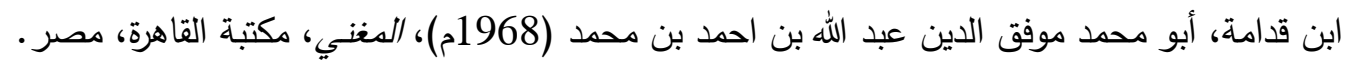
ابن القيم، محمد بن أبي بكر بن أيوب بن سعد، الطرق الحكمية، دار البيان.

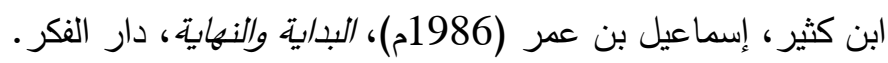

ابن ماجه، محمد بن يزيد القزويني، سنن ابن ماجه، تحقيق: محمد فؤاد عبد الباقي، دار إحياء الكتب العربية.

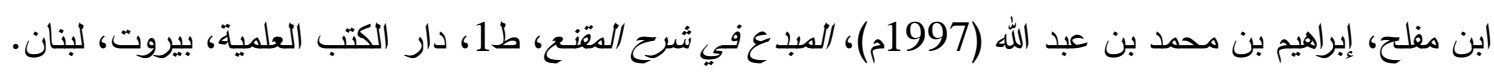

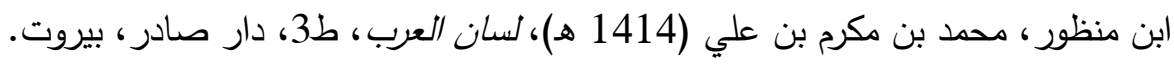

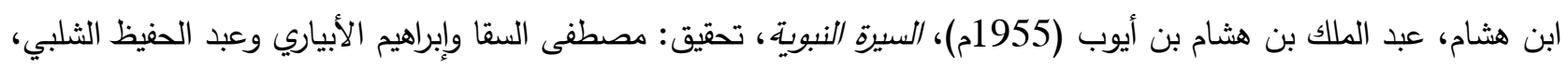

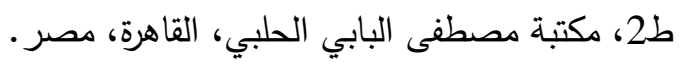

أبو السعود، محمد بن محمد بن مصطفى، إرشاد العقل السليم إلى مزيا الكتاب الكريم، دار إحياء التراث العربي، بيروت، لبنان. أبو حيان، محمد بن يوسف بن علي (1420 هـ)، البحر المحيط في التنسير، دار الفكر ، بيروت، لبنان لبنان.

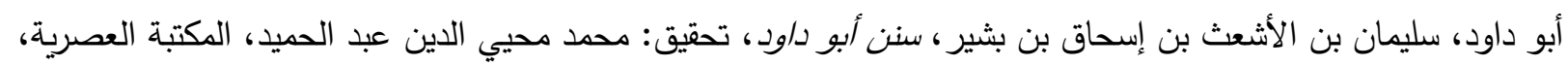
صيدا، لبنان.

أبو غالي، رائد جمال(2017م)، قياس الأمن الغذائي والاكتفاء الذاتي في الأراضي الفلسطينية 2003 - 2014م، بحث محكم

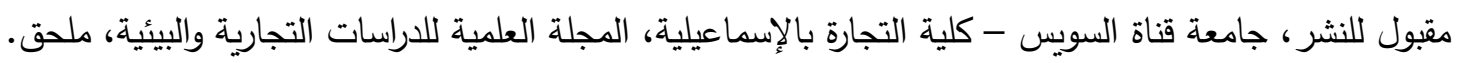

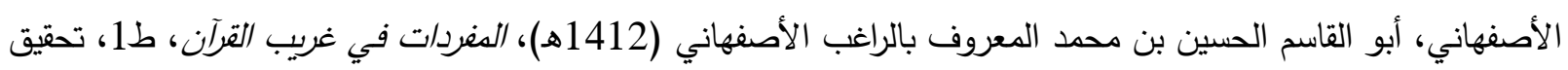
صفوان عدنان الداودي، دار القلم، دمشق. الأفغاني، سعيد بن محمد بن أحمد (1974م)، أسواق العرب في الجاهلية والإسلام، دار الفكر ، بيروت، لبنان.

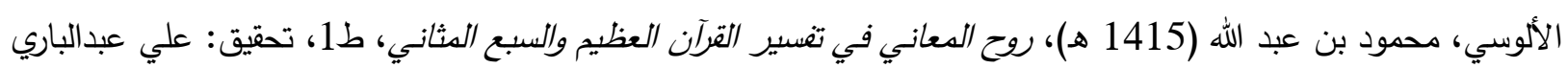
عطية، دار الكتب العلمية، بيروت، لبنان.

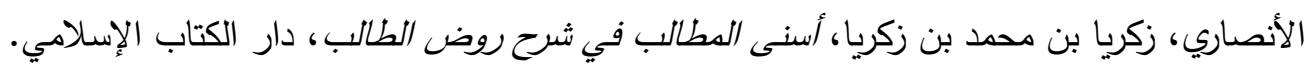

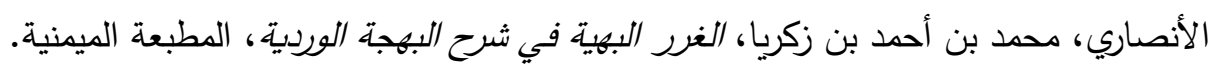
البخاري، محمد بن إسماعيل (1422هـ)، ط1، تحقيق: محمد زهير بن ناصر الناصر ، دار طوق النجاة، القاهرة، مصر . 
البغوي، حسين بن مسعود بن محمد (1420 هـ)، معالم التنزيل في تغسير القرآن، ط1، دار إحياء التراث العربي، بيروت، لبنان. ابن إبراهيم، عبد الله بن لام(2003م)، أحكام الأغنياء، ط1، دار النماء النفائس، عمان، الأردن. البهوتي، منصور بن يونس (2000م)، كثاف القناع عن متن الإقناع، ط1، تحقيق لجنة متخصصة من وزارة العدل، الناشر: وزارة العدل، المملكة العربية السعودية

البيهقي، أحمد بن الحسين بن علي بن موسى (2003م)، شعب الإييان، ط1، تحقيق د. عبد العلي عبد الحميد حامد، مكتبة

$$
\text { الرشد، الرياض، السعودية. }
$$

الترمذي، محمد بن عيسى بن سَوْرة بن موسى بن الضحاك (1975م)، سنن الترهذي، ط2، تحقيق، فؤاد عبد الباقي وإبراهيم عطوة عوض، مكتبة ومطبعة المصطفى البابي الحلبي، القاهرة، مصر .

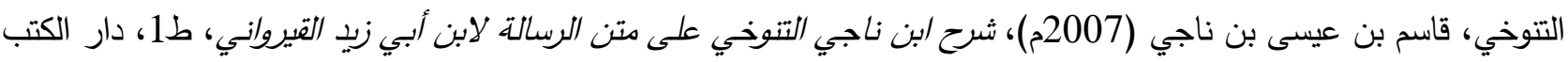

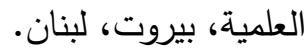
الجندلي، أيمن محمد ضو(2016م)، لمحة نظرية عن التتمية المستد/مة، بحث محكم مقبول للنشر ، المؤسسة العربية للاستشارات العلمية وتتمية الموارد البشرية، المجلة العربية للعلوم الاجتماعية. الجويني، عبد الملك بن عبد الله بن يوسف (1401 هـ)، غياث الأمم في التياث الظلم، ط2، تحقيق: عبد العظيم الديب، مكتبة إمام الحرمين.

الحاكم، محمد بن عبدالله النسابوري (1990م)، المستدرك على الصحيحين، ط1، تحقيق: مصطفى عبد القادر عطا، دار الكتب

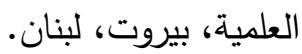

حبيب، مطانيوس، الاكتفاء الذاتي، الموسوعة العربية، الجمهورية العربية السورية، دمشق، سوريا.

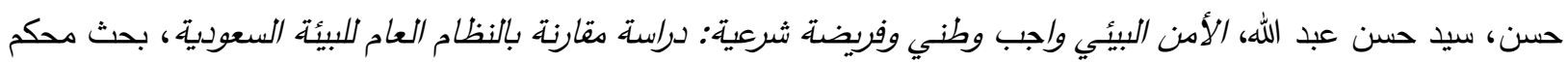

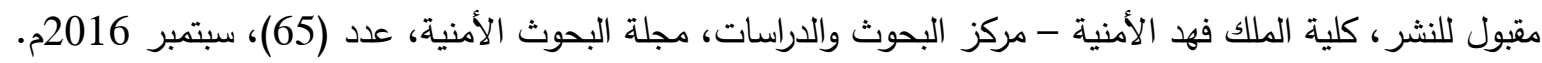

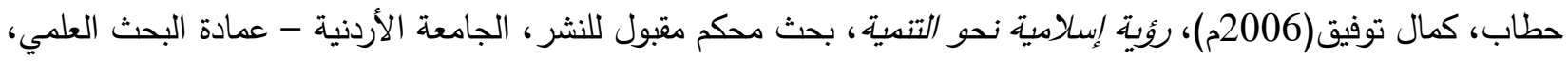
دراسات - علوم الثريعة والقانون.

الحطاب، محمد بن محمد بن عبد الرحمن (1992م)، مواهب الجليل في شرح مختصر خليل، ط3، دار الفكر .

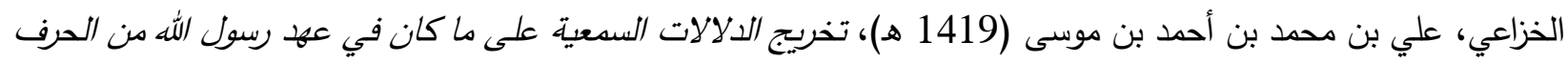
والصنائع والعمالات الثرعية، ط2، تحقيق: د. إحسان عباس، دار الغرب الإسلامي، بيروت، لبنان.

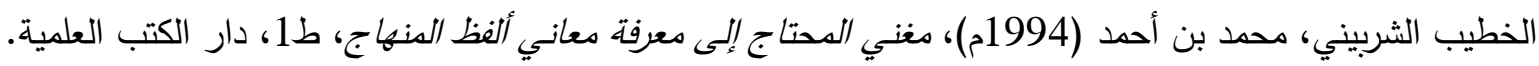

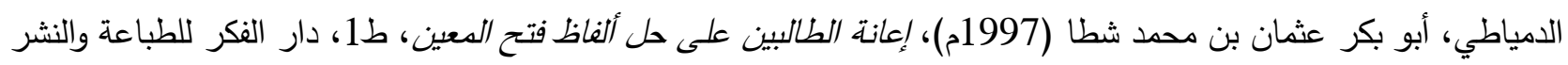
والتوزيع، بيروت، لبنان.

ابن فارس، أحمد بن فارس بن زكرياء (1979م)، معجم مقاييس اللغة، تحقيق عبد السلام محمد هارون، دار الفكر .

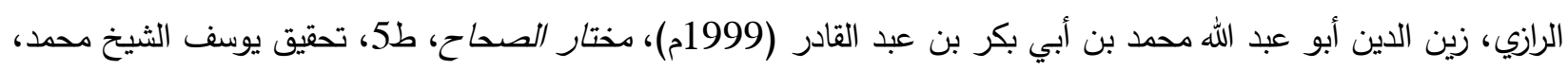

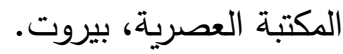

الرازي، محمد بن عمر بن الحسن (1420هـ)، مغاتيح الغيب، ط3، دار إحياء التراث العربي، بيروت، لبنان.

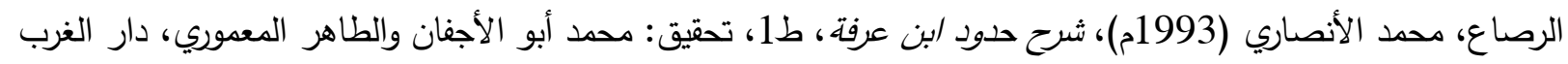
الرملي، محمد بن أحمد بن حمزة (1984م)، نهاية الدحتاج إلى شرح الدنهاج، دار الفكر ، بيروت، لبنان. 
الزبيدي، أبو الفيض محمد بن محمد بن عبد الرزاق الملب بمرتضى، تاج العروس من جواهر القاموس، دار الهداية.

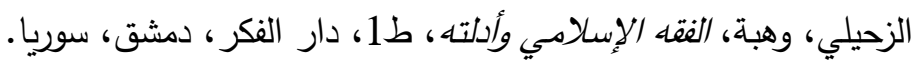
الزركثي، محمد بن عبد الله بن بهادر (1985م)، المنثور في القواعد الفقهية، ط2، وهن، وزارة الأوقاف الكويتية.

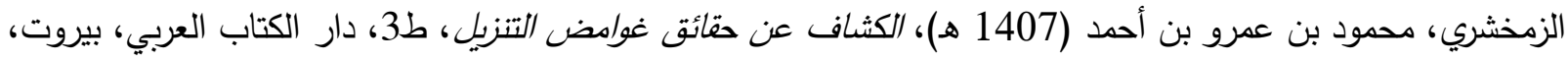
لبنان. الزيلعي، عثمان بن علي بن محجن (1313هـ)، تبيين الحقائق شرحكنز الدقائق، ط1، المطبعة الكبرى الأميرية -بولاق، القاهرة، مصر السبكي، تقي الدين علي بن عبد الكافي وابنه تاج الدين عبد الوهاب (1995م)، الإبهاج في شرح الهنهاج، دار الكتب العلمية،

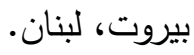
السرخسي، محمد بن أحمد بن أبي سهل، المبسوط، دار المعرفة، بيروت، لبنان.

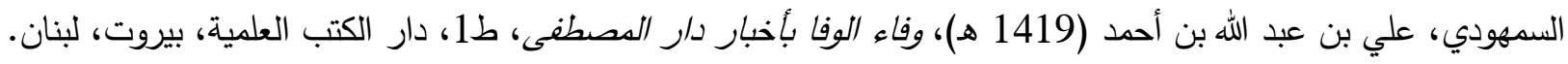

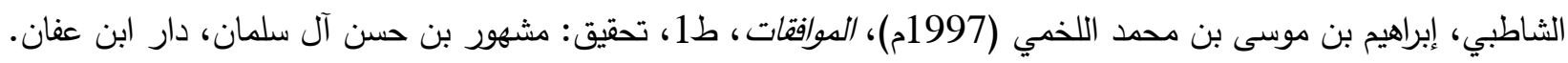

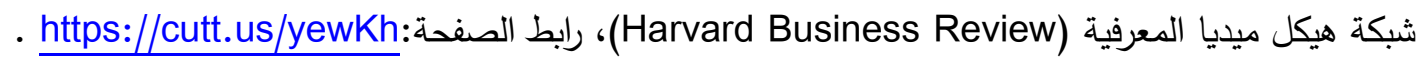

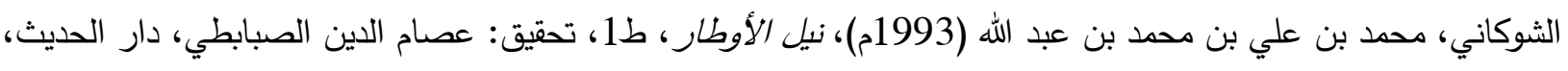

الشوكاني، محمد بن علي بن محمد بن عبد الله، السيل الجرار الهتدفق على حدائق الأزهار، ط1، دار ابن حزم. طاهر ، جميل، وعصفور ، صالح(1996)، الدليل الموحد لهفاهيم ومصطلحات التخطيط في دول مجلس التعاون لدول الخليج

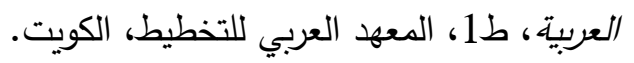

الطبري، محمد بن جرير بن يزيد بن كثير (1387هـ)، تاريخ الرسل والملوك، ط2، دار، دار التراث، بيروت، لبنان.

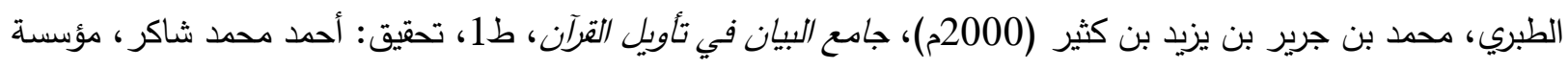
الرسالة.

عبد الرزاق، عبد الرزاق بن همام بن نافع الحميري اليماني (1403هـ)، الهصنف، ط2، تحقيق: حبيب الرحمن الأعظمي، الدكتب الإسلامي، بيروت، لبنان. مواق، محمد بن يوسف بن أبي القاسم بن يوسف (1994م)، التاج والإكليل لمختصر خليل، ط1، دار الكتب العلمية. العسقلاني، أحمد بن علي بن حجر (1379 هـ)، فتح الباري شرح صحيح البخاري، دار المعرفة، بيروت، لبنان. عكاشة، أحمد خالد، نظرية التفضيل الثرعي في الاقتصاد الإسلامي، بحث محكم مقبول للنشر ، الجامعة الإسلامية للدراسات

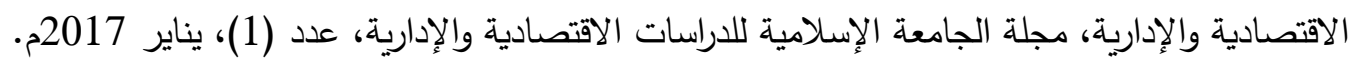
الغزالي، محمد بن محمد بن محمد، إحياء علوم الدين، دار المعرفة، بيروت، لبنان. فريد، عبد الله محمد (2004م)، القاموس الفريد في العال والاقتصاد، مكتبة النصر الوطنية. الفنجري، محمد شوقي (1981م)، الإسلام والمشكلة الاقتصادية، ط2، مكتبة السلام العالمية، القاهرة، مصر.

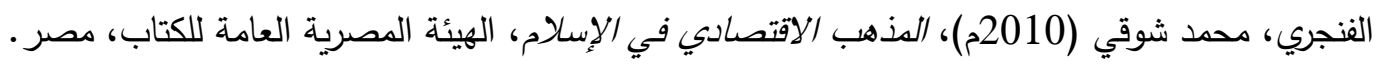
الفيومي، أحمد بن محمد بن علي، المصباح المنير في غريب الثرح الكبير، المكتبة العلمية، بيروت، لبنان.

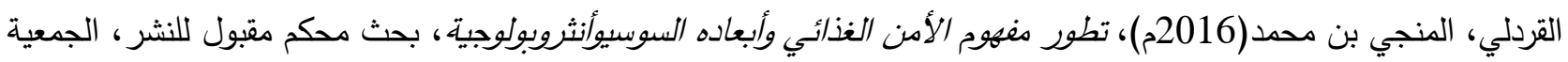
المصرية للأخصائيين الاجتماعيين، مجلة الخدمة الاجتماعية. 
القرطبي، محمد بن أحمد بن أبي بكر بن فرح (1964م)، الجامع لأحكام القرآن، ط2، تحقيق أحمد البردوني وإبراهيم أطفيش، دار

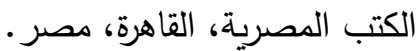

الكاساني، علاء الدين أبو بكر بن مسهود بن أحمد، بدائع الصنائع في ترتيب الشرائع، دار الكتب العلمية، بيروت، لبنان.

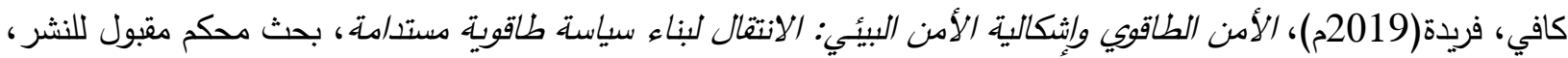
مركز البحث وتطوير الموارد البشرية، مجلة رماح للبحوث والدراسات.

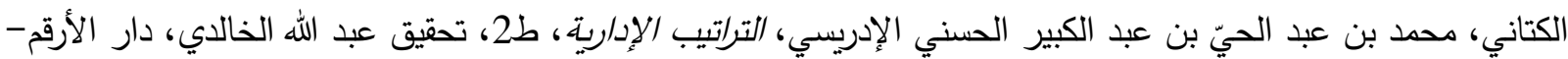
بيروت.

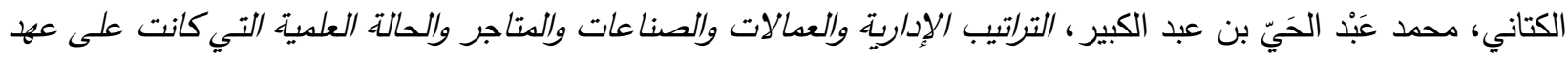
تأسيس الددنية الإسلامية في المدينة المنورة العلمية، ط2، تحقيق: عبد الله الخالدي، دار الأرقم، بيروت، لبنان.

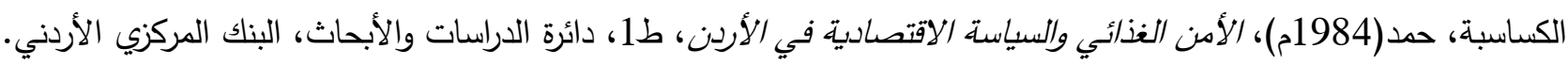

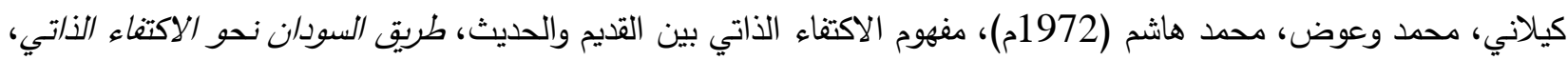
معهد الدراسات الإضافية - جامعة خرطوم، الخرطوم، السودان. الماوردي، علي بن محمد بن محمد بن حبيب (1999م)، الحاوي الكبير في فقه مذهب الإمام الثافعي وهو شرح مختصر المزني، تحقيق علي محمد معوض وعادل أحمد عبد الموجود، ط1، دار الكتب العلمية، بيروت، لبنان.

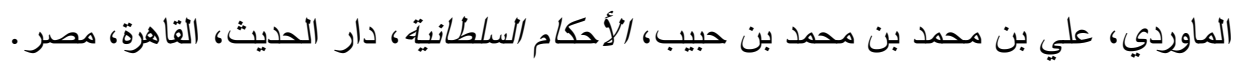

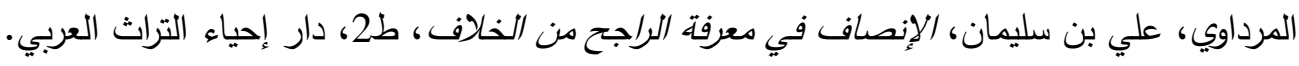
مسلم، مسلم بن حجاج القشيري، صحيح مسلم، المحقق: محمد فؤاد عبد الباقي، دار إحياء التراث العربي - بيروت. المشهور ، أبو بكر العدني بن علي(2016م)، الأسس والمنطلقات في تحليل وتفصيل غوامض فقه التحولات وما يرتبط به من سنن المواقف والدلالات المستنبطة من علامات الساعة وأحاديثها البينات، ط3، دار المعين للنشر والتوزيع، عمان، الأردن. ابن مفلح، محمد بن مفلح بن محمد بن مفرج (2003م)، كتاب الفروع، ط1، تحقيق: عبد الله بن عبد المحسن التركي، مؤسسة

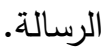

ملا خسرو، محمد بن فرامرز بن علي، درر الحكام شرح غرر الأحكام، دار إحياء الكتب العربية.

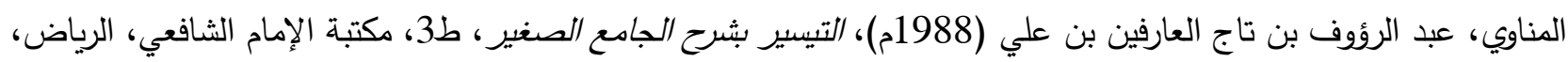

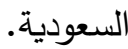

المناوي، عبد الرؤوف بن تاج العارفين بن علي بن زين العابدين (1356 هـ)، فيض القدير شرح الجامع الصغير، ط1، المكتبة

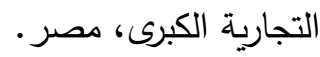

منصور ، أحمد إبراهيم، عدالة التوزيع والتتنية الاقتصادية رؤية إبلامية مقارنة، ط1، مركز دراسات الوحدة العربية. الموصلي، عبد الله بن محمود بن مودود (1937م)، الاختيار لتعليل المختار، مطبعة الحلبي، القاهرة، مصر .

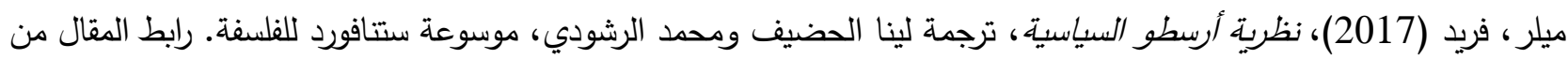

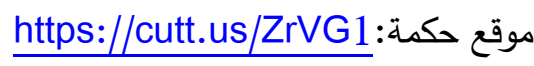
النسائي، أحمد بن شعيب أبو عبد الرحمن، السنن الكبرى، ط2، تحقيق: عبد الفتاح أبو غدة، مكتب المطبوعات الإسلامية، حلب،

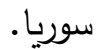
النكري، عبد النبي بن عبد الرسول الأحمد (2000م)، دستور العلماء = جامع العلوم في اصطلاحات الفنون، ط1، عرّب عباراته الفارسية: حسن هاني فحص، دار الكتب العلمية، بيروت، لبنان. 


$$
\begin{aligned}
& \text { النووي، أبو زكريا محيي الدين يحيى بن شرف (1392م)، الدنهاج شرح صحيح مسلم بن الحجاج، ط2، دار إحياء التراث العربي، }
\end{aligned}
$$

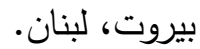

$$
\begin{aligned}
& \text { النووي، أبو زكريا محيي الدين يحيى بن شرف (1991م)، روضة الطالبين وعمدة الففتين، ط3، تحقيق: زهير الثاويش، المكتب }
\end{aligned}
$$

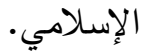

$$
\begin{aligned}
& \text { النووي، محيي الدين يحيى بن شرف، المجموع شرح المهذب، دار الفكر. } \\
& \text { هوشات، فوزيـة(2018م)، الأمن البيئي بين مقاربة الأمن الوطني والأمن الإنسانس، بحث محكم مقبول للنشر ، جامعة منتوري } \\
& \text { قسنطينة، مجلة العلوم الإنسانية. } \\
& \text { الهيتمي، أحمد بن محمد بن علي بن حجر (1983م)، تحفة المحتاج في شرح المنهاج، المكتبة التجارية الكبرى، مصر . } \\
& \text { وزارة الأوقاف والثؤون الإسلامية، الموسوعة الفقهية الكوتية، ط2 الأجزاء من 1-23، دار السلاسل، الكويت، ط1 الأجزاء من } \\
& 24 \text { - 38، دار صفوة، مصر ، ط2 الأجزاء من } 39 \text { - 45، طبع الوزارة، 45م، } 1404 \text { - 1427هـهـ الإهنه }
\end{aligned}
$$

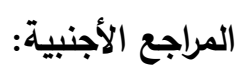

Abdul-Razzaq, Abdul-Razzaq Bin Hammam Bin Nafi Al-Hamiri Al-Yamani (1403 AH), Compiler,

Edition 2, Edited by: Habib Al-Rahman Al-Azami, The Islamic Office, Beirut, Lebanon

Abu Al-Saud, Muhammad bin Muhammad bin Mustafa, Guiding the Sound Mind to the Advantages of the Noble Book, House of Revival of Arab Heritage, Beirut, Lebanon.

Abu Dawud, Suleiman bin Al-Ash'ath bin Ishaq bin Bashir, Sunan Abu Dawud, investigation by:

Muhammad Muhi al-Din Abd al-Hamid, Modern Library, Sidon, Lebanon.

Abu Ghaly, Raed Jamal (2017 AD), Measuring Food Security and Self-Sufficiency in the Palestinian Territories 2003-2014, Refereed Research Accepted for Publication, Suez Canal University - Ismailia College of Commerce, Scientific Journal of Commercial and Environmental Studies, Supplement.

Abu Hayyan, Muhammad bin Yusuf bin Ali (1420 AH), Al-Bahr Al-Muheet in Interpretation, Dar Al-Fikr, Beirut, Lebanon.

Al-Afghani, Saeed bin Muhammad bin Ahmed (1974 AD), Arab markets in pre-Islamic times and Islam, Dar Al-Fikr, Beirut, Lebanon.

Al-Alousi, Mahmoud bin Abdullah (1415 AH), The Spirit of Meanings in the Interpretation of the Great Qur'an and the Mathani Seven, ed. 1, edited by: Ali Abdul-Bari Attiyah, Dar Al-Kutub Al-Ilmiyya, Beirut, Lebanon.

Al-Ansari, Muhammad bin Ahmed bin Zakaria, The Glorious Arrogance in Explaining the Rosary Delight, The Yemeni Press.

Al-Ansari, Zakaria bin Muhammad bin Zakaria, is the best student in explaining Rawdat Al-Talib, Dar Al-Kitab Al-Islami.

Al-Asqalani, Ahmad bin Ali bin Hajar (1379 AH), Fath al-Bari Sharh Sahih al-Bukhari, House of Knowledge, Beirut, Lebanon.

Al-Baghawi, Hussein bin Masoud bin Muhammad (1420 AH), Landmarks of Revelation in Interpretation of the Qur'an, 1st Edition, House of Revival of Arab Heritage, Beirut, Lebanon.

Al-Bahouti, Mansour Bin Yunis (2000 A.D.), Scouts Al-Maska 'on the body of Al-Iqna', 1st Edition, investigation by a specialized committee from the Ministry of Justice, Publisher: Ministry of Justice, Kingdom of Saudi Arabia

Al-Bayhaqi, Ahmad Bin Al-Hussein Bin Ali Bin Musa (2003 AD), Sha`b Al-Iman, 1st Edition, edited by Dr. Abdul-Ali Abdul-Hamid Hamid, Al-Rashed Library, Riyadh, Saudi Arabia.

Al-Bukhari, Muhammad bin Ismail (1422 AH), ed. 1, edited by: Muhammad Zuhair bin Nasser AlNasser, Dar Touq Al-Najat, Cairo, Egypt. 
Al-Damiati, Abu Bakr Othman bin Muhammad Shata (1997 AD), Helping Students to Dissolve Moin Fath Words, 1st Edition, Dar Al-Fikr for Printing, Publishing and Distribution, Beirut, Lebanon.

Al-Fangari, Mohamed Shawky (2010 AD), The Economic Doctrine in Islam, The Egyptian General Book Authority, Egypt.

Al-Fangary, Mohamed Shawky (1981 AD), Islam and the Economic Problem, 2nd Edition, Peace International Library, Cairo, Egypt.

Al-Fayoumi, Ahmed bin Muhammad bin Ali, the illuminating lamp in Gharib al-Sharh al-Kabir, The Scientific Library, Beirut, Lebanon.

Al-Ghazali, Muhammad bin Muhammad bin Muhammad, Revival Sciences of Religion, House of Knowledge, Beirut, Lebanon.

Al-Hakim, Muhammad bin Abdullah Al-Nisabouri (1990 AD), Al-Mustadrak Ali Al-Sahihin, ed. 1, verified by: Mustafa Abdel-Qader Atta, Dar Al-Kutub Al-Ulmiyyah, Beirut, Lebanon.

Al-Hattab, Muhammad Ibn Muhammad Ibn Abd al-Rahman (1992 AD), Talents of Galilee in Sharh Mukhtasar Khalil, 3rd Edition, Dar Al Fikr.

Al-Hitmi, Ahmed bin Muhammad bin Ali bin Hajar (1983 AD), Tuhfat al-Muhtaj fi Sharh alMinhaj, The Great Commercial Library, Egypt.

Al-Isfahani, Abu al-Qasim al-Husayn ibn Muhammad, known as al-Ragheb al-Isfahani (1412 AH), Vocabulary in Gharib al-Qur'an, First Edition, edited by Safwan Adnan al-Daoudi, Dar alQalam, Damascus.

Al-Jandali, Ayman Muhammad Daou (2016 AD), A theoretical overview of sustainable development, a refereed research accepted for publication, the Arab Foundation for Scientific Consulting and Human Resources Development, The Arab Journal of Social Sciences.

Al-Juwaini, Abd al-Malik bin Abdullah bin Yusuf (1401 AH), Ghiyath al-Ummah fi al-Tiyath injustice, 2nd edition, edited by: Abd al-Azim al-Deeb, Imam al-Haramayn Library.

Al-Kasani, Ala Al-Din Abu Bakr Bin Masoud Bin Ahmed, Bada` Al-Sanai`a in the Arrangement of Shari`s, Dar Al-Kutub Al-Ulmiyyah, Beirut, Lebanon.

Al-Kattani, Muhammad Abd al-Hayy bin Abd al-Kabir, the administrative arrangements, workers, industries, stores, and the scientific status that existed during the era of the establishment of the Islamic civilization in Al-Madina Al-Munawwarah Al-Madinah Al-Munawwarah, ed. 2, edited by: Abdullah Al-Khalidi, Dar Al-Arqam, Beirut, Lebanon.

Al-Kettani, Muhammad Ibn Abd al-Hayy Ibn Abd al-Kabir al-Hasani al-Idrisi, Administrative Arrangements, 2nd Edition, Abdullah Al-Khalidi investigation, Dar Al-Arqam - Beirut.

Al-Khatib Al-Sherbini, Muhammad bin Ahmed (1994 AD), the singer of the needy to know the meanings of the term Al-Minhaj, First Edition, Dar Al-Kutub Al-Ilmiyya

Al-Khuzaie, Ali bin Muhammad bin Ahmed bin Musa (1419 AH), graduation of audio indications of what was in the era of the Messenger of God in terms of crafts, crafts and legal currencies, $i$ 2, verification by: Ihsan Abbas, Dar Al-Gharb Al-Islami, Beirut, Lebanon.

Al-Manawi, Abd Al-Raouf Bin Taj Al-Arifin Bin Ali (1988 AD), Al-Tayseer with Explanation of Al-Saghir Mosque, 3rd Edition, Imam Al-Shafi'i Library, Riyadh, Saudi Arabia.

Al-Manawi, Abd Al-Raouf Bin Taj Al-Arifin Bin Ali Bin Zain Al-Abidin (1356 AH), Fayd AlQadeer Sharh Al-Saghir Mosque, First Edition, The Great Commercial Library, Egypt.

Almashhor, Abu Bakr Al-Adani bin Ali (2016 AD), The foundations and principles in analyzing and detailing the ambiguities of the jurisprudence of transformations and the associated Sunnahs of attitudes and indications inferred from the signs of the hour and their hadiths of evidence, 3rd Edition, Dar Al-Moein for Publishing and Distribution, Amman, Jordan.

Al-Mawardi, Ali bin Muhammad bin Muhammad bin Habib (1999 AD), the great author of the jurisprudence of the Imam al-Shafi'i doctrine, which is an explanation of the summary of alMuzni, the investigation of Ali Muhammad Muawad and Adel Ahmad Abd al-Muawjid, First Edition, Dar al-Kutub al-Ilmiyya, Beirut, Lebanon 
Al-Mawardi, Ali bin Muhammad bin Muhammad bin Habib, Al-Ahkam Al-Sultania, Dar AlHadith, Cairo, Egypt.

Al-Mawsili, Abdullah bin Mahmoud bin Mawdud (1937 CE), The Choice for Explanation of AlMukhtar, Al-Halabi Press, Cairo, Egypt.

Al-Mirdawi, Ali Bin Sulaiman, Insafia in Knowing the Most Corrected Difference, Edition 2, House of Revival of Arab Heritage.

Al-Nasa'i, Ahmad Bin Shuaib Abu Abdul Rahman, Al-Sunan Al-Kubra, ed. 2, Edited by: Abd AlFattah Abu Ghuddah, Islamic Publications Office, Aleppo, Syria.

Al-Nawawi, Abu Zakaria Muhyiddin Yahya Bin Sharaf (1392 AD), Al-Minhaj Sharh Sahih Muslim Ibn Al-Hajjaj, Edition 2, House of Revival of Arab Heritage, Beirut, Lebanon.

Al-Nawawi, Abu Zakaria Muhyiddin Yahya Bin Sharaf (1991 AD), Kindergarten of the Talibin and the Mayor of the Muftis, 3rd Edition, edited by: Zuhair Al-Shawish, The Islamic Office.

Al-Nawawi, Muhyiddin Yahya Bin Sharaf, Al-Majmoo 'Sharh Al-Muhdhab, Dar Al-Fikr.

Al-Nukri, Abd al-Nabi Ibn Abd al-Rasul al-Ahmad (2000 CE), Dustur al-Ulema = Jami` al-Ulama fi Iqlim al-Fann, 1st Edition, Arabicized his Persian phrases: Hassan Hani Fahs, Dar al-Kutub al-Ulmiyyah, Beirut, Lebanon.

Al-Qardali, Al-Munji Bin Mohamed (2016 AD), Evolution of the concept of food security and its socio-anthropological dimensions, an arbitrated research accepted for publication, Egyptian Society of Social Workers, Journal of Social Service.

Al-Qurtubi, Muhammad Ibn Ahmad Ibn Abi Bakr Ibn Farah (1964 AD), Al-Jami Al-Ahkam AlQur`an, 2nd Edition, edited by Ahmed Al-Bardouni and Ibrahim Atfeesh, Dar Al-Kutub AlMasrya, Cairo, Egypt.

Al-Ramli, Muhammad bin Ahmad bin Hamza (1984 AD), The End of the Needy to Explain the Minhaj, House of Fikr, Beirut, Lebanon.

Al-Razi, Muhammad bin Omar bin Al-Hassan (1420 AH), Keys of the Unseen, 3rd Edition, House of Revival of Arab Heritage, Beirut, Lebanon.

Al-Razi, Zain Al-Din Abu Abdullah Muhammad Ibn Abi Bakr Ibn Abd al-Qadir (1999 AD), Mukhtar Al-Sahih, 5th Edition, Editing by Yusef Al-Sheikh Muhammad, Al-Asriyya Library, Beirut.

Al-Risaa, Muhammad Al-Ansari (1993 AD), Explanation of Hudud Ibn Arafa, 1st Edition, edited by: Muhammad Abu Al-Ajfan and Al-Taher Al-Maamouri, Dar Al-Gharb Al-Islami.

Al-Samhoudi, Ali bin Abdullah bin Ahmed (1419 AH), Wafa Al-Wafa News of Dar Al-Mustafa, 1st Edition, Dar Al-Kutub Al-Ilmiyya, Beirut, Lebanon.

Al-Sarkhasi, Muhammad bin Ahmed bin Abi Sahl, Al-Mabsut, House of Knowledge, Beirut, Lebanon.

Al-Shatibi, Ibrahim bin Musa bin Muhammad al-Lakhmi (1997 CE), approvals, ed1, verified by: Mashhour bin Hassan Al Salman, Dar Ibn Affan.

Al-Shawkani, Muhammad bin Ali bin Muhammad bin Abdullah (1993 AD), Neil Al-Awtar, 1st Edition, edited by: Essam Al-Din Al-Sabbati, Dar Al-Hadith, Egypt.

Al-Shawkani, Muhammad bin Ali bin Muhammad bin Abdullah, The Precious Stream that flows over the flower gardens, 1st floor, Dar Ibn Hazm.

Al-Sobky, Taqi al-Din Ali bin Abd al-Kafi and his son Taj al-Din Abd al-Wahhab (1995 CE), The Joy in Explaining the Minhaj, Dar Al-Kutub Al-Ilmiyya, Beirut, Lebanon.

Al-Tabari, Muhammad bin Jarir bin Yazid bin Katheer (2000 AD), Jami al-Bayan fi Ta'wil alQur'an, ed. 1, edited by: Ahmad Muhammad Shakir, Foundation for the Risalah.

Al-Tabari, Muhammad bin Jarir bin Yazid bin Kathir (1387 AH), History of the Apostles and Kings, 2nd Edition, Dar Al Turath, Beirut, Lebanon.

Al-Tanukhi, Qasim bin Isa bin Naji (2007 CE), Ibn Naji al-Tanukhi explained on board the message by Ibn Abi Zaid al-Qayrawani, 1st edition, Dar al-Kutub al-Ilmiyya, Beirut, Lebanon. 
Al-Tirmidhi, Muhammad bin Issa bin Surah bin Musa bin al-Dhahak (1975 CE), Sunan alTirmidhi, ed. 2, edited by: Ahmad Muhammad Shaker, Muhammad Fuad Abd al-Baqi and Ibrahim Atwa Awad, al-Mustafa al-Babi al-Halabi library and printing press, Cairo, Egypt.

Al-Zamakhshari, Mahmoud bin Amr bin Ahmed (1407 AH), The Discovery of the Ambiguous Facts of the Download, 3rd Edition, Arab Book House, Beirut, Lebanon.

Al-Zarkashi, Muhammad bin Abdullah bin Bahader (1985 AD), Al-Manthur in the Rules of Jurisprudence, 2nd Edition, Kuwaiti Ministry of Endowments.

Al-Zayla'i, Othman bin Ali bin Muhajin (1313 AH), Explanation of the facts, Explanation of Treasure of Dawaqi'a, First Edition, Al-Amiriya Grand Press - Bulaq, Cairo, Egypt.

Al-Zubaidi, Abu Al-Fayd Muhammad bin Muhammad bin Abdul-Razzaq, nicknamed Murtaza, Crown of the Bride, one of the jewels of the dictionary, the house of guidance.

Al-Zuhaili, Wehbe, Islamic Jurisprudence and Its Evidence, 1st Edition, Dar Al-Fikr, Damascus, Syria.

Farid, Abdullah Muhammad (2004 AD), The Unique Dictionary of Finance and Economics, AlNasr National Library.

Habib, Matanius, Self-Sufficiency, The Arab Encyclopedia, the Syrian Arab Republic, Damascus, Syria.

Hassan, Syed Hassan Abdullah, Environmental Security is a national duty and legal obligation: a comparative study of the general Saudi environment system, an arbitrated research accepted for publication, King Fahd Security College - Research and Studies Center, Security Research Journal, Issue (65), September 2016 AD.

Hattab, Kamal Tawfiq (2006 AD), An Islamic vision towards development, an arbitrated research accepted for publication, The University of Jordan - Deanship of Scientific Research, Studies Sharia and Law Sciences.

Hoshat, Fawzia (2018 AD), Environmental Security between the National Security and Human Security Approach, Arbitrator Research Accepted for Publication, University of Mentouri Constantine, Journal of Human Sciences.

Ibn Abd al-Barr, Yusuf bin Abdullah bin Muhammad (1387 AH), preface to the meanings and chain of transmission in al-Muwatta, edited by Mustafa bin Ahmed al-Alawi and Muhammad Abd al-Kabir al-Bakri, Ministry of General Endowments and Islamic Affairs, Morocco.

Ibn Abdeen, Muhammad Amin bin Omar bin Abdul Aziz (1992 AD), The Response of the Confused to Al-Durr Al-Mukhtar, 2nd Edition, Dar Al-Fikr, Beirut, Lebanon.

Ibn Abi Shaybah, Abdullah bin Muhammad (1409 AH), the compiler, ed. 1, edited by Kamal Yusef al-Hout, Al-Rushd Library, Riyadh, Saudi Arabia.

Ibn Al-Qayyim, Muhammad bin Abi Bakr bin Ayyub bin Saad, Al-Tareeq Al-Hakamiah, Dar AlBayan.

Ibn Ashour, Muhammad al-Taher bin Muhammad bin Muhammad al-Taher (1984 CE), Editing and Enlightenment, "Liberating the Good Meaning and Enlightening the New Mind from the Interpretation of the Glorious Book", Tunisian Publishing House, Tunisia.

Ibn Ashour, Muhammad al-Taher bin Muhammad bin Muhammad al-Taher, Maqasid al-Sharia, investigation by: Muhammad al-Habib Ibn al-Khujah, Ministry of Endowments and Islamic Affairs, Qatar.

Ibn Faris, Ahmad bin Faris bin Zakaria (1979 AD), Dictionary of Language Standards, edited by Abd al-Salam Muhammad Harun, Dar al-Fikr.

Ibn Hanbal, Ahmad Ibn Muhammad Ibn Hanbal Ibn Hilal Ibn Asad Al-Shaibani, Al-Musnad, the investigator: Ahmed Muhammad Shaker, Dar Al-Hadith - Cairo.

Ibn Hisham, Abd al-Malik bin Hisham bin Ayyub (1955 CE), The Biography of the Prophet, edited by: Mustafa Al-Sakka, Ibrahim Al-Abyari and Abdel-Hafeez Al-Shalabi, 2nd Edition, Mustafa Al-Babi Al-Halabi Library, Cairo, Egypt. 
Ibn Ibrahim, Abdullah bin Lam (2003 AD), Ahkam Al-Ghuniya, 1st Edition, Dar Al-Nafaes, Amman, Jordan.

Ibn Katheer, Ismail bin Omar (1986 AD), The Beginning and the End, Dar Al Fikr.

Ibn Khaldun, Abd al-Rahman ibn Muhammad (2004 CE), Introduction to Ibn Khaldun, First Edition, Verification by Abdullah Muhammad Darwish, Dar Yarub, Damascus, Syria.

Ibn Majah, Muhammad ibn Yazid al-Qazwini, Sunan Ibn Majah, edited by: Muhammad Fuad Abd al-Baqi, House of Revival of Arabic Books.

Ibn Manzur, Muhammad bin Makram bin Ali (1414 AH), Lisan al-Arab, 3rd Edition, Dar Sader, Beirut.

Ibn Muflih, Ibrahim bin Muhammad bin Abdullah (1997 AD), the creator in Sharh Al-Muqin ', 1st Edition, Dar Al-Kutub Al-Ulmiyyah, Beirut, Lebanon.

Ibn Muflih, Muhammad bin Muflih bin Muhammad bin Mufarraj (2003 CE), Kitab al-Furoo ', ed1, edited by: Abdullah bin Abdul-Mohsen al-Turki, Foundation for the message.

Ibn Qudamah, Abu Muhammad Muwaffaq al-Din Abdullah bin Ahmed bin Muhammad (1968 AD), Al-Mughni, Cairo Library, Egypt

Ibn Shabah, Umar bin Shabah bin Ubaidah al-Basri (1399 AH), History of Medina, edited by: Fahim Muhammad Shaltout.

Kafi, Farida (2019 AD), Energy Security and the Environmental Security Problem: The Transition to Build a Sustainable Energy Policy, Refined Research Accepted for Publication, Center for Research and Human Resources Development, Rumah Journal for Research and Studies.

Kasasbeh, Hamad (1984 AD), Food Security and Economic Policy in Jordan, 1st Edition, Studies and Research Department, Central Bank of Jordan.

Kilani, Muhammad and Awad, Muhammad Hashem (1972 AD), The concept of self-sufficiency between the old and the modern, Sudan's road towards self-sufficiency, Institute of Additional Studies - University of Khartoum, Khartoum, Sudan.

Mansour, Ahmed Ibrahim, Distribution Justice and Economic Development A Comparative Islamic View, 1st Edition, Center for Arab Unity Studies.

Mawaq, Muhammad bin Yusuf bin Abi Al-Qasim bin Yusuf (1994 AD), The Crown and the Crown by Khalil's Mukhtasar, First Edition, Dar Al-Kutub Al-Ilmiyyah.

Media Knowledge Structure Network ((Harvard Business Review), page link: https://cutt.us/yewKh.

Miller, Fred (2017), Aristotle's Political Theory, translated by Lina Al-Hudhaif and Muhammad AlRashoudi, Stanford Encyclopedia of Philosophy. Article link from Hikma website: https://cutt.us/ZrVG1

Ministry of Endowments and Islamic Affairs, Kuwaiti Fiqh Encyclopedia, Edition 2, Parts 1-23, Dar Al-Salasil, Kuwait, Edition 1, Parts from 24 - 38, Dar Safwa, Egypt, Edition 2, Parts from 39 - 45, Ministry Press, 45 AD, 1404-1427 AH .

Mulla Khusraw, Muhammad ibn Framers bin Ali, Darr al-Hakam, Explaining Gharar Al-Ahkam, House of Revival of Arabic Books.

Muslim, Muslim bin Hajjaj al-Qushayri, Sahih Muslim, investigator: Muhammad Fuad Abd alBaqi, House of Revival of Arab Heritage - Beirut.

Okasha, Ahmed Khaled, The Theory of Sharia Preference in Islamic Economics, Arbitrator Research Accepted for Publication, Islamic University for Economic and Administrative Studies, Journal of the Islamic University for Economic and Administrative Studies, Issue (1), January 2017.

Taher, Jamil, and Asfour, Saleh (1996 AD), The Unified Guide for Planning Concepts and Terminology in the Countries of the Cooperation Council for the Arab Gulf States, 1st Edition, The Arab Planning Institute, Kuwait. 